\author{
UNIVERSIDADE DE SÃO PAULO \\ ESCOLA DE ENGENHARIA DE SÃO CARLOS \\ DEPARTAMENTO DE GEOTECNIA
}

\title{
PREVISÃO DA CURVA TENSÃO-RECALQUE EM SOLOS TROPICAIS ARENOSOS A PARTIR DE ENSAIOS DE CONE SÍSMICO
}

TIAGO DE JESUS SOUZA

Dissertação apresentada à Escola de Engenharia de São Carlos da Universidade de São Paulo, como parte dos requisitos para a obtenção do título de Mestre em Ciências, Programa de Pós Graduação em Geotecnia.

ORIENTADOR: PROF. DR. HERALDO LUIZ GIACHETI

SÃO CARLOS -SP 
AUTORIZO A REPRODUÇÃO E DIVULGAÇÃO TOTAL OU PARCIAL DESTE TRABALHO, POR QUALQUER MEIO CONVENCIONAL OU ELETRÔNICO, PARA FINS DE ESTUDO E PESQUISA, DESDE QUE CITADA A FONTE.

Ficha catalográfica preparada pela Seção de Tratamento da Informação do Serviço de Biblioteca - EESC/USP

Souza, Tiago de Jesus.

$5725 p$

Previsão da curva tensão-recalque em solos tropicais arenosos a partir de ensaios de cone sísmico / Tiago de jesus Souza ; orientador Heraldo Luiz Giacheti. -- São Carlos, 2011.

Dissertação (Mestrado-Programa de Pós-Graduação em Geotecnia) -- Escola de Engenharia de São Carlos da Universidade de São Paulo, 2011.

1. Investigação do subsolo. 2. Solos tropicais. 3. Cone sísmico. 4. Fundações diretas. 5.Curva tensãorecalque. 6. Sucção. I. Título. 


\section{FOLHA DE JULGAMENTO}

Candidato: Engenheiro TIAGO DE JESUS SOUZA

Titulo da dissertação: Previsão da curva tensão-recalque em solos tropicais arenosos a partir de ensaios de cone sísmico.

Data da defesa; 19/09/2011:

Comissĩo Julgadora:

Resultado:

Prof. Dr. Heraldo Luiz Giacheti (Orientador)

Aprovado

(Universidade Estadual Paulista "Julio de Mesquita Filho"/UNESP/campus de Bauru)

Prof. Dr. Paulo José Rocha Albuquerque

$\triangle P R O U \triangle D O$

(Universidade Estadual de Campinas/UNICAMP)

Profe, Dr ${ }^{a}$. Cristina de Hollanda Cavaleanti Tsuha

Qporador

(Escola de Engenharia de São Carlos/EESC)

Coordenador do Programa de Pós-Graduação em Geotecnia:

Prof. Titular Osni José Pejon

Presidente da Comissão de Pós-Graduação:

Prof. Associado Paulo Cesar Lima Segantine 


\section{EPÍGRAFE}

“ Nada que é suficiente hoje será daqui a cinco anos. $O$ nível de exigência por novas soluções aumenta rapidamente".

Victor F.B. de Mello 


\section{AGRADECIMENTOS}

À Deus, por me conceder a dádiva da vida, e mais do que tudo ter me concedido força, sabedoria e persistência durante esta jornada.

Ao prof. Dr. Heraldo Luiz Giacheti pela orientação, pelas sugestões para o desenvolvimento da pesquisa e os ensinamentos transmitidos.

Ao prof. Dr. Paulo José Rocha Albuquerque pelas sugestões apresentadas para melhoria desse presente trabalho

A todos os professores do Departamento de Geotecnia da EESC/USP pelo conhecimento transmitido, em especial aos professores José Carlos Ângelo Cintra, Cristina Tshua e Nelson Aoki pelas sugestões no trabalho, pelo convívio agradável ao longo das aulas, e no programa de estágio PAE.

Aos professores Alexandre Duarte Gusmão (UFPE), Erundino Pousada Presa (UNIFACS), Luiz Edmundo Prado Campos (UFBA), Sandra Oda (COPPE-UFRJ), Marcelo Rios (UNIFACS) pelo apoio prestado para que eu fizesse o mestrado e pelo incentivo constante no decorrer da minha especialização.

À minha noiva Manuela, pelo apoio, compreensão, incentivo e longas conversas durante os últimos 2 anos.

À tia Marli, tia Gracinha, minha avó Olga (in memorian), meu Tio Rogério (in memorian), Lucas Santos (cunhado), Tâmara (irmã), aos irmãos da igreja Batista dos Mares (BA) pela amizade, juntamente com os demais familiares e amigos. 
A todos os meus colegas do departamento de Geotecnia, em especial: Mariana Alher (SP), Pablo Noreña (Peru), Albano Maparagem (Moçambique), Vivian Canello (SP), Jenny Paricahua (Peru), Osvaldo Vitali (SP), Nestor Barros (SP), Thiago Peixoto (RJ), Vinícius Peixoto (SE), Gian Franco (Peru), Liliana Castilho (Peru), Thiago Santos (AL).

A Brás, Edvaldo, Sr. José, Pastor Jarbas e a Primeira igreja Batista de São Carlos pela amizade construída em SP durante o período da minha pesquisa.

A CNPq pela concessão da bolsa de estudos.

À USP e a UNESP por colocar à minha disposição suas estruturas.

Finalmente, um sincero e especial agradecimento a meus pais, por tudo que eles representam em minha vida. 


\section{RESUMO}

SOUZA, T. J. Previsão da curva tensão-recalque em solos tropicais arenosos a partir de ensaios de cone sísmico. 86 P. Dissertação de Mestrado. Escola de Engenharia de São Carlos, Universidade de São Paulo, São Carlos, 2011.

Apresenta-se neste trabalho a aplicação de um método para a previsão da curva tensãorecalque de fundações diretas assentes em solos tropicais arenosos a partir de resultados de ensaios de cone sísmico (SCPT). Os locais estudados foram os campos experimentais de fundações da EESC/USP - São Carlos e da UNESP-Bauru, onde existem resultados de provas de carga realizados a diferentes profundidades, assim como resultados de ensaios SCPT. As previsões realizadas apresentaram bons resultados, após ajustes dos parâmetros $\mathrm{f}$ e $\mathrm{g}$, pois as curvas tensão-recalque estimadas foram próximas a aquelas obtidas a partir de provas de carga em placa, para as profundidades maiores que 1,5 metros. Verifica-se assim a aplicabilidade do método, após seu ajuste, para reproduzir a curva tensão-recalque neste tipo de solo, empregando uma abordagem mais racional, com menor dependência de correlações empíricas. Destaca-se nesta pesquisa que existe uma variabilidade dos resultados de ensaios SCPT e de provas de carga que está relacionada com a mudança de sucção no solo. Para o campo experimental de São Carlos foi possível ainda fazer uma avaliação da variabilidade nas previsões realizadas, pois existe maior número de resultados de ensaios de campo e provas de cargas disponíveis.

Palavras-chave: Investigação do subsolo, solos tropicais, cone sísmico, módulo de cisalhamento máximo, fundações diretas, curva tensão-recalque. 


\section{ABSTRACT}

SOUZA, T. J. Prediction of stress-settlement curve on tropical sandy soils based on seismic cone test. 86 P. Master Dissertation. School of Engineering at São Carlos, University of São Paulo, São Carlos, 2011.

It is presented in this dissertation the use of a method for predicting the stress-settlement curve of shallow foundations on tropical sandy soils based on seismic cone (SCPT) test results. The studied sites were the experimental research sites from USP - São Carlos, and UNESP - Bauru, Brazil, where there are results from plate load tests conducted at various depths, as well as SCPT test results. The stress-settlement curve predictions show good results, after adjusting the parameters $\mathrm{f}$ and $\mathrm{g}$, because the estimated curves were close to those obtained from plate load tests, to depths greater than 1.5 meters. The applicability of the method, after its adjustment, to reproduce the stress-settlement curve for this type of soil, was verified employing a more rational approach with less reliance on empirical correlations. It is highlighted in this research that there is variability on SCPT and plate load test results, which is related to the change in soil suction. It was also possible to access the variability on the prediction for the USP - São Carlos site, since there is a greater number of in situ and plate load tests in this site.

Keywords: Site Investigation, tropical soils, seismic cone, maximum shear modulus, shallow foundations, stress-settlement curve. 


\section{SUMÁRIO}

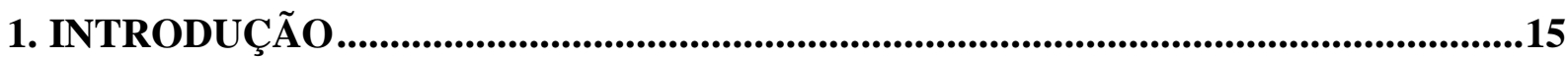

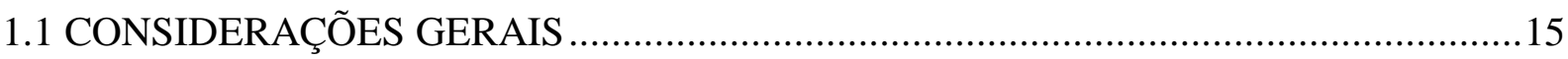

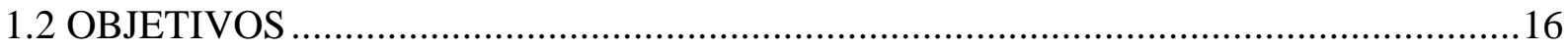

1.3 ORGANIZAÇÃO E DISTRIBUIÇÃO DOS ASSUNTOS ...........................................16

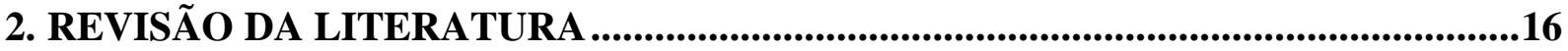

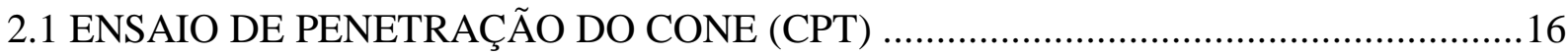

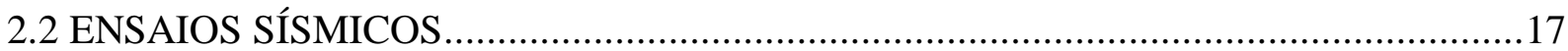

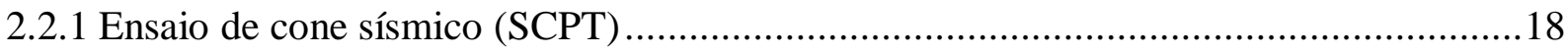

2.2.1.1 Métodos para a determinação do intervalo de tempo e da velocidade ........................22

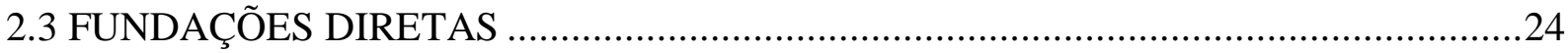

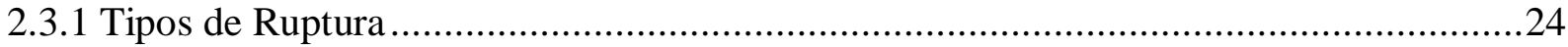

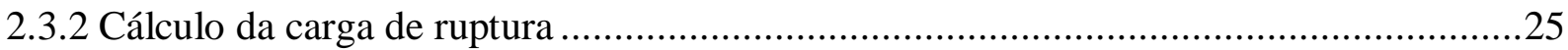

2.3.3 Recalque em Fundações Diretas na condição elástico-linear .......................................26

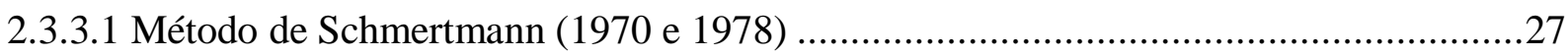

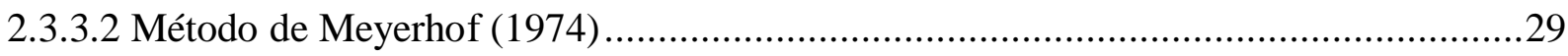

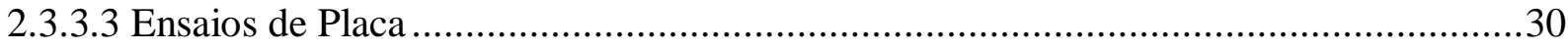

2.3.3.4 Prova de carga em placa com carregamento lento ...................................................

2.3.3.5 Prova de carga em placa com carregamento rápido ...............................................31

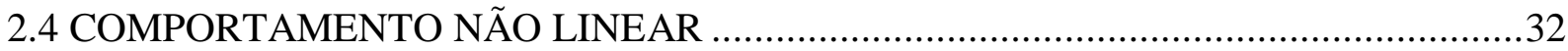

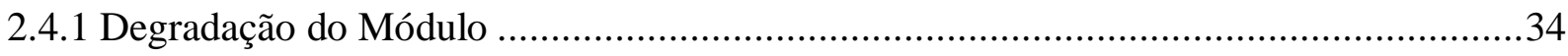

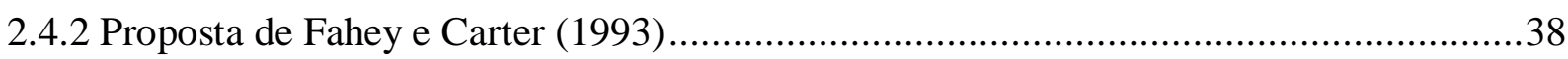

2.4.3 Modelo de Mayne (2000) para a previsão da curva tensão-recalque .............................42

2.5 INFLUÊNCIA DA SUCÇÃO NOS PARÂMETROS GEOTÉCNICOS DO SOLO .........43

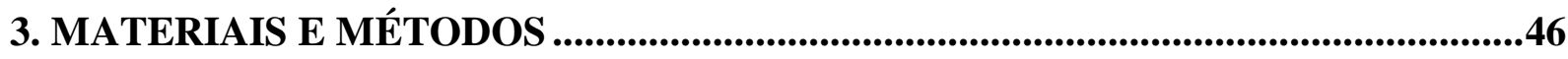

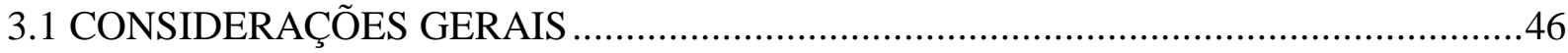

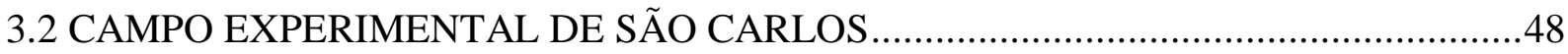

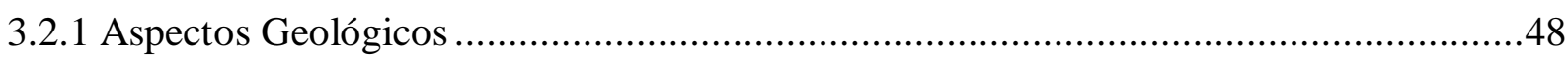

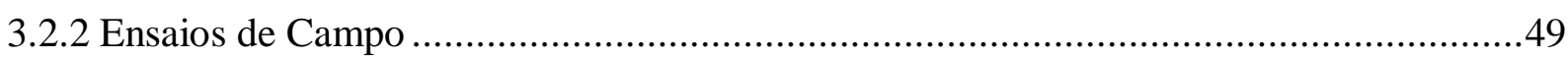

3.2.2.1 Posição dos ensaios de campo ........................................................................49

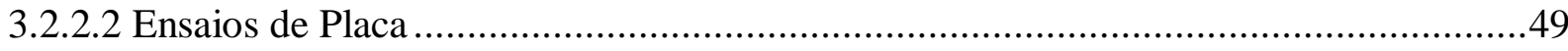




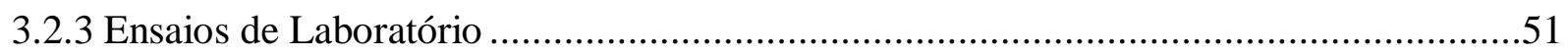

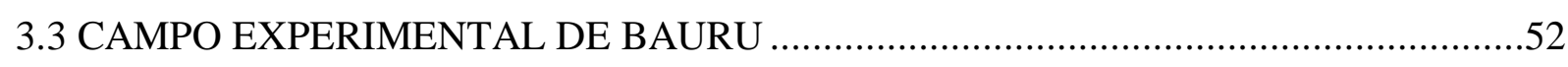

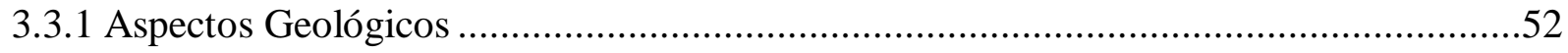

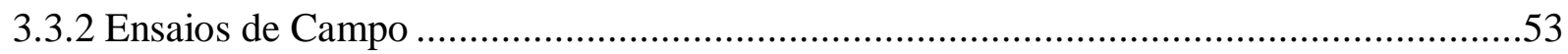

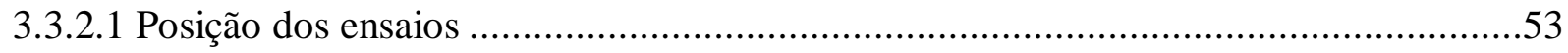

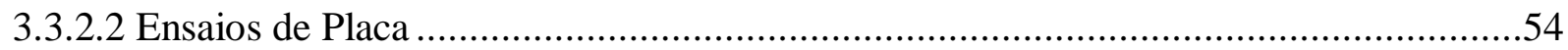

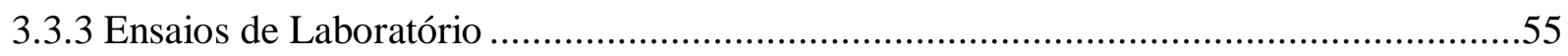

4. RESULTADOS E DISCUSSÕES ............................................................................56

4.1 AJUSTE DOS PARÂMETROS DO MODELO DE MAYNE (2000) ..............................56

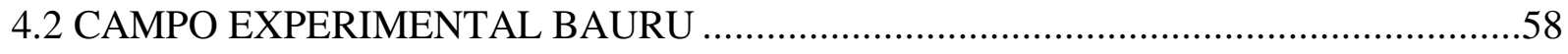

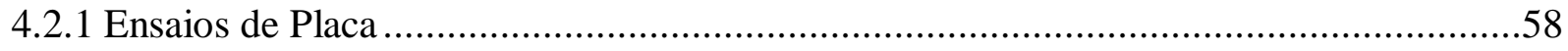

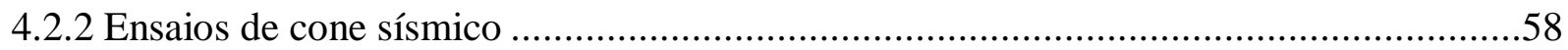

4.2.3 Comparação entre Previsão e Resultados de Provas de Carga .....................................61

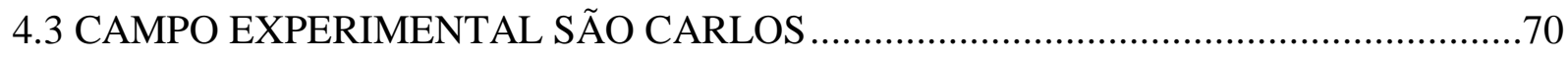

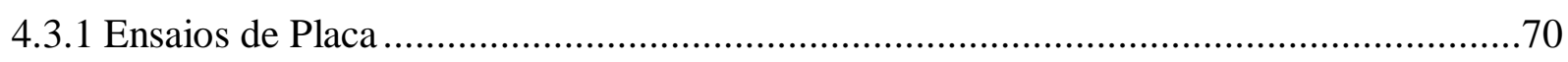

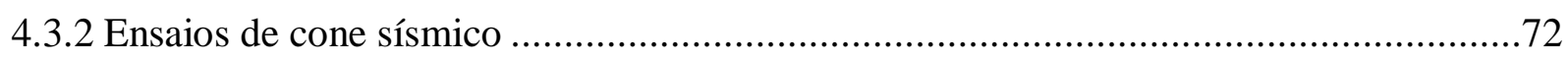

5. CONSIDERAÇÕES fINAIS .........................................................................................77

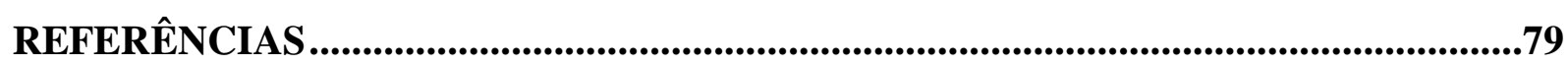




\section{LISTA DE FIGURAS}

Figura 2.1- Desenho esquemático de um ensaio crosshole (Luna e Jadi, 2000). 18

Figura 2.2- Desenhos esquemáticos dos ensaios (a) uphole e (b) downhole (Luna e Jadi,

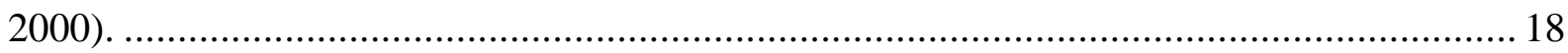

Figura 2.3- Piezocone sísmico (SCPTU) (Davies e Campanella, 1995) ................................ 19 Figura 2.4- Procedimento para realização do cone sísmico (adaptado de Rice, 1984) ........... 20 Figura 2.5- Martelo sísmico utilizado no caminhão de ensaios da UBC/Canadá (Giacheti, 2001)

Figura 2.6- Parâmetros possíveis de serem obtidos em um ensaio de piezocone sísmico utilizados para caracterização geotécnica em região sujeita à terremoto (Mayne e Schneider, 2000).

Figura 2.7- Representação esquemática de um ensaio SCPT downhole (Campanella e Stewart, 1992).

Figura 2.8- Determinação do intervalo de tempo através do método do cross correlation no domínio do tempo (Campanella e Stewart, 1992) ................................................................. 23

Figura 2.9- Modos de Ruptura (Vesic, 1975)............................................................... 25

Figura 2.10- Fator de influência na deformação vertical (Schmertmann, 1970).................... 27

Figura 2.11- Fator de influência na deformação vertical (Schmertmann, 1978).................... 29

Figura 2.12- Cuidados na interpretação dos ensaios de placa: diferentes bulbos de pressão

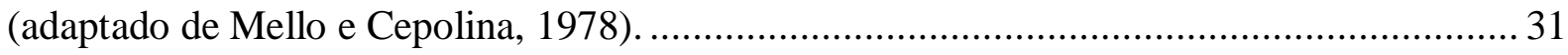

Figura 2.13 - Desenho esquemático de Sistema de reação para (a) cargueira, (b) tirantes, (c)

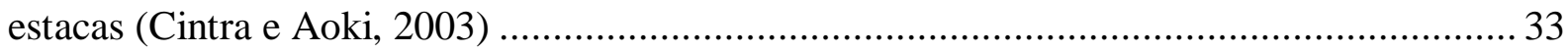

Figura 2.14- comportamento tensão deformação: a) elástico-linear, b) elástico não linear, c)

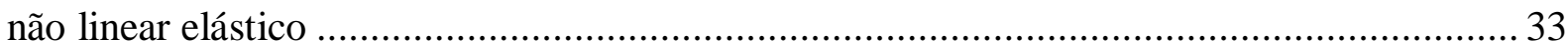

Figura 2.15- Comportamento linear do aço (a) e não linear do solo (b) (adaptado de Nogueira,

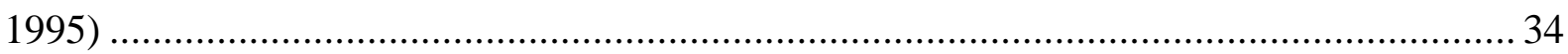

Figura 2.16- Curva típica de carregamento e definição dos módulos de deformabilidade (Pinto, 1996) .................................................................................................. 35

Figura 2.17- Representação esquemática do efeito da amplitude de deformação no módulo de cisalhamento (Stokoe, 1980). .................................................................................... 35

Figura 2.18- Representação esquemática da curva de degradação do módulo (Giacheti, 2001).

Figura 2.19- Curvas de degradação normalizada obtidas nos ensaios e confrontadas com duas

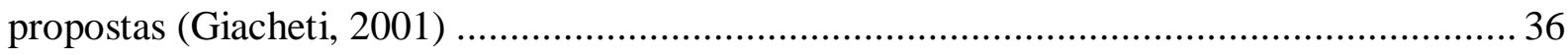

Figura 2.20- Curva tensão-deformação típica de ensaios triaxiais. ...................................... 39

Figura 2.21- Funções Hiperbólicas não lineares que relacionam o parâmetro de ajuste g e a deformação normalizada para carregamento drenado em placa circular (Ealkim, 2005)........ 40 Figura 2.22 - Funções Hiperbólicas não lineares que relacionam o parâmetro de ajuste g e a deformação normalizada para carregamento drenado em sapata corrida (Ealkim, 2005)...... 40 
Figura 2.23- Funções Hiperbólicas não lineares que relacionam o parâmetro de ajuste g e a deformação normalizada para carregamento não drenado, para fundação circular e fundação

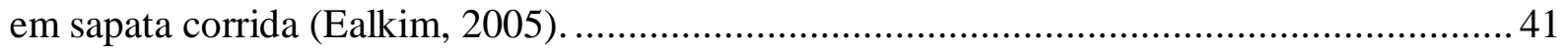

Figura 2.24- Representação da degradação para a areia do Toyoura do Japão

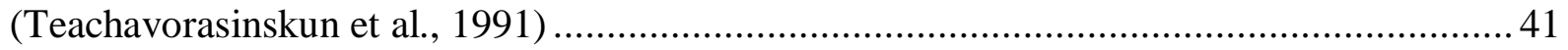

Figura 2.25- Representação da curva carga-recalque para areia do College Station - Texas e resultados de prova de carga (Mayne, 2000).................................................................. 42

Figura 2.26- Representação da curva carga-recalque para um solo argiloso da Escócia e os resultados de prova de carga (Mayne, 2000)................................................................... 43 Figura 2.27- Variação do módulo de cisalhamento máximo com a sucção em uma argila de alta plasticidade (Marinho et al, 1995) ................................................................... 44 Figura 2.28- Capacidade de carga em função da sucção matricial (Fredlund e Rahardjo, 1993)

Figura 2.29- Curvas tensão x recalque de provas de carga sobre placa em solo não-saturado com diferentes sucções (Costa, 1999).

Figura 3.1-Perfis típicos e resultados de sondagens SPT realizadas nos campos experimentais de (a) Bauru, (b) São Carlos (Giacheti et al, 2004).

Figura 3.2- Faixa de variação das curvas granulométricas para os solos das duas áreas

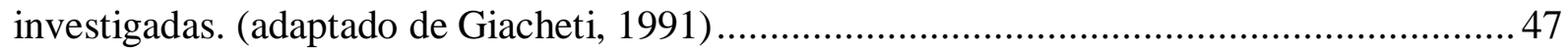
Figura 3.3- Variação do tamanho das partículas com a profundidade para os solos das duas

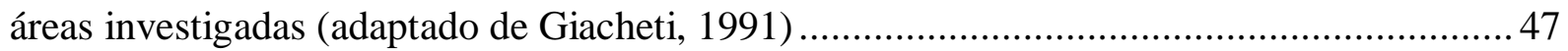
Figura 3.4- Seção esquemática da geologia de pequena profundidade em São Carlos

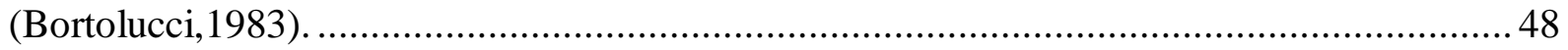
Figura 3.5- Posição dos ensaios de campo realizados no campo experimental da EESC/USP São Carlos.

Figura 3.6- Curvas características de sucção do solo para a profundidade de 2,0m (Machado, 1998).

Figura 3.7 - Curvas características de sucção do solo para a profundidade de 5,0 m (Machado, 1998).

Figura 3.8- Curvas características de sucção do solo para a profundidade de 8,0 m (Machado, 1998). .52

Figura 3.9- Desenho esquemático da formação geológica da cidade de Bauru (DAEE, 1976 in Ferreira, 1991).

Figura 3.10- Posição dos ensaios de campo realizados no campo experimental da UNESP Bauru (adaptado de Agneli, 1997 e Giacheti, 2001)..

Figura 3.11- Curva Característica típica de solos que ocorrem próximo no campo experimental de Bauru de uma amostra de solo coletada a 5,0m, (Giacheti e Rohm, 1996)...55

Figura 4.1 - Representação da degradação variando os parâmetros de ajuste (Ealkim, 2005) 56 Figura 4.2- Representação da curva de degradação do módulo para o solo que ocorre no campo experimental de São Carlos. 
Figura 4.3- Resultados de provas de carga sobre placa em solo natural na profundidade $1 \mathrm{~m}$. Campo Experimental da Unesp de Bauru, SP (Agnelli, 1997). ........................................59 Figura 4.4- Resultados de provas de carga sobre placa em solo natural na profundidade $2 \mathrm{~m}$. Campo Experimental da Unesp de Bauru, SP (Agnelli, 1997).

Figura 4.5- Resultados de provas de carga sobre placa em solo natural na profundidade $3 \mathrm{~m}$. Campo Experimental da Unesp de Bauru, SP (Agnelli, 1997).

Figura 4.6- Resultados de provas de carga sobre placa em solo natural na profundidade $4 \mathrm{~m}$. Campo Experimental da Unesp de Bauru, SP (Agnelli, 1997).

Figura 4.7- Resultados de dois ensaios SCPT realizados no Campo Experimental da UnespBauru ( adaptado de De Mio, 2005).

Figura 4.8 - Previsão do comportamento de fundações diretas utilizando o ensaio SCPT, com resultados das provas de carga em placa assentadas a $1 \mathrm{~m}$ de profundidade para o campo experimental de Bauru.

Figura 4.9- Previsão do comportamento de fundações diretas utilizando o ensaio SCPT, com resultados das provas de carga em placa assentadas a $2 \mathrm{~m}$ de profundidade para o campo experimental de Bauru.

Figura 4.10- Previsão do comportamento de fundações diretas utilizando o ensaio SCPT, com resultados das provas de carga em placa assentadas a $3 \mathrm{~m}$ de profundidade para o campo experimental de Bauru.

Figura 4.11- Previsão do comportamento de fundações diretas utilizando o ensaio SCPT, com resultados das provas de carga em placa assentadas a $4 \mathrm{~m}$ de profundidade para o campo experimental de Bauru.

Figura 4.12- Fator de influência (Iz) para as profundidades estudadas ............................... 65

Figura 4.13- Curva tensão-recalque para diferentes níveis de sucção na profundidade $1,5 \mathrm{~m}$ para o campo experimental de São Carlos (Menegotto, 2004). ......................................... 71

Figura 4.14- Curva tensão-recalque para diferentes níveis de sucção na profundidade 4,0m para o campo experimental de São Carlos (Menegotto, 2004). ....................................... 71

Figura 4.15- Curva tensão-recalque para diferentes níveis de sucção na profundidade $6,0 \mathrm{~m}$ para o campo experimental de São Carlos (Menegotto, 2004). ......................................... 72 Figura 4.16- Resultados de ensaios SCPT, Downhole e Crosshole realizados no Campo Experimental de São Carlos (Vitali, 2011). ................................................................... 73 Figura 4.17- Representação da variação de valores de $\mathrm{q}_{\mathrm{c}}$ e $\mathrm{G}_{\max }$ em ensaios SCPT e CrossHole ao longo da profundidade bem como valores médios, média mais desvio, média menos desvio e coeficiente de variação (CV).

Figura 4.18- Previsão do comportamento de fundações diretas utilizando ensaio SCPT, com resultados de provas de carga em placa assentadas a $1,5 \mathrm{~m}$ de profundidade no campo experimental de São Carlos.

Figura 4.19- Previsão do comportamento de fundações diretas utilizando ensaio SCPT, com resultados de provas de carga em placa assentadas a 4,0m de profundidade no campo experimental de São Carlos............................................................................. 75 Figura 4.20- Previsão do comportamento de fundações diretas utilizando ensaio SCPT, com resultados de provas de carga em placa assentadas a $6,0 \mathrm{~m}$ de profundidade no campo experimental de São Carlos. 


\section{LISTA DE TABELAS}

Tabela 2.1 - Fatores que afetam o módulo de cisalhamento em solos arenosos e coesivos (Hardin e Drnevich, 1972). 37

Tabela 2.2 - Valores típicos do coeficiente de Poisson (Bowles, 1988). ................................ 40

Tabela 2.3 - Fator de influência (I) (adaptado de Perloff e Baron, 1976).............................. 44

Tabela 3.1 - Características das provas de carga em placa com diâmetro de 0,80m (Menegotto, 2004).

Tabela 3.2 - Índices físicos médios para o campo experimental São Carlos (Giacheti, 2001) 51 Tabela 3.3 - Índices físicos médios para os solos que ocorrem no campo experimental de

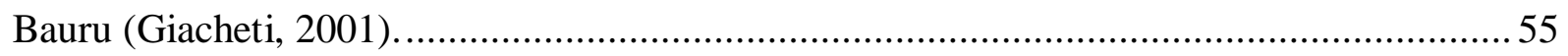

Tabela 4.1 - Dispersão dos valores de $\mathrm{G}_{\min }$ obtidos em ensaios triaxiais com a profundidade e

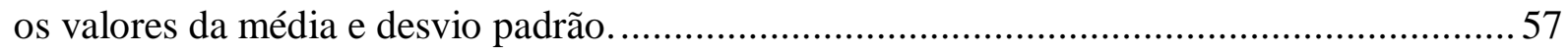

Tabela 4.2 - Deformação normalizada $\left(\mathrm{X}_{\mathrm{L}}\right)$ com a profundidade. ......................................... 57

Tabela 4.3 - Dados necessários para o cálculo de recalques aplicando-se o método de

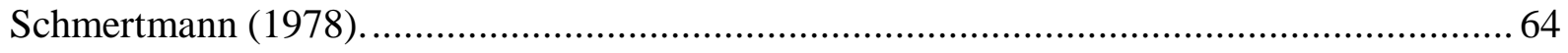

Tabela 4.4 - Somatória dos recalques das sub camadas a $1 \mathrm{~m}$ de profundidade. ..................... 66

Tabela 4.5 - Somatória dos recalques das sub camadas a $2 \mathrm{~m}$ de profundidade. .................... 66

Tabela 4.6 - Somatória dos recalques das sub camadas a $3 \mathrm{~m}$ de profundidade. ....................67 67

Tabela 4.7 - Somatória dos recalques das sub camadas a $4 \mathrm{~m}$ de profundidade. .....................67

Tabela 4.8 - Aplicação do Método de Meyerhof (1974) nas profundidades estudadas........... 68

Tabela 4.9 - Valores de recalques segundo diferentes métodos e medidos em provas de carga

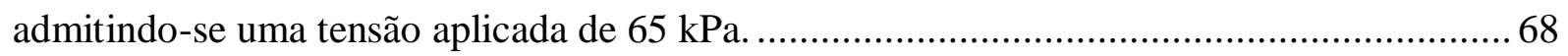

Tabela 4.10 - Erro em relação a média das Provas de Carga. Valores em porcentagem......... 69 


\section{INTRODUÇÃO}

\subsection{CONSIDERAÇÕES GERAIS}

É de conhecimento geral que as principais funções da investigação do subsolo consistem em identificar detalhadamente o perfil estratigráfico e permitir a estimativa de parâmetros mecânicos e hidráulicos de cada camada de um perfil de solo. De acordo com Milititsky et al (2008) na etapa de análise e projeto de fundações, um dos motivos de insucesso em obras geotécnicas, se dá pela representação inadequada do subsolo. A experiência adquirida com a previsão do comportamento de um certo tipo de solo por meio de modelos matemáticos, faz com que o emprego das correlações empíricas sejam pertinentes, contudo, generalizar essa questão para todo o tipo de obra geotécnica, poderá resultar em uma representação do solo de maneira equivocada.

Em alguns casos, por exemplo, engenheiros de projeto contam apenas com resultados de um único tipo de ensaio, para fornecer todos os dados de projeto, e isso é discutido por alguns pesquisadores que propõem a realização de ensaios que possibilitem a aquisição de vários parâmetros em campo, a exemplo dos ensaios de cone sísmico (SCPT), que além de medir a resistência de ponta e o atrito lateral, mede parâmetros de deformabilidade a partir da velocidade de propagação de ondas no solo, conforme discute Mayne (2000). Com a instalação de sensores sísmicos no interior de um cone padrão, o SCPT permite determinar a chegada de uma onda gerada pelo golpe de um martelo em uma fonte sísmica situada na superfície do local onde está sendo realizado o ensaio. Dessa maneira, através desse ensaio, é possível prever, tanto a capacidade de carga de fundações utilizando-se os valores de resistência de ponta $\left(\mathrm{q}_{\mathrm{c}}\right)$, como o recalque, empregando o módulo de cisalhamento máximo $\left(G_{\max }\right)$ determinado nesse ensaio. Um ensaio de campo que permite medir parâmetros de resistência através de uma ponteira ao mesmo tempo em que mede velocidades de ondas sísmicas é um recurso interessante para o projeto de fundações. Destaque deve ser dado ao fato de que o parâmetro de deformabilidade é determinado utilizando-se a Teoria da Elasticidade sem a necessidade de empregar correlações empíricas. 


\subsection{OBJETIVOS}

O presente estudo tem por objetivo avaliar a aplicabilidade da abordagem proposta por Mayne (2000) para a previsão da curva tensão-recalque de fundações diretas assentes em solos tropicais arenosos, a partir de resultados de ensaios de cone sísmico. Os locais estudados foram os solos dos campos experimentais da UNESP de Bauru e da EESC-USP de São Carlos. A principal contribuição desta pesquisa é mostrar que o ensaio SCPT é aplicável para reproduzir o comportamento de uma fundação direta em um solo de comportamento nãoconvencional após ajustes dos parâmetros do modelo, empregando uma abordagem mais racional.

\subsection{ORGANIZAÇÃO E DISTRIBUIÇÃO DOS ASSUNTOS}

A dissertação está organizada em cinco capítulos: o primeiro, Introdução, destaca a importância da pesquisa e seu objetivo; o segundo, Revisão da Literatura, apresenta uma síntese da literatura consultada; o terceiro, Materiais e Métodos, trata dos equipamentos utilizados, dos ensaios realizados, da sua interpretação, bem como descreve os locais estudados; o quarto Resultados e Discussões, apresenta os resultados de ensaios sísmicos previamente realizados, apresenta os resultados das previsões das curvas tensão-recalque com base no modelo empregado e os compara com os resultados de provas de cargas disponíveis; finalmente no capítulo 5, são apresentadas as principais Conclusões, com destaque para a possibilidade de emprego da proposta do Mayne (2000) para a previsão da curva tensão- recalque, em solos arenosos não saturados, após devidos ajustes nos parâmetros do modelo.

\section{REVISÃO DA LITERATURA}

\subsection{ENSAIO DE PENETRAÇÃO DO CONE (CPT)}

De acordo com Barentsen (1936), em meados da década de 30, a investigação geotécnica na Holanda era fundamentada nos ensaios de cone. Há registros históricos de que os ensaios de penetração estática foram realizados pela ferrovia estatal da Suécia, em 1917, e pelas ferrovias dinamarquesas, em 1927, Cestari (1900). Estes primeiros equipamentos eram mecânicos e apresentavam uma célula de carga posicionada no topo das hastes, medindo a 
força necessária para a cravação da ponteira. No Brasil, o ensaio de cone começou a ser empregado no final da década de 50 limitando-se a prospecção de petróleo. Esta tendência foi revertida na década de 90, observando-se um crescente interesse pelo uso do ensaio de cone impulsionado por experiências de pesquisas desenvolvidas nas universidades brasileiras, De Mio (2005). São inúmeros os exemplos de pesquisa, desenvolvimento e relato de casos que refletem a prática brasileira (Rocha Filho e Alencar, 1985; Rocha Filho e Sales, 1994; Almeida, 1996; Brugger e outros, 1994).

A introdução da medida do atrito lateral através de uma luva metálica foi feita por Beggemann (1963) seguidos dos primeiros cones elétricos, propiciando grande incremento no uso a partir da década de 60 , em função da precisão e rapidez na obtenção dos resultados. Estudos em grandes áreas objetivando mapeamentos estratigráficos, e avaliações de riscos têm sido realizados com sucesso usando ensaio de cone com sensores adicionais, conforme discutem Schneider et al. (2001) e Amorisi e Marchi (1999).

Segundo Mayne (2000) tanto o avanço da eletrônica como a rápida evolução da informática vem proporcionando o desenvolvimento de equipamentos mais apropriados, menores, mais robustos e econômicos, permitindo assim o projeto e a construção de novas ferramentas mais adequadas para a obtenção de parâmetros do solo. Neste contexto destaca-se

o CPT, que se caracteriza por constituir uma ferramenta que possibilita a descrição contínua do perfil geotécnico, definição do nível d'água e do regime hidrológico e para a estimativa de parâmetros mecânicos do solo. O mesmo autor diz que aos poucos o CPT tem tido maior aplicação, como um ensaio mais rápido, mais prático, mais confiável e com a possibilidade de trabalhar com sensores adicionais para a medição de outros parâmetros, a exemplo do piezocone, cone óptico, cone pressiométrico, cone resistivo e o cone sísmico.

\subsection{ENSAIOS SÍSMICOS}

De acordo com Barros (1997), a determinação de parâmetros dinâmicos pode ser feita realizando ensaios crosshole e downhole. Esses ensaios impõem níveis baixos de deformação do solo, com amplitudes de deformações cisalhantes inferiores a 0,001\%. Segundo esse mesmo autor esse nível de deformação permite determinar o módulo de cisalhamento máximo $\left(\mathrm{G}_{\max }\right)$.

Para o ensaio cross-hole são necessários pelo menos dois furos de sondagem, e consiste em medir a velocidade de propagação de uma onda gerada no interior de um furo para o outro com o receptor. A Figura 2.1 ilustra o ensaio. 


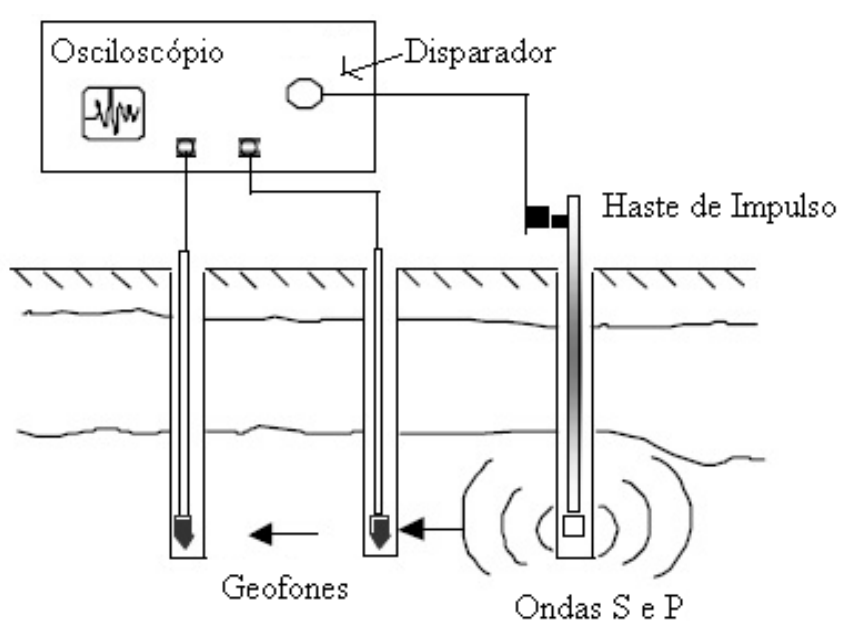

Figura 2.1- Desenho esquemático de um ensaio crosshole (Luna e Jadi, 2000).

Os ensaios downhole e uphole são outras alternativas para a determinação da velocidade de propagação de ondas no solo, porém para estes ensaios são necessários apenas um furo de sondagem. O ensaio downhole se diferencia do uphole pelo posicionamento da fonte geradora das ondas, que é colocada na superfície e o sensor que é instalado em várias profundidades no interior do furo de sondagem. Já, no ensaio uphole, a posição do sensor é fixa na superfície e as ondas são geradas em diferentes profundidades. A Figura 2.2 ilustra esses dois ensaios.
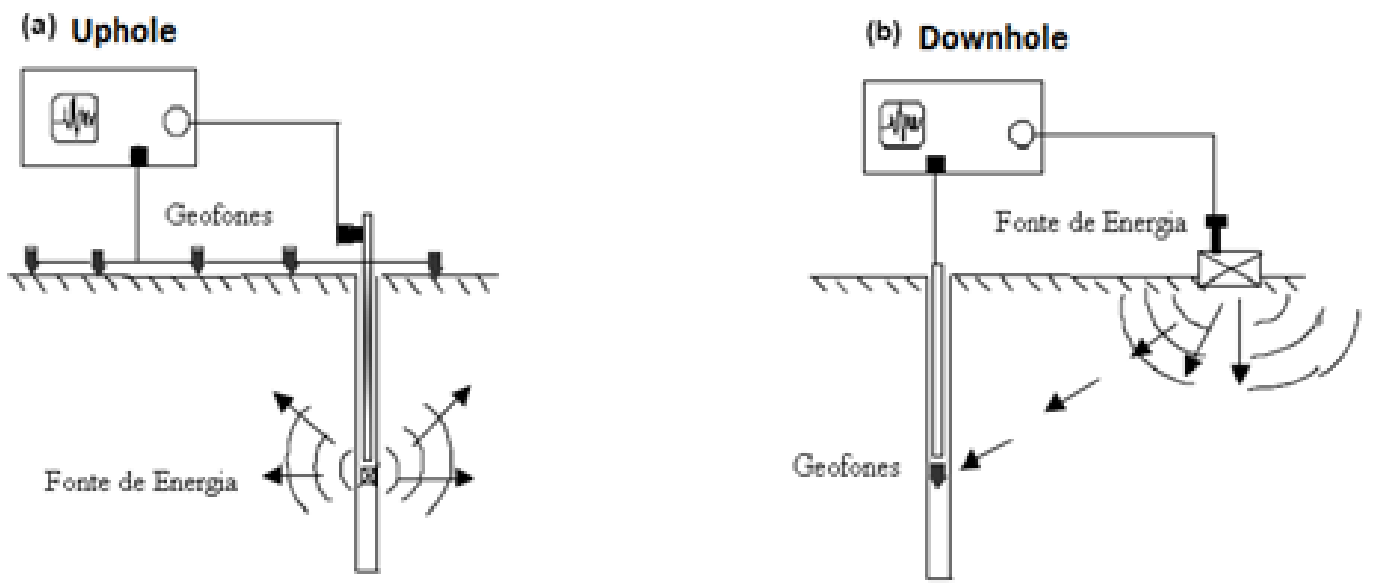

Figura 2.2- Desenhos esquemáticos dos ensaios (a) uphole e (b) downhole (Luna e Jadi, 2000).

\subsubsection{Ensaio de cone sísmico (SCPT)}

Segundo Davies e Campanella (1995), o ensaio de cone sísmico foi desenvolvido pela empresa Fulgro Inc. com a parceria da UBC (University British of Columbia) no início da década de 80. A adição de transdutores sísmicos (geralmente geofones ou acelerômetros) ao 
cone padrão do ensaio CPT deu origem ao cone sísmico. O ensaio é conhecido por SCPT (Seismic Cone Penetration Test), conforme Robertson et al. (1986). A Figura 2.3 ilustra a ponteira, onde nela existe também um sensor para medida de poropressão, sendo, portanto, um piezocone sísmico.

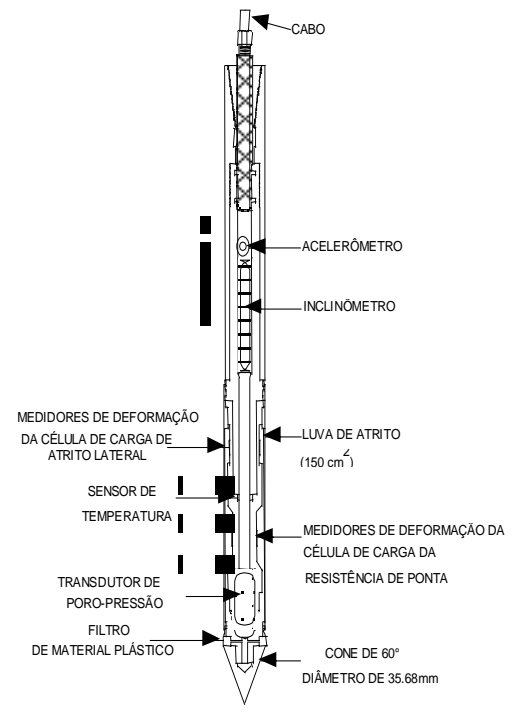

Figura 2.3- Piezocone sísmico (SCPTU) (Davies e Campanella, 1995)

O ensaio SCPT é realizado da mesma forma que é feito com o cone elétrico no que diz respeito ao procedimento de preparação e medidas de resistência de ponta $\left(\mathrm{q}_{\mathrm{c}}\right)$ e atrito lateral $\left(\mathrm{f}_{\mathrm{s}}\right)$. O ensaio downhole com a utilização do SCPT consiste em 3 etapas: medida do tempo de chegada das ondas $\mathrm{S}$, determinação da velocidade da onda $\mathrm{S}\left(\mathrm{V}_{\mathrm{s}}\right)$ para cada profundidade de ensaio e cálculo do módulo de cisalhamento máximo $\left(\mathrm{G}_{\max }\right)$ para cada uma dessas profundidades.

A determinação da velocidade de propagação das ondas pode ser feita a cada parada de penetração do cone, seja tanto no momento da cravação, como no momento da sua retirada. Quando não se conhece o perfil do terreno, a realização do ensaio sísmico à medida que o cone é retirado apresenta vantagens. A Figura 2.4 apresenta um diagrama do procedimento passo-a-passo para realização desse ensaio.

Para facilitar a identificação da chegada das ondas é recomendado utilizar uma fonte que tenha capacidade de gerar grande quantidade de ondas $S$, tenha repetição permita reversão e seja de fácil transporte. Na Figura 2.5 pode-se ver um esquema de como é uma fonte sísmica, composta de um martelo e uma placa de aço, a qual é golpeada em ambos os lados do caminhão. 


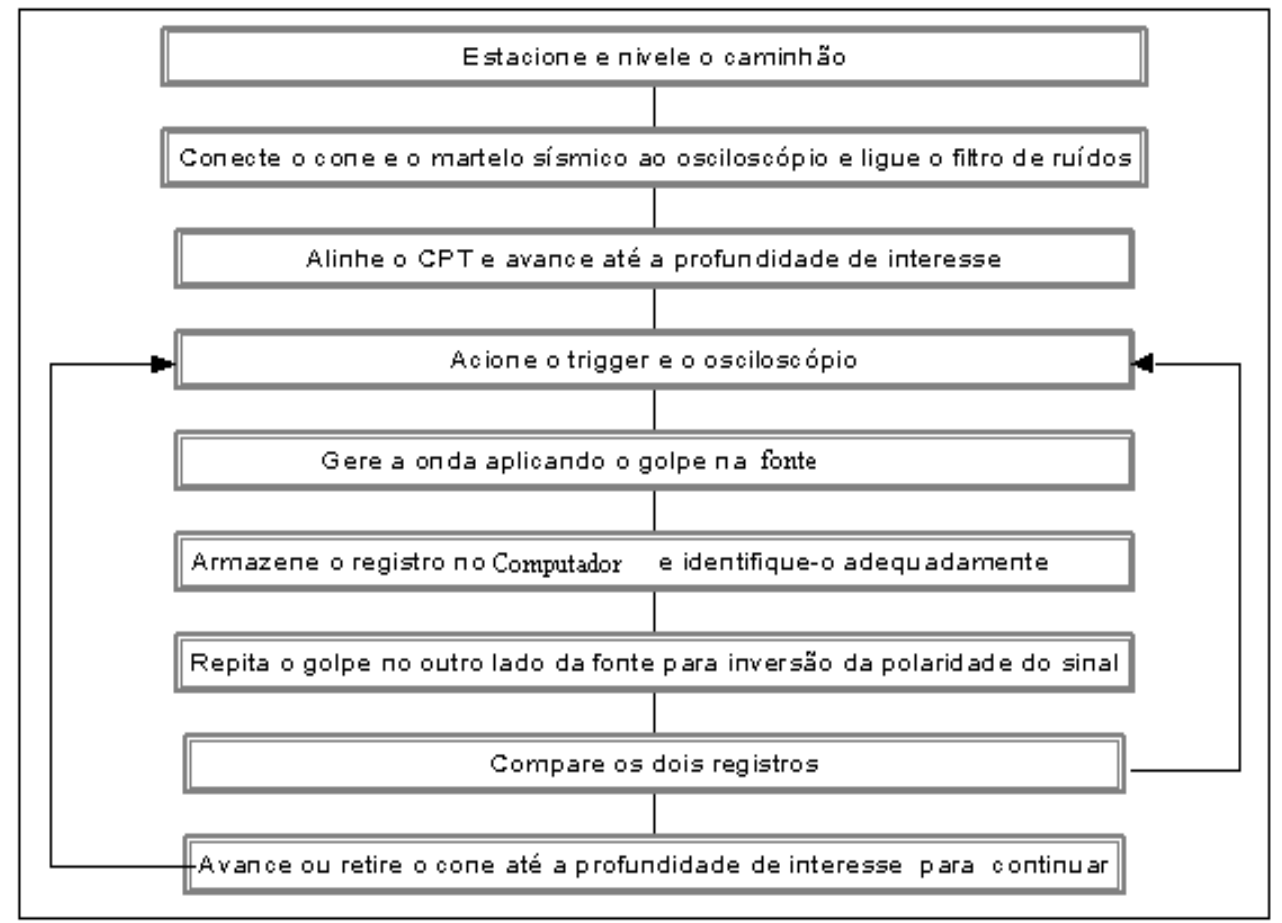

Figura 2.4- Procedimento para realização do cone sísmico (adaptado de Rice, 1984)
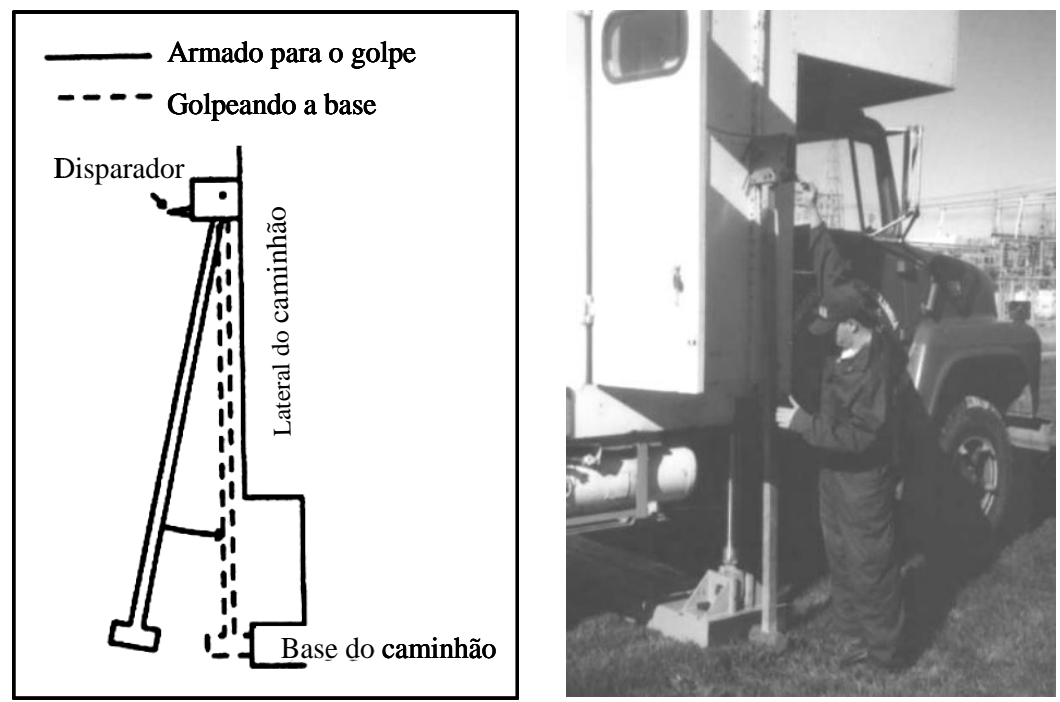

Figura 2.5- Martelo sísmico utilizado no caminhão de ensaios da UBC/Canadá (Giacheti, 2001)

Mayne e Schneider (2000), estudando a liquefação do solo causada por terremoto (Figura 2.6), apresentam as informações possíveis de serem obtidas a partir do ensaio SCPT:

- Tipo de solo e estratigrafia $\left(\mathrm{q}_{\mathrm{T}}, \mathrm{R}_{\mathrm{f}}=\mathrm{f}_{\mathrm{s}} / \mathrm{q}_{\mathrm{T}}\right.$.100);

- Medida direta da velocidade de ondas cisalhantes $\left(\mathrm{V}_{\mathrm{s}}\right)$, e conseqüentemente o módulo de cisalhamento máximo $\left(\mathrm{G}_{\max }\right)$;

- Suscetibilidade a liquefação através de análise direta $\left(\mathrm{q}_{\mathrm{c}} \mathrm{e} \mathrm{V}_{\mathrm{s}}\right)$; 
- Estimativa de parâmetros geotécnicos para emprego em projetos ( coesão, ângulo de atrito, densidade relativa, OCR e outros parâmetros).

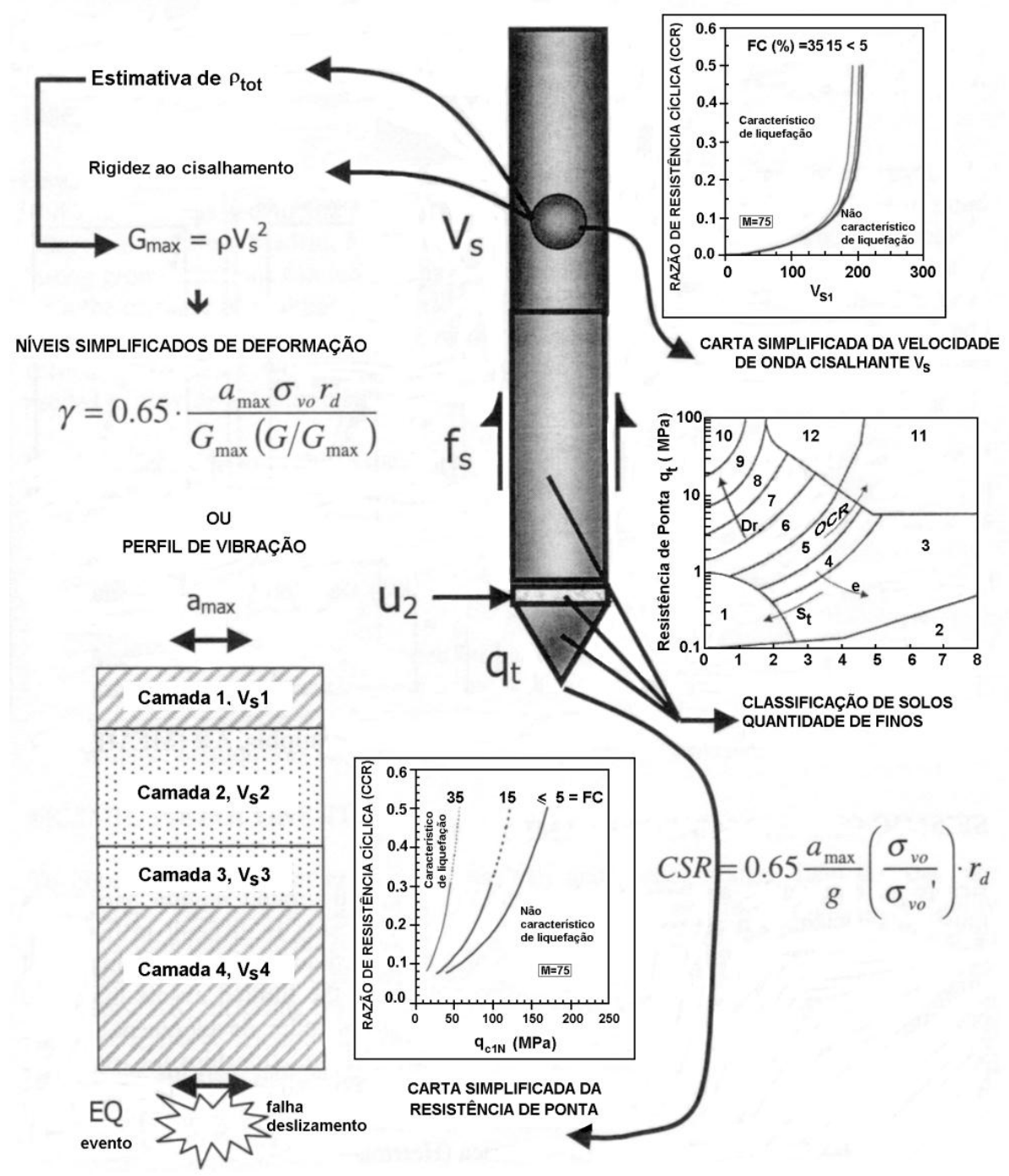

Figura 2.6- Parâmetros possíveis de serem obtidos em um ensaio de piezocone sísmico utilizados para caracterização geotécnica em região sujeita à terremoto (Mayne e Schneider, 2000).

Não obstante haver referências apontando um custo relativamente mais baixo quando comparado à outras técnicas sísmicas de prospecção, e a obtenção pontual em alguns trabalhos científicos de valores das velocidades de propagação das ondas cisalhantes, quando comparados com, por exemplo, a técnica do cross-hole sísmico, alguns autores Roberston et al (1986), e Davies e Campanella (1995) assinalam a importância de um julgamento rigoroso quanto à equivalência entre as diferentes técnicas, atendendo às heterogeneidades e as condições de anisotropia envolvidas.

De acordo com Vitali (2009), o procedimento de cravação do cone proporciona um contato mecânico bastante eficiente entre o solo e o geofone, permitindo uma excelente 
recepção do sinal. Além disso, a orientação do geofone pode ser controlada, para garantir a qualidade dos registros sísmicos e identificação exata do momento de chegada das ondas sísmicas.

Um arranjo típico utilizado no ensaio SCPT envolve um circuito disparador, um martelo e um osciloscópio digital com recurso de armazenamento de dados. Como fonte sísmica, utiliza-se uma das bases niveladoras do equipamento de cravação, que proporciona um excelente contato com o solo devido às elevadas tensões estáticas ali presentes (Figura 2.7). Os detalhes do equipamento, bem como os procedimentos para a execução do ensaio e a interpretação dos resultados encontram-se em Vitali (2011).

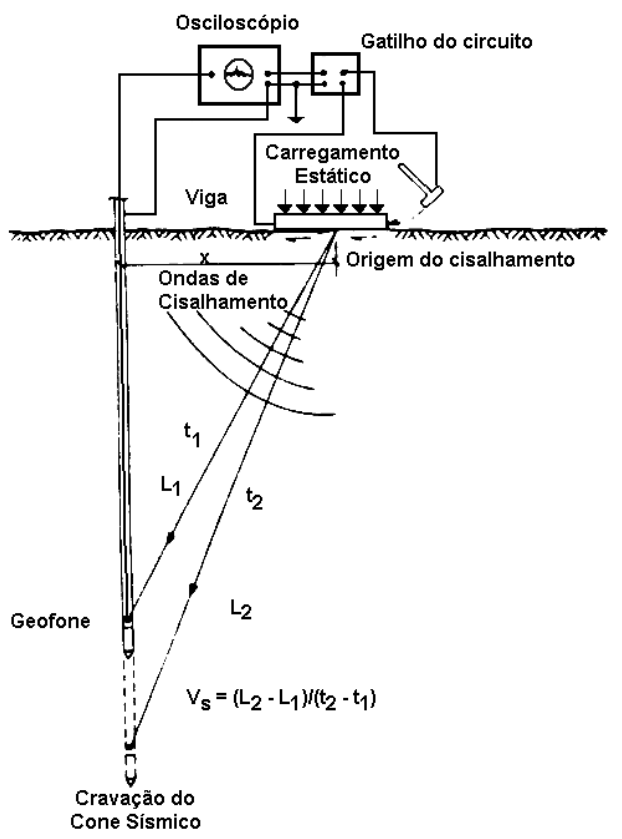

Figura 2.7- Representação esquemática de um ensaio SCPT downhole (Campanella e Stewart, 1992).

A etapa mais importante da interpretação do ensaio downhole é a medida precisa do tempo de chegada da onda $\mathrm{S}$. A velocidade de onda cisalhante $\left(\mathrm{V}_{\mathrm{s}}\right)$ pode ser determinada dividindo-se a diferença das distâncias percorridas pela onda S, para duas profundidades diferentes, pela diferença de tempo entre dois sinais registrados.

\subsubsection{Métodos para a determinação do intervalo de tempo e da velocidade}

De acordo com Butcher et al (2005), o intervalo de tempo pode ser determinado utilizando dois ou mais transdutores posicionados em profundidades diferentes (intervalo verdadeiro de tempo) ou utilizando apenas um transdutor posicionado em diferentes profundidades sucessivamente (pseudo-intervalo de tempo). 
Rice (1984) comparou os resultados empregando o intervalo verdadeiro e o pseudo intervalo e obteve diferença inferior a 1,5\%, o que indica que os métodos são equivalentes desde que o trigger e as ondas geradas sejam repetitivos. Contudo, de acordo com o mesmo autor, caso não se tenha um trigger adequado, a utilização do pseudo intervalo não é confiável.

Para a determinação de $\mathrm{V}_{\mathrm{s}}$ existem três métodos, que são discutidos detalhadamente por Vitali (2011): métodos do primeiro tempo de chegada, do cross over e do cross correlation.

De acordo com Campanella e Stewart (1992), o método cross correlation não é afetado por distorções localizadas no sinal sendo considerado pelos autores o que conduz a resultados mais confiáveis e consistentes. Entretanto, é um método muito mais complexo que requer o emprego de um software para sua utilização. Esses mesmos autores dizem que o método pode ser aplicado tanto no domínio dos tempos como no domínio das frequiências. No domínio dos tempos, este método consiste em deslocar no eixo das abscissas (tempo) um sinal em relação ao outro, o intervalo de tempo que fornecer a maior correlação entre os sinais é o intervalo de tempo utilizado para o cálculo de $\mathrm{V}_{\mathrm{s}}$. A Figura 2.8 ilustra a aplicação deste método.

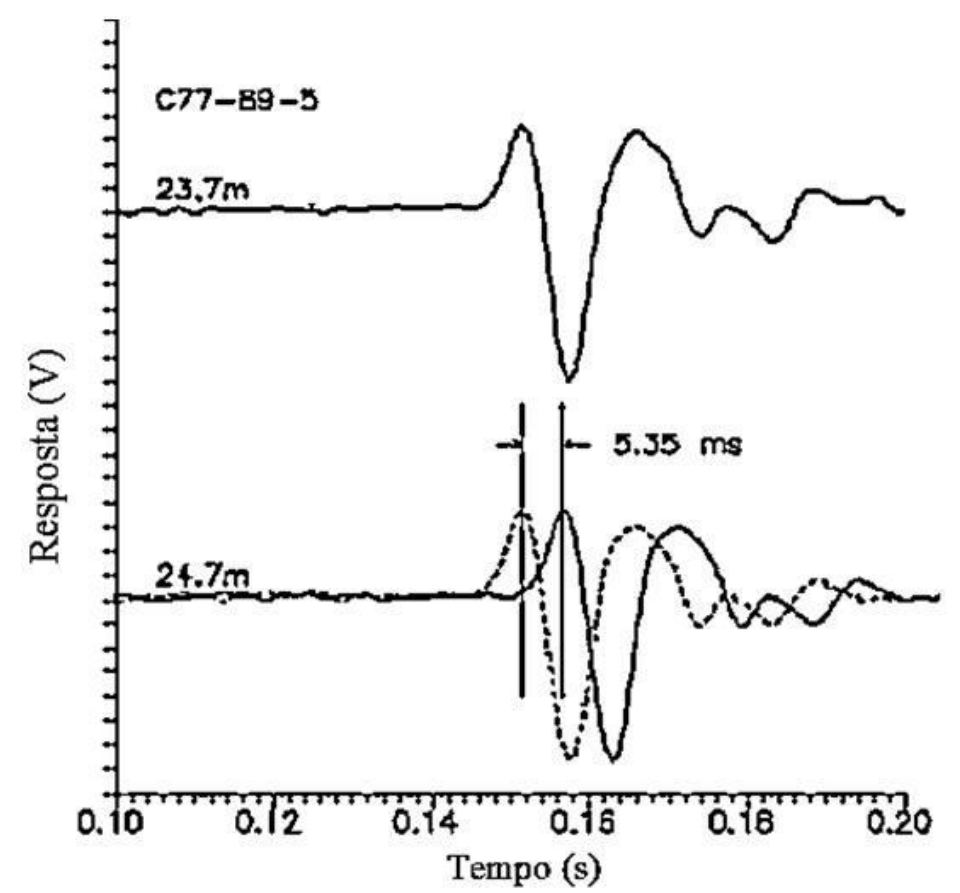

Figura 2.8- Determinação do intervalo de tempo através do método do cross correlation no domínio do tempo (Campanella e Stewart, 1992).

Os registros antecessores e posteriores ao pulso principal da onda $\mathrm{S}$ interferem na interpretação dos resultados, sendo conveniente remove-los. Campanella e Stewart (1992) recomendam selecionar uma revolução completa do pulso principal da onda $\mathrm{S}$ e destacam que 
esse método assume semelhança entre os dois sinais registrados em profundidades subseqüentes. De acordo com os autores, para distâncias menores ou iguais a um metro isto normalmente ocorre.

\subsection{FUNDAÇÕES DIRETAS}

De acordo com a NBR 6122/2010, fundação direta é aquela em que a carga é transmitida ao solo, predominantemente pelas tensões distribuídas sob a base do elemento estrutural de fundação. Exemplo de elementos de fundações diretas são as sapatas, blocos, radiers, baldrame e etc.

\subsubsection{Tipos de Ruptura}

Terzaghi (1943) diferencia dois mecanismos de ruptura em fundações: a ruptura geral, para solos compactos e rijos, e a ruptura local para solos mais compressíveis. Posteriormente Vesic (1975) acrescenta um terceiro modo de ruptura aqueles definidos por Terzaghi que é a ruptura por puncionamento, muito comum em solos moles e fofos.

De acordo com Vesic (1975), a ruptura geral é caracterizada pela existência de uma superfície de deslizamento contínua que vai da borda da base do elemento estrutural de fundação e vai até a superfície do terreno, conforme mostra a Figura 2.9 a. A ruptura é repentina e a carga é bem definida. Observa-se deslocamento do solo na superfície e a ruptura é acompanhada por tombamento do elemento estrutural de fundação.

A ruptura local é claramente definida apenas na base do elemento estrutural de fundação, conforme mostra a Figura $2.9 \mathrm{~b}$ e apresenta características dos outros modos de ruptura. Trata-se, portanto, de um caso intermediário.

Já, a ruptura por puncionamento, de acordo com o mesmo autor, é o contrário da ruptura geral. O solo externo a área carregada praticamente não é afetado e não há movimentação do solo na superfície, conforme mostra a Figura 2.9c. Com a aplicação da carga, o elemento estrutural tende a penetrar continuamente em decorrência da compressão do solo subjacente. 
(a)
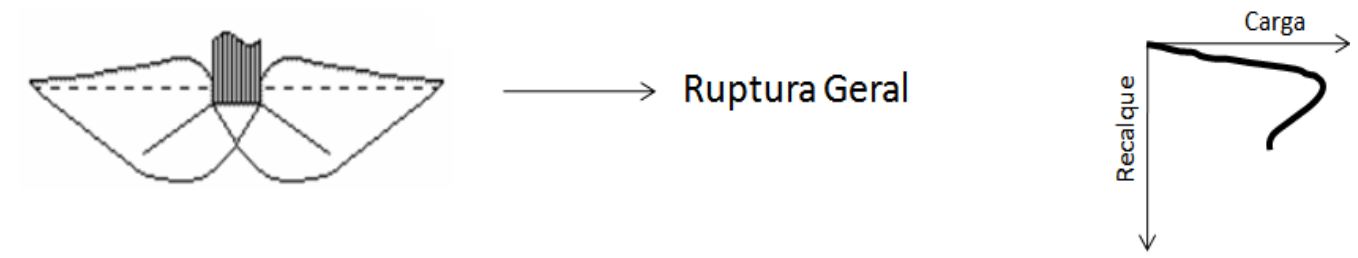

(b)
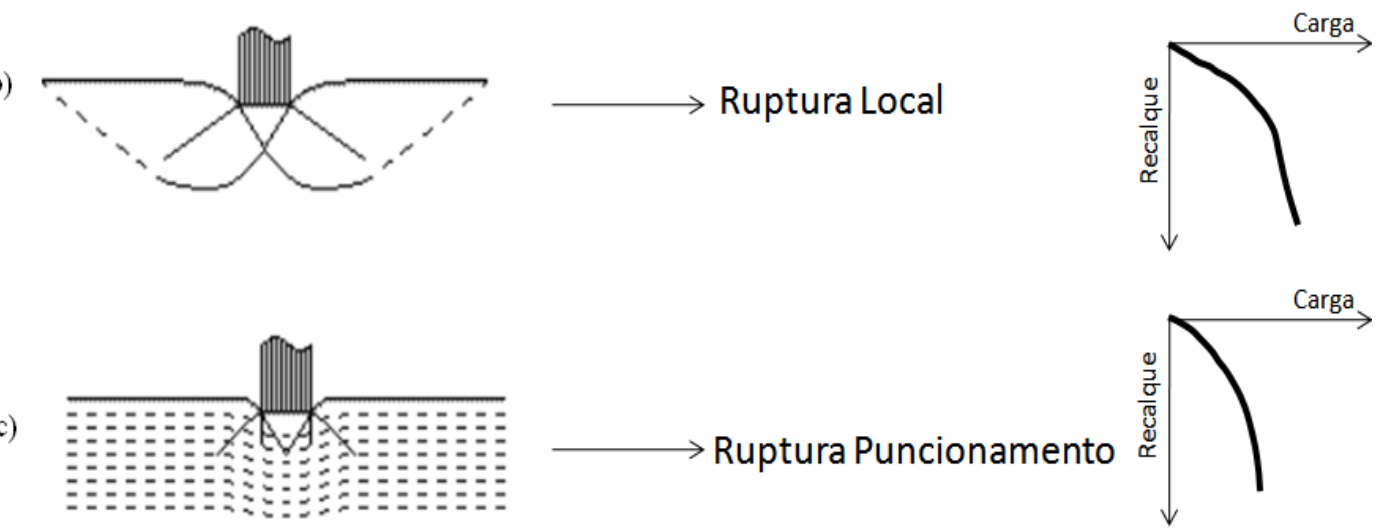

Figura 2.9- Modos de Ruptura (Vesic, 1975).

Em solos arenosos, Vesic (1975) mostra que ao aumentar suficientemente a profundidade de apoio da base do elemento estrutural de fundação ocorrerá apenas a ruptura por puncionamento, qualquer que seja o solo. A forma típica da curva carga-recalque para os três tipos de ruptura, também pode ser visto na Figura 2.9.

\subsubsection{Cálculo da carga de ruptura}

Muitos autores têm trabalhado no desenvolvimento de métodos da capacidade de carga de fundações por sapatas, partindo de hipóteses um pouco diferentes das de Terzaghi e às vezes, tratando de casos específicos, como a proposta de Meyerhof (1956). Este método utiliza de maneira direta os resultados do ensaio de penetração de cone (CPT), bem como os resultados do ensaio de placa, sem a necessidade empregar correlações empíricas para o cálculo da carga última ( $\left.\mathrm{q}_{\mathrm{ult}}\right)$.

Para determinação da carga de ruptura de um elemento de fundação direta utilizando-se os resultados do ensaio de cone, o método de Meyerhof (1956) é dado pela equação abaixo:

$$
q_{u l t}=\overline{q_{c}}\left(\frac{B}{12,2}\right)\left(1+\frac{D_{f}}{B}\right)
$$


Sendo:

$\overline{q_{c}}=$ média aritmética dos valores de qc, variando da cota de apoio, até a profundidade 1,5.B abaixo da sapata;

$\mathrm{B}=$ diâmetro ou lado da sapata;

$\mathrm{D}_{\mathrm{f}}=$ profundidade de apoio da sapata.

A tensão atuante na base da sapata ou em tubulões é admitida uniformemente distribuída. Esta deve ser sempre menor ou igual à tensão admissível do solo considerando seus respectivos fatores de segurança.

\subsubsection{Recalque em Fundações Diretas na condição elástico-linear}

A expressão conveniente para a estimativa do recalque imediato de fundação direta do tipo sapata admitindo o módulo de elasticidade de solo $\left(\mathrm{E}_{\mathrm{s}}\right)$ constante, é dado pela seguinte expressão, oriunda da Teoria da Elasticidade (Timoshenko e Goodier, 1951):

$$
\delta=\frac{q \cdot B \cdot I}{E_{s}}
$$

Onde:

$\delta=$ Recalque;

$\mathrm{q}=\mathrm{Q} / \mathrm{S}=$ Tensão líquida da sapata;

$\mathrm{Q}=$ força axial;

$\mathrm{S}=$ área de apoio da sapata;

$\mathrm{B}=$ menor lado da sapata retangular ou diâmetro da sapata circular;

I= fator de influência que leva em consideração a profundidade da camada impenetrável do solo, a rigidez da fundação e o coeficiente de Poisson do solo (Poulos e Davies, 1974);

$\mathrm{E}_{\mathrm{s}}=$ módulo de deformabilidade do solo.

Existem vários métodos para o cálculo de recalques imediatos em fundações diretas. Nesta pesquisa será apresentado as seguintes propostas clássicas: os métodos de Schmertmann (1978) e o método de Meyerhof (1974). 


\subsubsection{Método de Schmertmann (1970 e 1978)}

Dado um carregamento que induz no solo uma tensão vertical $(\sigma)$ atuando na superfície de um semi-espaço elástico, isotrópico e homogêneo com o módulo de elasticidade $\mathrm{E}_{\mathrm{s}}$, a deformação vertical $\varepsilon_{\mathrm{z}}$ à profundidade $\mathrm{z}$, sob o centro do carregamento, pode ser expressa por:

$$
\varepsilon_{z}=\frac{\sigma}{E_{s}} I_{z}
$$

Onde:

$I_{z}=$ fator de influência na deformação.

Por meio de análises teóricas, estudos em modelos, e simulações pelo método dos elementos finitos, Schmertmann, (1970) observou que a deformação máxima não ocorre no contato com a base da sapata, mas a uma certa profundidade, em torno de $\mathrm{z}=\mathrm{B} / 2$, onde $\mathrm{B}$ é a largura da sapata. A partir dessa profundidade, as deformações diminuem gradualmente e podem ser desprezadas para profundidade $\mathrm{z}=2 \mathrm{~B}$.

Como conseqüência disso, o autor propõe uma distribuição triangular do fator de influência na deformação, para o cálculo de recalque de sapatas rígidas em areias, conforme apresentada na Figura 2.10.

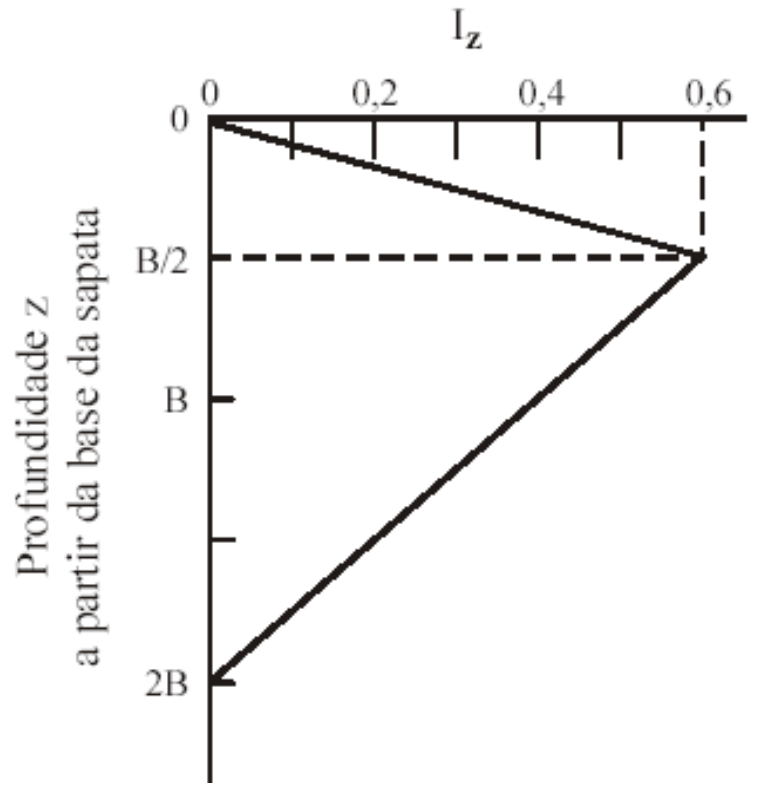

Figura 2.10- Fator de influência na deformação vertical (Schmertmann, 1970). 
Considerando que um maior embutimento da sapata no solo pode reduzir o recalque em até $50 \%$, o autor define um fator de correção do recalque $\mathrm{C}_{1}$, dado por:

$$
C_{1}=1-0,5\left(\frac{q}{\sigma^{*}}\right) \geq 0,5
$$

Onde:

$\mathrm{q}=$ tensão vertical efetiva $(\gamma \times \mathrm{z})$;

$\sigma^{*}=$ tensão líquida aplicada pela sapata $\left(\sigma^{*}=\sigma-q\right)$

Portanto, essa redução não ocorre quando a sapata se encontra à superfície do terreno ( $\mathrm{q}=0$ ) e é máxima quando a profundidade de embutimento resulta $\mathrm{q}=\sigma / 2$ (ou $\mathrm{q}=\sigma^{*}$ ).

O monitoramento do comportamento das sapatas em areia mostra que além do recalque imediato, outra parcela de recalque se desenvolve com o tempo, como um fenômeno de creep, ou a semelhança da compressão secundária em argilas. Por isso, o autor também adota um outro fator de correção $\mathrm{C}_{2}$ dado por:

$$
C_{2}=1+0,2 \log \left(\frac{t}{0,1}\right)
$$

Onde:

$\mathrm{t}=$ tempo expresso em anos.

Finalmente, o recalque de sapatas rígidas em areia é dado pelo somatório das deformações:

$$
{ }_{\Sigma} \rho_{i}=C_{1} C_{2} \sigma^{*} \sum_{i=1}^{n}\left(\frac{I_{z}}{E_{s}} \Delta Z\right)_{i}
$$

Onde:

$\mathrm{I}_{\mathrm{z}}=$ fator de influência na deformação à meia altura da i-ésima camada (com no máximo duas decimais);

$\mathrm{E}_{\mathrm{s}}=$ módulo de deformabilidade da i-ésima camada; 
$\Delta \mathrm{z}=$ espessura da i-ésima camada;

$\mathrm{C}_{1}=$ fator de correção do recalque;

$\mathrm{C}_{2}=$ parcela de recalque que se desenvolve com o tempo;

$\sigma^{*}=$ tensão líquida aplicada pela sapata.

Deve-se destacar que o uso da tensão líquida é justificável porque a parcela correspondente à sobrecarga q representa a reposição do alívio de tensões provocado pela escavação e, portanto, não deve gerar recalque.

Em 1978, Schmertmann introduziu modificações para aperfeiçoar o método sugerido por ele em 1970. Essas modificações, confirmadas por Schmertmann et al. (1978), têm como objetivo principal separar os casos de sapata corrida e de sapata quadrada.

Para isso, dois novos diagramas para a distribuição do fator de influência na deformação são propostos (Figura 2.11). Para sapatas retangulares intermediárias $(1<\mathrm{L} / \mathrm{B}<10$ ), o autor recomenda que se calcule pelos dois casos e que se faça a interpolação.

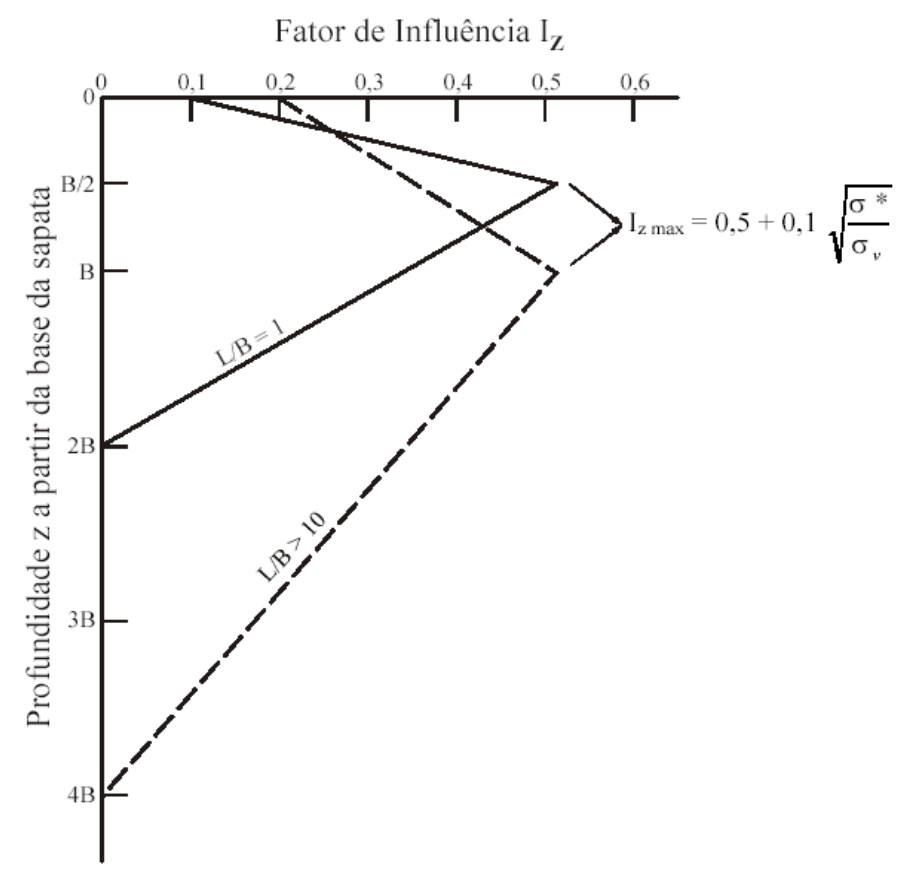

Figura 2.11- Fator de influência na deformação vertical (Schmertmann, 1978).

\subsubsection{Método de Meyerhof (1974)}

Meyerhof (1974) sugeriu que o recalque total S pode ser calculado usando a fórmula: 


$$
S=\frac{\Delta p B}{2 q_{c(\text { med })}}
$$

Onde:

$\mathrm{S}=$ recalque;

$\Delta \mathrm{p}=$ tensão líquida aplicada;

$\mathrm{B}=$ dimensão da sapata;

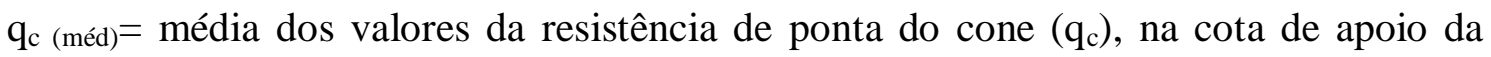
sapata, até a profundidade $\mathrm{Z}=\mathrm{B}$.

\subsubsection{Ensaios de Placa}

De acordo com Decourt e Quaresma Filho (1996) a forma mais adequada para definir as características da curva tensão-recalque, é a realização do ensaio de placa. Este é considerado um dos primeiros ensaios "in situ” para avaliar a deformabilidade do solo, Lancellota (1995). A curva tensão-recalque obtidos no ensaio de placa ou em sapatas, serve como principal fonte de informação para o projeto de fundações superficiais, Reznik (1995).

Teixeira (1966) afirma também que a execução de carregamento em solo por meio de placas, para dimensionamento de fundações, é um dos mais antigos ensaios de campo. De acordo com Barata (1984) as publicações pioneiras sobre o ensaio no Brasil pertencem ao professor Domingos José da Silva Cunha, de 1920.

É importante salientar que o ensaio de placa é aplicável para solos razoavelmente uniformes em profundidade, pois o bulbo de pressões mobilizado pela placa é bem menor que o bulbo gerado pelas sapatas, Cintra et al (2003). O ensaio deve reproduzir as condições de funcionamento previstas para a estrutura, Mello e Cepolina (1978). A Figura 2.12 mostra os diferentes bulbos de pressões gerados pelas placas, com diferentes dimensões, atingindo e camadas distintas do subsolo solos.

Se o bulbo de pressões da placa e da sapata estiverem inseridos em solos com mesmas características de resistência e deformabilidade, o resultado da prova de carga, é equivalente de uma fundação real, Alonso (1991). Portanto, é necessário o conhecimento adequado do perfil geotécnico do terreno para evitar interpretações inadequadas. 


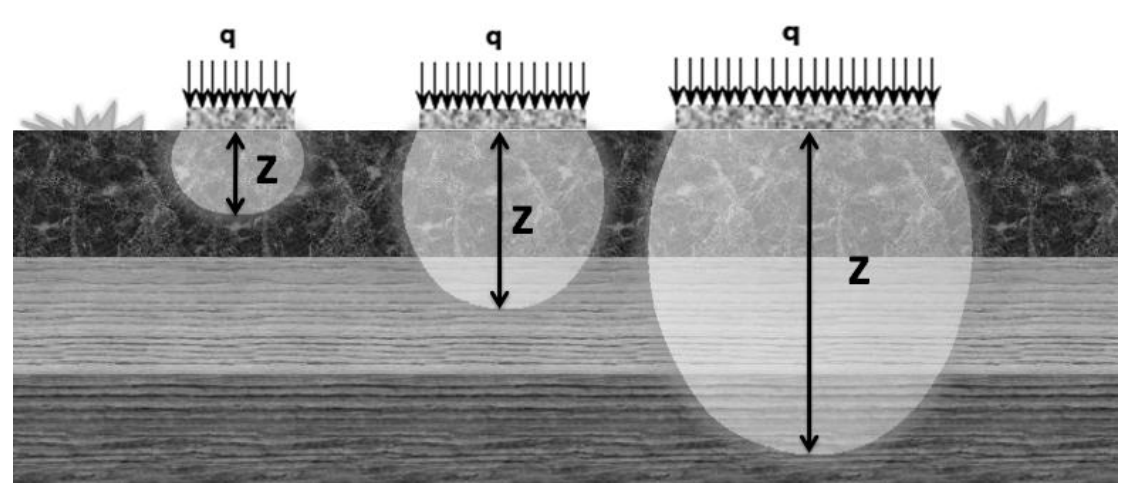

Figura 2.12- Cuidados na interpretação dos ensaios de placa: diferentes bulbos de pressão (adaptado de Mello e Cepolina, 1978).

\subsubsection{Prova de carga em placa com carregamento lento}

No Brasil este ensaio é normatizado pela NBR 6489/84 a qual especifica que, numa prova de carga em placa, o carregamento é realizado em estágios de carga com incrementos de no máximo $20 \%$ da carga admissível prevista (no mínimo 10 estágios se não houver ruptura). As leituras de recalque em cada estágio devem ser realizadas após a aplicação da carga nos tempos $0,2,4,8,15,30,60,90,120$ minutos até se atingir a estabilização. Em cada estágio, a carga deve ser mantida por no mínimo 30 min.

Assume-se que a estabilização dos recalques ocorre quando a diferença entre as leituras realizadas nos tempos t e t/2 corresponder a, no máximo, 5\% do deslocamento total do estágio.

O descarregamento deve ser feito em, no mínimo, 4 estágios. Cada estágio deve ser antido até a estabilização dos deslocamentos, seguindo o mesmo critério para a fase de carregamento.

\subsubsection{Prova de carga em placa com carregamento rápido}

No Brasil não há uma norma específica para a realização do ensaio rápido em placa, por isso, costuma-se adotar as recomendações da NBR 12131/2006 a qual especifica que, numa prova de carga em placa, o carregamento é realizado em estágios de carga com incrementos de no máximo $10 \%$ da carga admissível prevista (no mínimo 20 estágios, se não houver ruptura). Em cada estágio, a carga deve ser mantida por pelo menos $5 \mathrm{~min}$, independente da estabilização dos recalques. Os recalques devem ser lidos no início e no final de cada estágio. O descarregamento deve ser feito em, no mínimo, 4 estágios. Cada estágio deve ser mantido também por pelo menos $5 \mathrm{~min}$. 
Existe também o ensaio misto onde a primeira parte do ensaio é realizada tal como o ensaio lento e a segunda como ensaio rápido.

Os esforços podem ser aplicados axialmente tanto de compressão ou de tração. Os tipos de sistema de reação para os ensaios de compressão são:

(a) Plataforma carregada- A carga na plataforma pode ser transmitida pelo peso de diversos materiais (blocos de concreto pré-fabricado, tanques de água, peças de aço, areia). A massa total deve superar a carga máxima prevista para a prova em pelo menos $15 \%$.

(b) Estacas de reação - Estruturas fixadas no terreno são projetadas com capacidade de carga à tração ao menos 1,5 vezes maior que a capacidade prevista para o ensaio.

(c) Tirantes - Conjunto de tirantes ancorados no terreno é projetado com a capacidade de carga à tração de 1,2 vezes maior a capacidade prevista na prova.

Os três sistemas de reação podem ser vistos na Figura 2.13.

\subsection{COMPORTAMENTO NÃO LINEAR}

A curva tensão-deformação de um solo é afetada por vários fatores: composição granulométrica, índice de vazios, grau de saturação, permeabilidade e trajetória de tensões.

Em algumas situações, para determinação direta da curva tensão-deformação, pode-se realizar ensaios, de compressão triaxial, cisalhamento simples, que podem chegar a níveis de deformação de 0,01 a $0,05 \%$. Os resultados assim obtidos podem não ser muito precisos. Por conta disso, para o estudo da curva tensão-deformação, é necessário o auxílio da Teoria da elasticidade, embora o solo não seja um material elástico perfeito, pois com o descarregamento, as deformações não são recuperáveis, ou então são parcialmente reversíveis. O emprego desta teoria se justifica por ser razoável a hipótese do comportamento tensãodeformação linear até as tensões admissíveis suficientes afastados da ruptura.

É importante entender que um material pode ser elástico-linear, elástico não linear e linear não elástico como mostra a Figura 2.14 mediante a comparação das curvas de carregamento e descarregamento. 


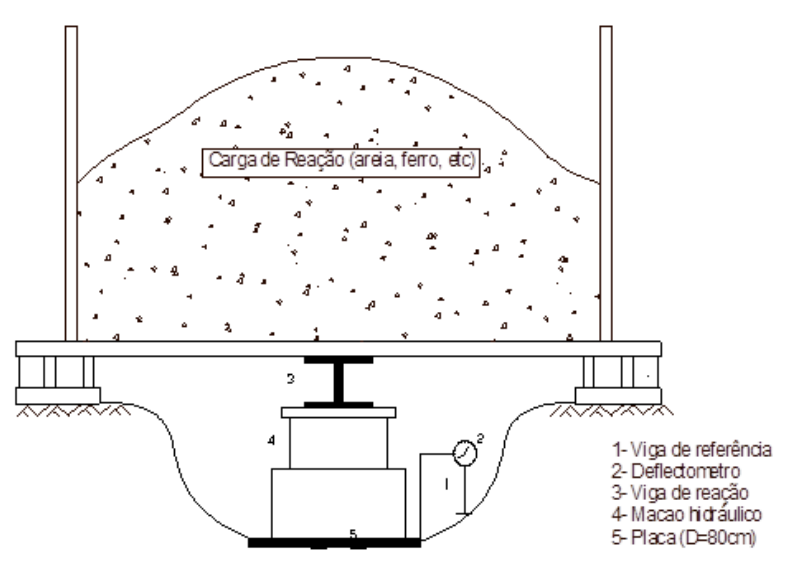

(a)

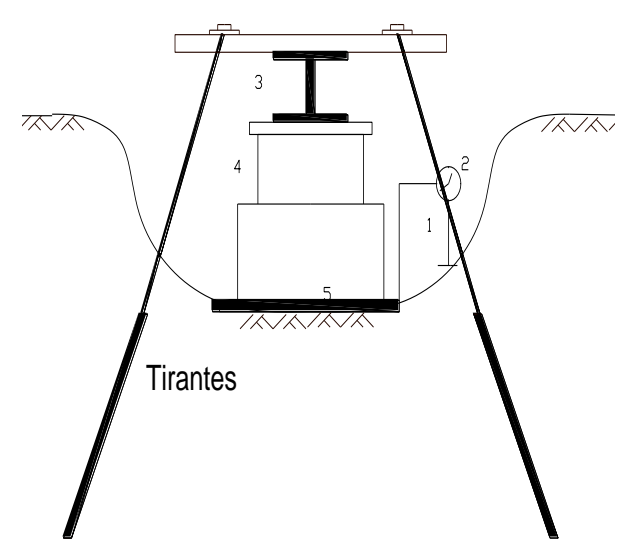

(b)

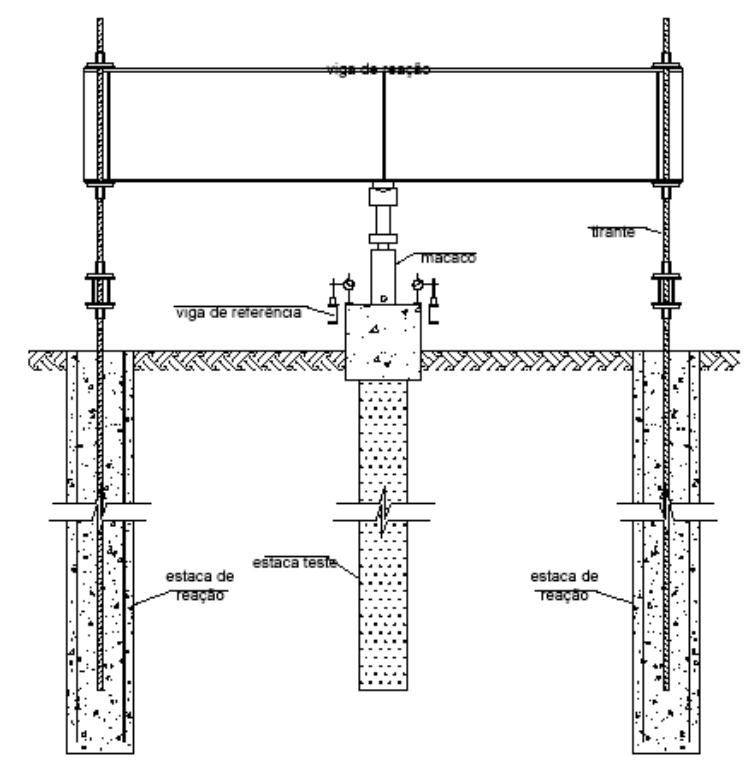

(c)

Figura 2.13 - Desenho esquemático de Sistema de reação para (a) cargueira, (b) tirantes, (c) estacas (Cintra e Aoki, 2003)
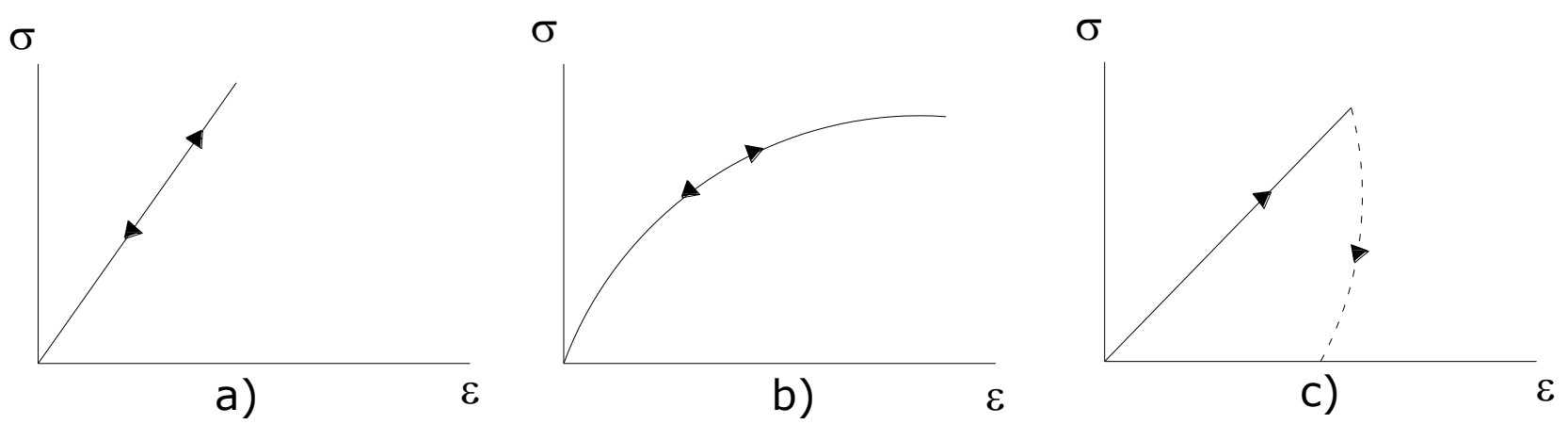

Figura 2.14- comportamento tensão deformação: a) elástico-linear, b) elástico não linear, c) não linear elástico 
De acordo com Nogueira (2005), diferentemente do aço e do concreto, que podem ser considerados materiais mais homogêneos, em face do processo de fabricação, o solo é um material heterogêneo. A Figura 2.15 mostra uma representação esquemática da tensão e deformação e da rigidez com o nível de deformação para o aço que é constante, enquanto que para o solo a relação é não linear.

a)
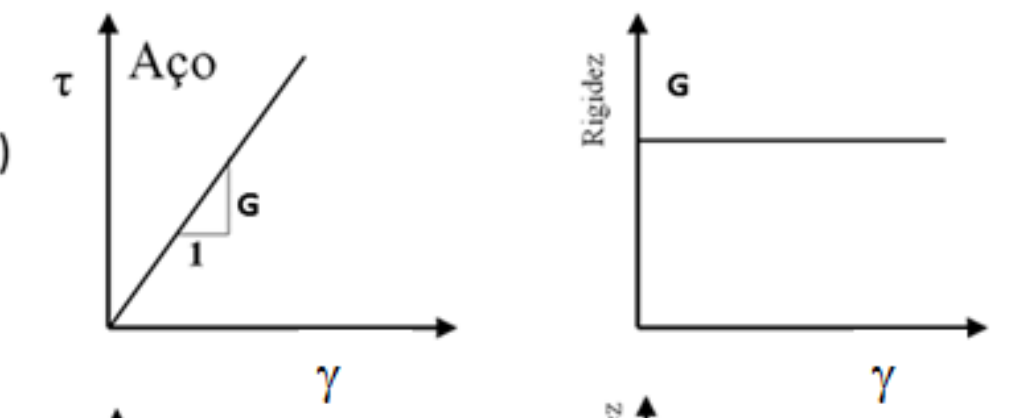

b)

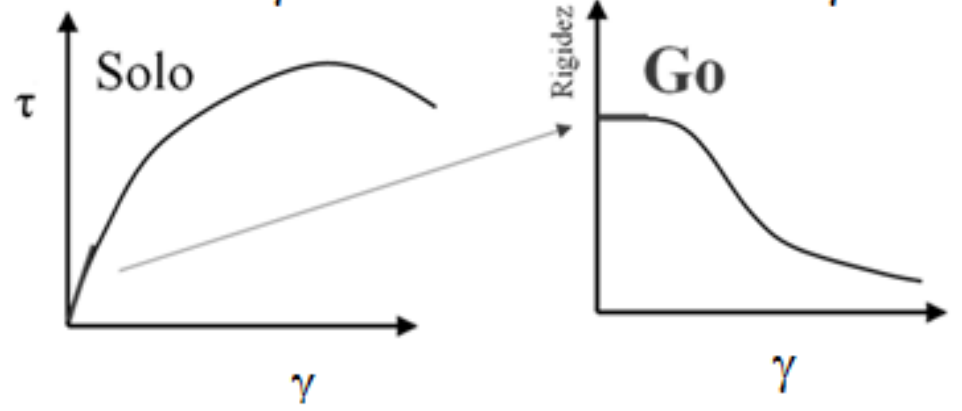

Figura 2.15- Comportamento linear do aço (a) e não linear do solo (b) (adaptado de Nogueira, 1995)

Segundo Mayne (2000), o comportamento tensão-deformação não linear do solo é função do tipo descarregamento, da anisotropia do solo, da história de tensões e, principalmente, do nível de deformação. Segundo Campanella e Robertson (1986) essa relação pode ser estabelecida conhecendo o módulo de cisalhamento máximo e a resistência ao cisalhamento do solo. Esses parâmetros podem ser obtidos através da realização de um ensaio híbrido, como o ensaio de cone sísmico (SCPT).

\subsubsection{Degradação do Módulo}

Segundo Pinto (1996), com base na curva tensão-deformação, dois procedimentos têm sido empregados para determinar o módulo de cisalhamento: o módulo tangente $\left(\mathrm{G}_{\mathrm{tg}}\right)$ que indica a relação tensão deformação no ponto considerado e o módulo secante $\left(\mathrm{G}_{\mathrm{Sec}}\right)$, que indica a relação tensão deformação entre dois pontos. Na origem os dois módulos são coincidentes caracterizando o módulo tangente inicial $\left(\mathrm{G}_{0}\right)$ como mostra a Figura 2.16. 


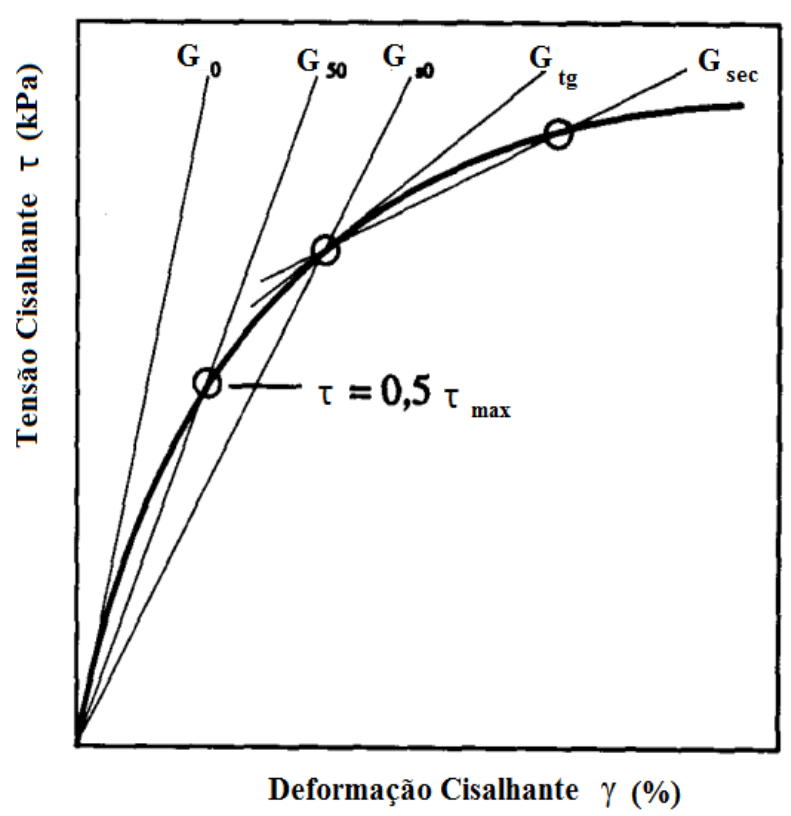

Figura 2.16- Curva típica de carregamento e definição dos módulos de deformabilidade (Pinto, 1996)

$\mathrm{O}$ símbolo $\mathrm{G}_{50}$ indica que o módulo corresponde a um acréscimo de tensão igual a $50 \%$ onde ocorre a ruptura, isto é, a deformabilidade do solo quando solicitado por um fator de segurança igual a dois.

De acordo com Stokoe (1980), a medida que a amplitude de deformação $(\gamma)$ aumenta além dos $0,001 \%$, têm-se a diminuição gradativa do módulo de cisalhamento $(\mathrm{G})$, conforme mostra a Figura 2.17.

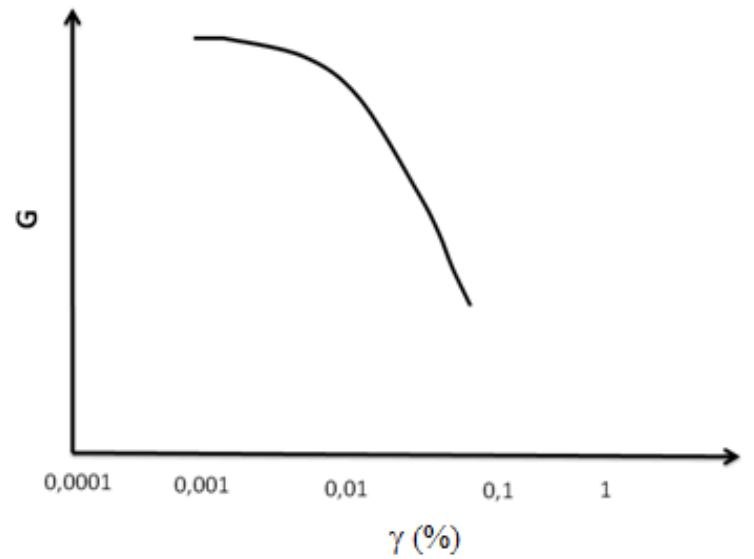

Figura 2.17- Representação esquemática do efeito da amplitude de deformação no módulo de cisalhamento (Stokoe, 1980).

É comum representar a variação do módulo de cisalhamento normalizado pelo módulo de cisalhamento máximo $\left(\mathrm{G} / \mathrm{G}_{\text {máx }}\right)$ com a amplitude de deformação através de um gráfico (Figura 2.18), e a curva resultante é denominada curva de degradação do módulo, conforme mostra Giacheti (2001). 


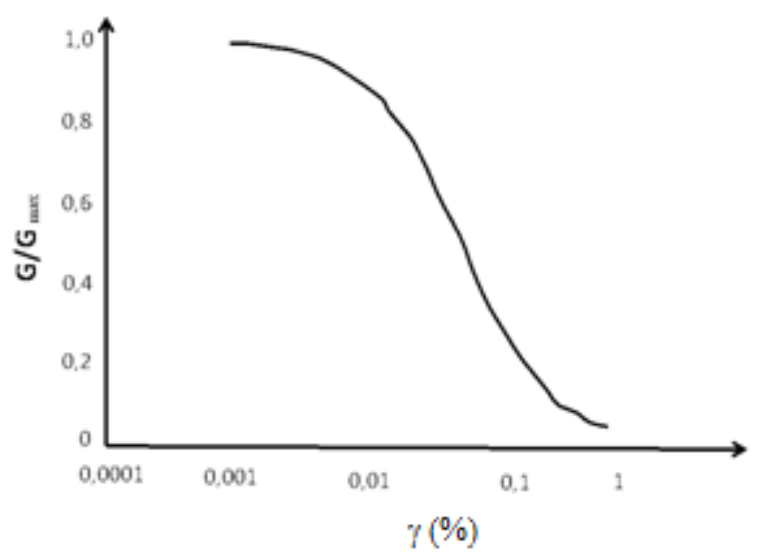

Figura 2.18- Representação esquemática da curva de degradação do módulo (Giacheti, 2001).

Para representar a curva da degradação do módulo, existem vários modelos. A Figura 2.19 mostra curvas de degradação normalizada para dois solos do interior de São Paulo obtidos a partir de resultados de ensaios de coluna ressonante. Observa-se na Figura 2.19 que a curva sugerida para areias apresenta uma degradação muito inferior a de todas as amostras ensaiadas.
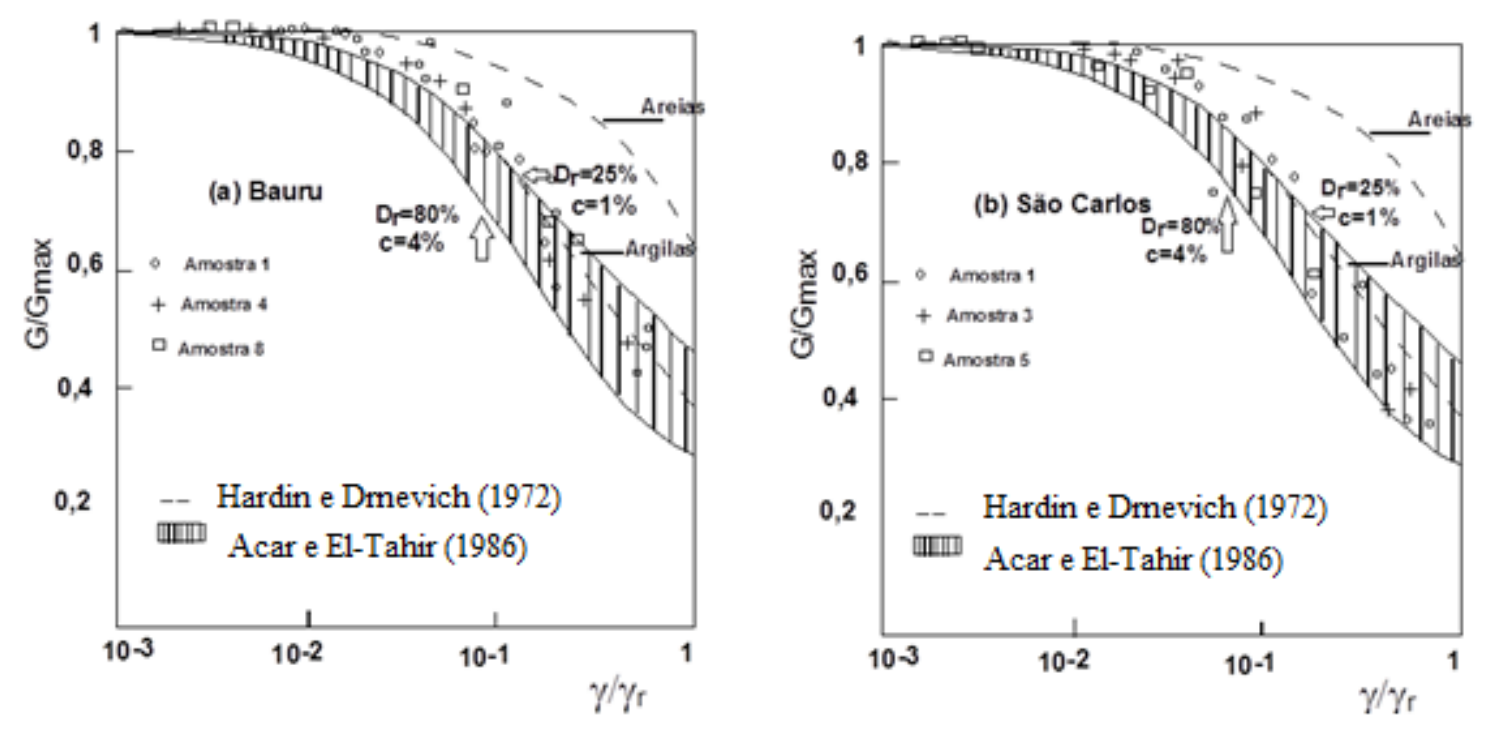

Figura 2.19- Curvas de degradação normalizada obtidas nos ensaios e confrontadas com duas propostas (Giacheti, 2001)

Conforme mostra a Tabela 2.1, há uma diversidade de fatores que afetam o módulo de cisalhamento dos solos. No entanto, alguns exercem mais influências que os outros, Giacheti (2001). Hardin e Drnevich (1972) agruparam estes fatores em 3 (três) categorias: fatores muito importantes (V), de menor importância (L), e relativamente sem importância (U e R). Este agrupamento baseia-se em resultados da pesquisa de Hardin e Drnevich (1972) bem como em outros trabalhos desenvolvidos na época. 
Tabela 2.1 - Fatores que afetam o módulo de cisalhamento em solos arenosos e coesivos (Hardin e Drnevich, 1972)

\begin{tabular}{|c|c|c|}
\hline \multirow[b]{2}{*}{ Fatores } & \multicolumn{2}{|c|}{ Módulo Cisalhamento } \\
\hline & $\begin{array}{c}\text { Areias } \\
\text { Limpas }\end{array}$ & $\begin{array}{c}\text { Solos } \\
\text { Coesivos }\end{array}$ \\
\hline Amplitude de deformação & $\mathrm{V}$ & $\mathrm{V}$ \\
\hline Tensão normal efetiva octaédrica & $\mathrm{V}$ & $\mathrm{V}$ \\
\hline Índice de vazios & $\mathrm{V}$ & V \\
\hline $\mathrm{n}^{\mathrm{o}}$ ciclos de carregamento & $\mathrm{R}$ & $\mathrm{R}$ \\
\hline grau de saturação & $\mathrm{R}$ & $\mathrm{V}$ \\
\hline Razão de sobreadensamento & $\mathrm{R}$ & $\mathrm{L}$ \\
\hline Envoltória de resistência efetiva & $\mathrm{L}$ & $\mathrm{L}$ \\
\hline Tensão cisalhante octaédrica & $\mathrm{L}$ & $\mathrm{L}$ \\
\hline Freqüência vibração ( >0,1 HZ ) & $\mathrm{R}$ & $\mathrm{R}$ \\
\hline Efeitos do tempo & $\mathrm{R}$ & $\mathrm{L}$ \\
\hline Características dos grãos & $\mathrm{R}$ & $\mathrm{R}$ \\
\hline Estrutura do solo & $\mathrm{R}$ & $\mathrm{R}$ \\
\hline Variação do volume devido a deformação cisalhante & $\mathrm{U}$ & $\mathrm{R}$ \\
\hline
\end{tabular}

Para representar a degradação do módulo, a conhecida expressão de Ramberg-Osgood requer quatro parâmetros, mas resulta em tensões de cisalhamento que aumente indefinidamente sem limite, Burghignoli et al. (1991).

Uma função periódica logarítmica também foi proposta por Jardine et al. (1986), e Puzrin e Burland (1998) apresentaram uma função logarítmica para representar o comportamento tensão-deformação para solos e rochas que utiliza um, três ou quatro parâmetros, dependendo das informações disponíveis.

Tais modelos são bastantes empregados na simulação do comportamento dinâmico de maciços terrosos e interação dinâmica solo-estrutura através de métodos numéricos como elementos finitos, Fahey (2001). A hipérbole simples de Kondner (1963) precisa de apenas dois parâmetros: (1) módulo de cisalhamento máximo, $\mathrm{G}_{\max }$, e (2) tensão máxima de cisalhamento, ou a resistência ao cisalhamento, $\tau_{\max }$. Notavelmente, a hipérbole simples não é adequada para representar o comportamento completo e complexo de solos na maioria dos casos em toda a gama de tensões, Tatsuoka e Shibuya (1992). Fahey e Carter (1993) sugere um modelo não linear concebido para solos arenosos e é interessante para ser utilizado em ensaios SCPT. 


\subsubsection{Proposta de Fahey e Carter (1993)}

A equação da hipérbole modificada proposta por Fahey e Carter (1993) para areias é uma maneira de representar a degradação do módulo a baixas amplitudes de deformação $\left(\mathrm{G}_{\max }\right)$ aos valores de rigidez secantes $(\mathrm{G})$ correspondentes aos diferentes níveis de deformação. A equação dessa hipérbole assume a seguinte forma:

$$
\frac{G}{G_{\max }}=1-f\left(\frac{\tau}{\tau_{\max }}\right)^{g}
$$

Onde: f e g são parâmetros de ajuste que controlam a não linearidade da curva tensãodeformação, $\mathrm{G}=$ módulo de cisalhamento $=\mathrm{E} /[2(1+v)]$ e o coeficiente de Poisson $(v)$ que pode ser assumido em função do tipo de solo.

Para uma hipérbole simples os parâmetros de ajuste seriam $\mathrm{f}=\mathrm{g}=1$. Já, para um carregamento monotônico em solos não-estruturados e não cimentados os resultados de ensaios triaxiais e ensaios de cisalhamento simples levaram a valores de $\mathrm{f}=1 \mathrm{e} \mathrm{g}=0,3$, Mayne (1995).

Ealkim (2005) propõe a determinação dos parâmetros de ajuste f e g através do cálculo da deformação normalizada $\left(\mathrm{X}_{\mathrm{L}}\right)$ :

$$
x_{L}=\frac{G_{\max }}{G_{\min }}
$$

Sendo que o $\mathrm{G}_{\max }$ pode ser obtido nos ensaios sísmicos, como o cross-hole ou de cone sísmico.

$O$ valor de $G_{\min }$ pode ser determinado a partir de resultados de ensaios triaxiais obtendose $E_{\min }$ e assumindo-se o coeficiente de Poisson (v). O valor do módulo secante ao ponto onde ocorre a tensão máxima $\left(\sigma_{1}-\sigma_{3}\right)$, em um ensaio triaxial, corresponde a rigidez mínima $\left(\mathrm{E}_{\min }\right)$, conforme mostra a Figura 2.20. 


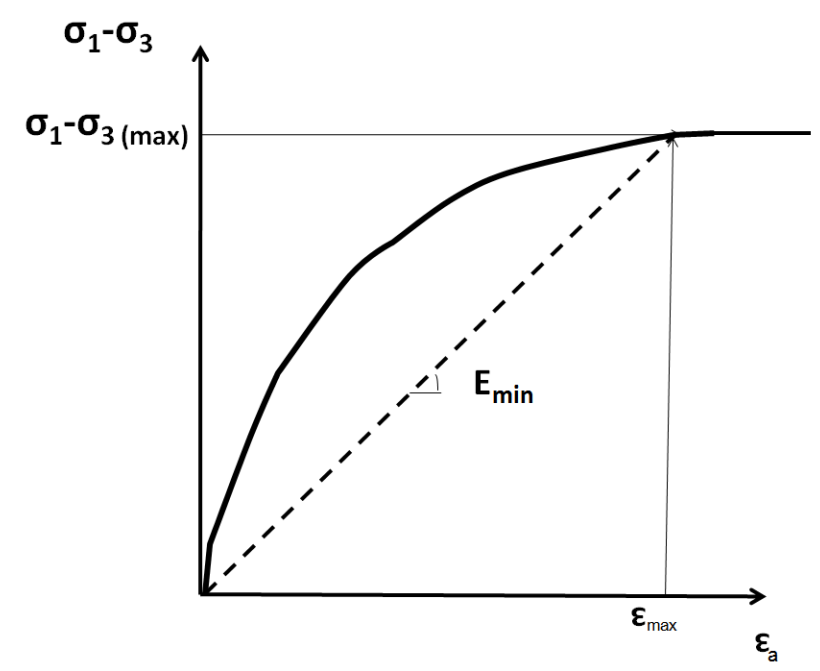

Figura 2.20- Curva tensão-deformação típica de ensaios triaxiais.

Com base na tensão desviadora e na deformação axial, é possível calcular o $\mathrm{E}_{\min }$ através da seguinte equação:

$$
E_{\min }=\frac{\left(\sigma_{1}-\sigma_{3}\right)}{\varepsilon_{\max }} \text { máx }
$$

Para o cálculo do $G_{\min }$ relaciona-se o módulo de deformabilidade $\left(E_{\min }\right)$ e o coeficiente de Poisson ( $v$ ) pela expressão:

$$
G_{\text {min }}=\frac{E_{\text {min }}}{2(1+v)}
$$

Costuma-se assumir para $v$ valores indicados na literatura como os da Tabela 2.2 sugeridos por Bowles (1988).

Para a condição drenada, considerando a placa circular, Ealkim, (2005) sugere a relação entre $\mathrm{X}_{\mathrm{L}}$ com o parâmetro de ajuste g, para os ângulos de atrito de $30^{\circ}, 35^{\circ}$ e $40^{\circ}$. A Figura 2.21 mostra a relação proposta. Para sapata corrida a Figura 2.22 mostra a relação do g com a deformação normalizada $\left(\mathrm{X}_{\mathrm{L}}\right)$. Pode-se observar nessas Figuras que o valor do parâmetro g diminui com o aumento da deformação normalizada.

A variação do parâmetro $g$ com a deformação normalizada $X_{L}$, tanto para fundações em placa circular e fundações em sapata corrida é plotada na Figura 2.23, para a condição não drenada. 
Tabela 2.2 - Valores típicos do coeficiente de Poisson (Bowles, 1988).

\begin{tabular}{cc}
\hline Tipo de Solo & $\mathbf{v}$ \\
\hline Argila saturada & $0,40-0,50$ \\
Argila parcialmente saturada & $0,10-0,30$ \\
Argila arenosa & $0,20-0,30$ \\
Silte & $0,30-0,45$ \\
Areia comum & $0,30-0,4$ \\
\hline
\end{tabular}

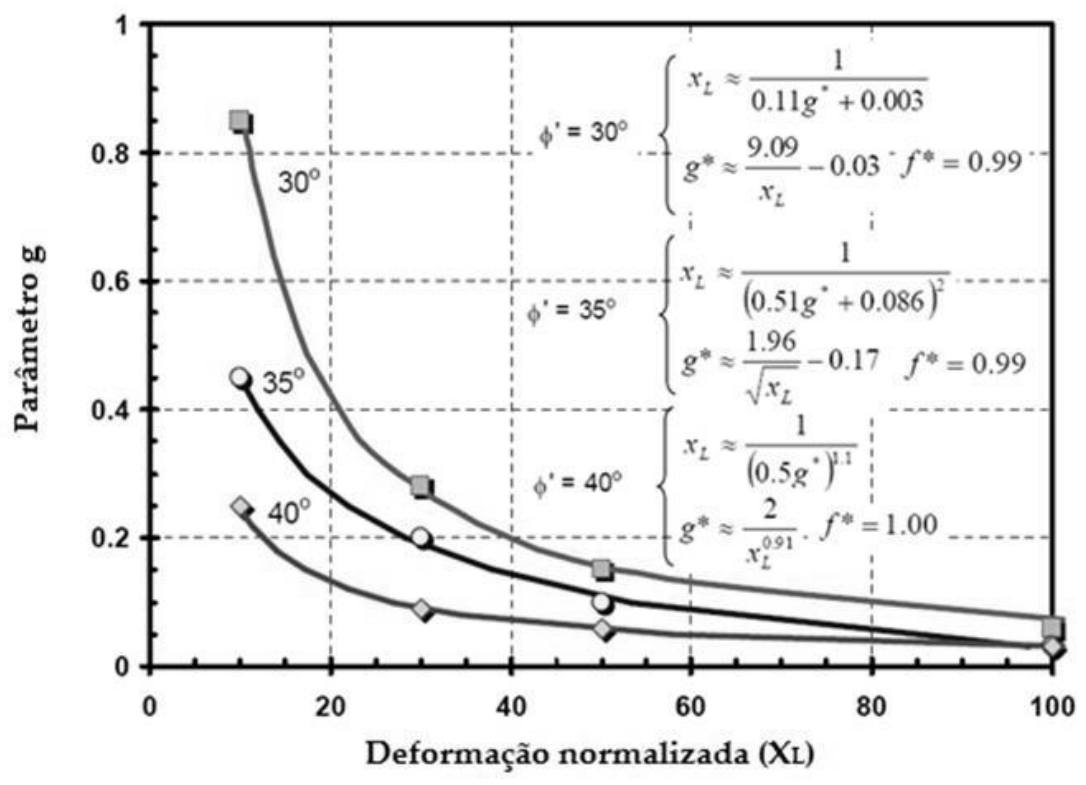

Figura 2.21- Funções Hiperbólicas não lineares que relacionam o parâmetro de ajuste g e a deformação normalizada para carregamento drenado em placa circular (Ealkim, 2005).

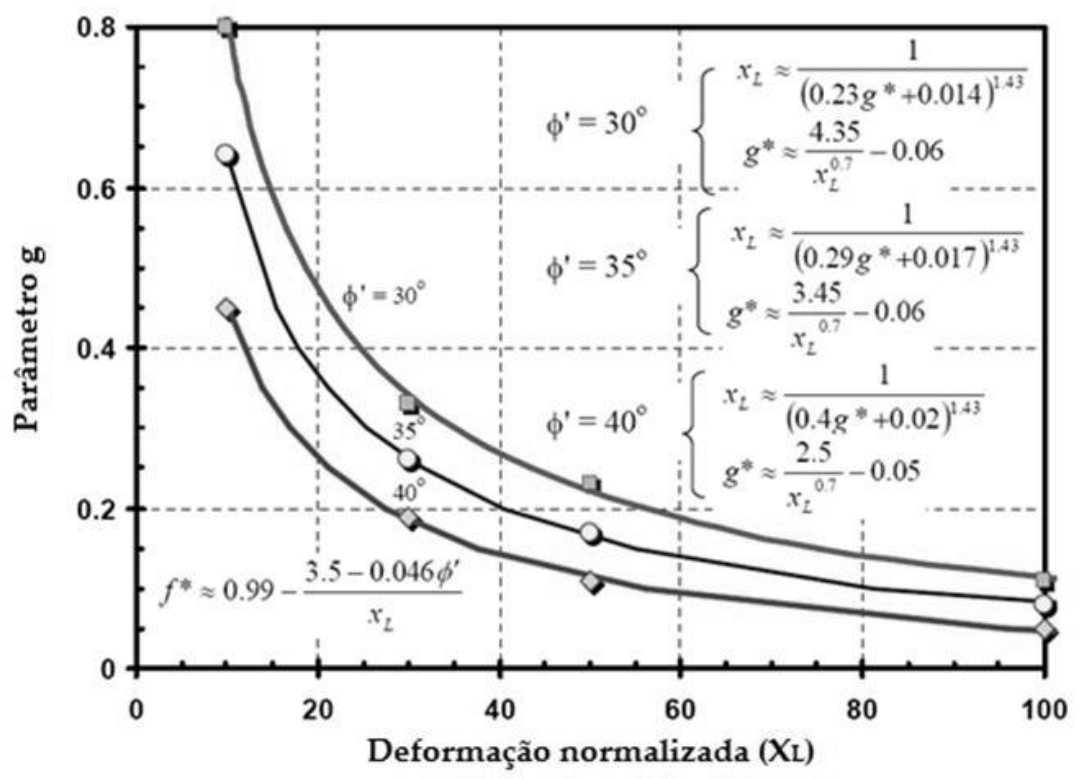

Figura 2.22 - Funções Hiperbólicas não lineares que relacionam o parâmetro de ajuste g e a deformação normalizada para carregamento drenado em sapata corrida (Ealkim, 2005). 


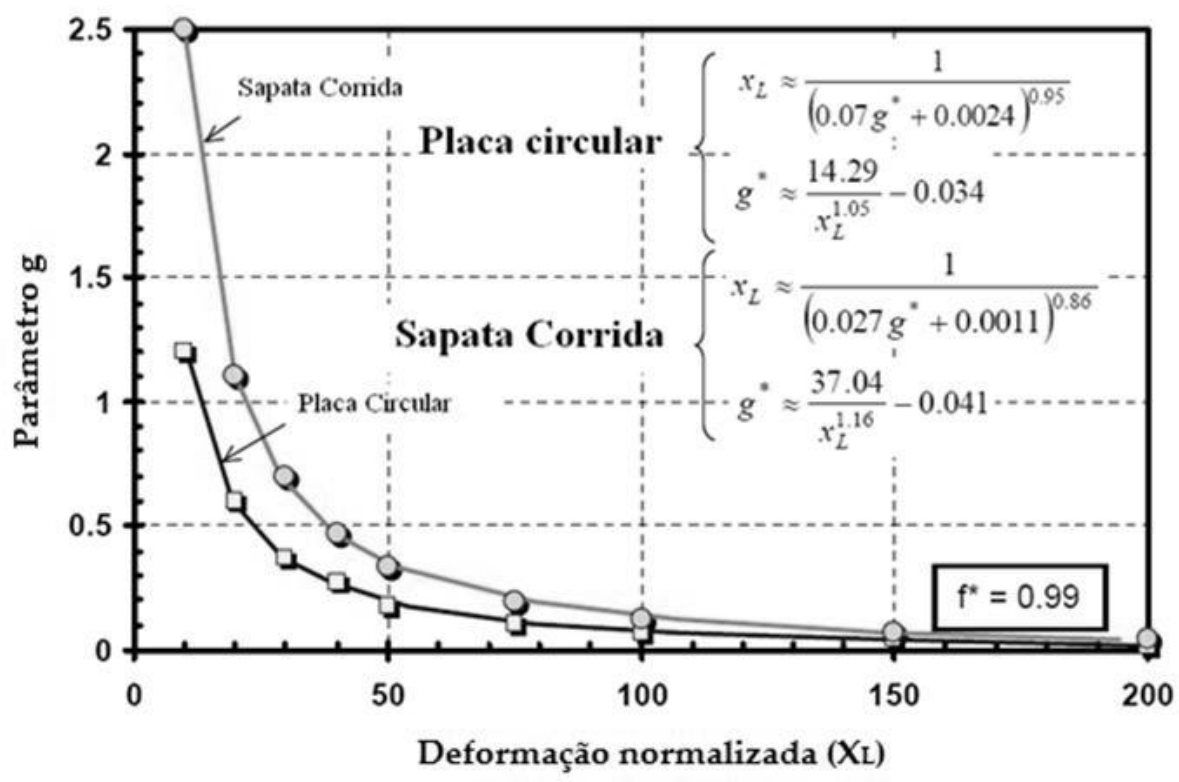

Figura 2.23- Funções Hiperbólicas não lineares que relacionam o parâmetro de ajuste g e a deformação normalizada para carregamento não drenado, para fundação circular e fundação em sapata corrida (Ealkim, 2005).

O valor do parâmetro f varia de acordo com o ângulo de atrito, e com a deformação normalizada $\left(\mathrm{X}_{\mathrm{L}}\right)$, sendo que Ealkim (2005) sugere valores de f variando de 0,99 a 1.

Usando o modelo hiperbólico proposto por Fahey e Carter (1993), resultados de ensaios de laboratório de cisalhamento simples mostram que a diminuição da rigidez é maior em ensaios de carregamento monotônico. Este fato é demonstrado para as areias da praia do Toyoura, na cidade de Yamagushi, no Japão (Figura 2.24).

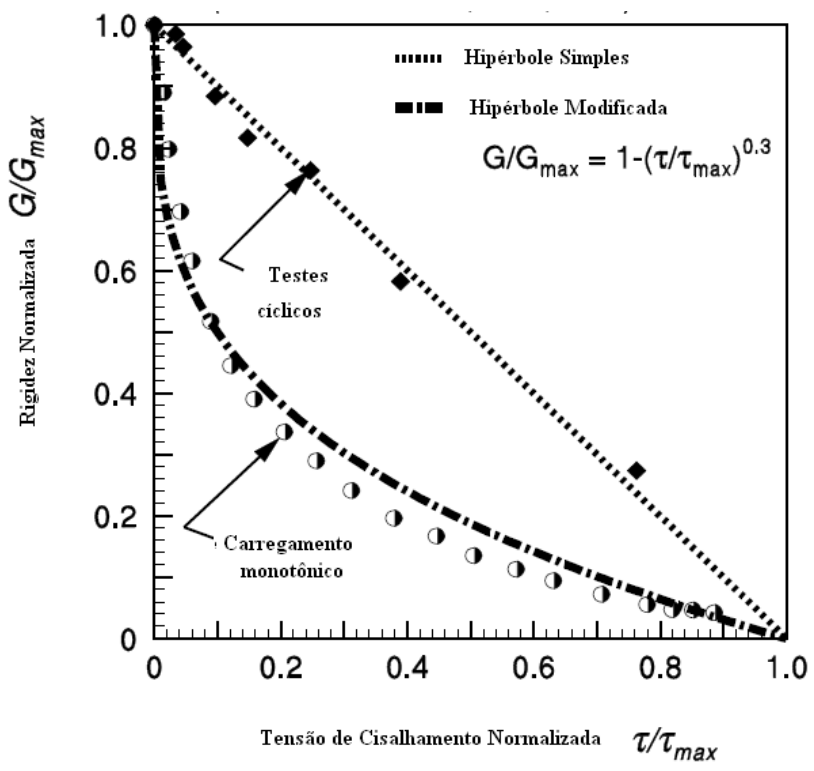

Figura 2.24- Representação da degradação para a areia do Toyoura do Japão (Teachavorasinskun et al., 1991) 
2.4.3 Modelo de Mayne (2000) para a previsão da curva tensão-recalque

Para considerar a não linearidade a partir do módulo de deformabilidade a pequenas deformações $\left(E_{\max }\right)$, determinados em ensaios sísmicos utiliza-se a hipérbole modificada de Fahey e Carter (1993), cuja equação é mostrada abaixo:

$$
E_{s}=E_{\max }\left[1-\left(\frac{Q}{Q_{u l t}}\right)^{g}\right]
$$

(eq. 12)

De acordo com Mayne (2000), através da Teoria da Elasticidade, e do modelo hiperbólico proposto por Fahey e Carter (1993), para recalque não linear em sapatas, têm-se a seguinte expressão:

$$
\delta=\frac{. Q . I}{B \cdot E_{\max }\left[1-\left(Q / Q_{u l t}\right)^{g}\right]}
$$

A Figura 2.25 mostra os resultados de prova de carga em conjunto com a previsão da curva carga-recalque empregando o modelo proposto por Mayne (2000), para solo arenoso, cujo valores de $\mathrm{E}_{\max }$ foram determinados através do ensaio crosshole.

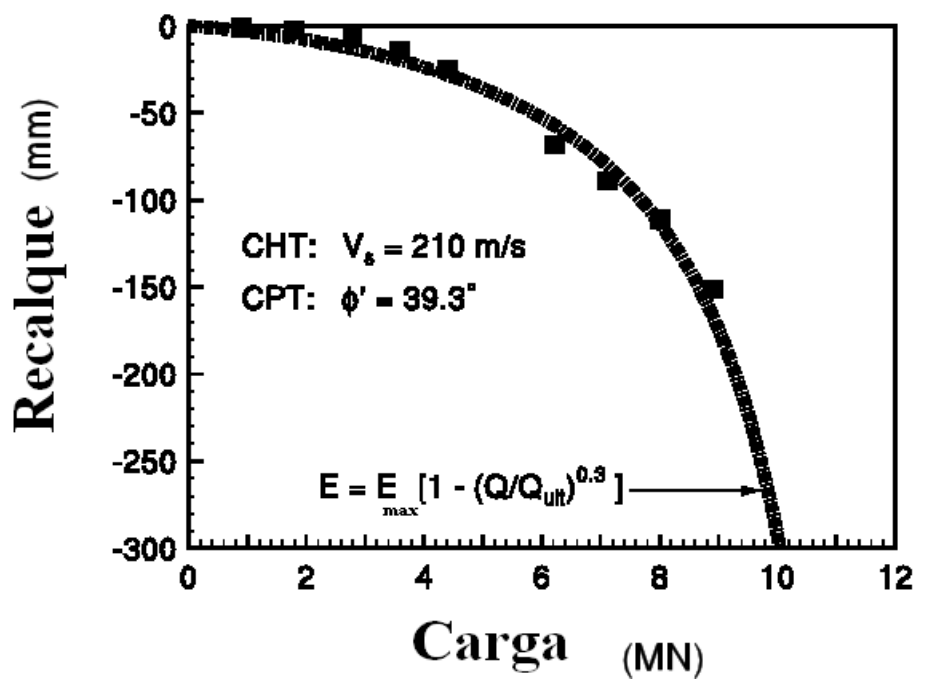

Figura 2.25- Representação da curva carga-recalque para areia do College Station - Texas e resultados de prova de carga (Mayne, 2000). 
Na Figura 2.26 está demonstrada a comparação de resultados de provas de carga com a previsão da curva tensão recalque por meio do modelo de Mayne, onde o valor de $G_{\max }$ e de $\tau_{\max }$ foram obtidos a partir do ensaio de cone sísmico. O solo estudado foi uma argila mole da Escócia.

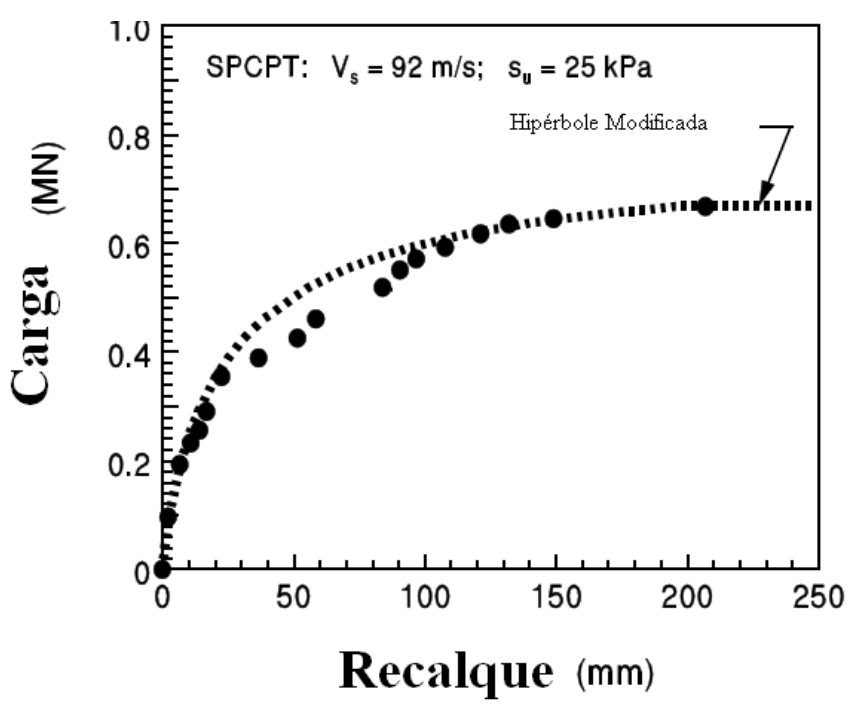

Figura 2.26- Representação da curva carga-recalque para um solo argiloso da Escócia e os resultados de prova de carga (Mayne, 2000).

Para o cálculo do fator de influência sob sapatas um grande número de soluções analíticas e numéricas estão disponíveis. Poulos e Davis (1974), Mayne e Poulos (1999) e outros autores, sugerem diversas soluções para avaliação de fatores de influência do deslocamento de apoios de várias formas (circular, quadrada, retangular), distribuição de carga (uniforme, parabólica, triangular), a rugosidade da fundação, o coeficiente de Poisson, homogeneidade do solo (módulo de deformabilidade do solo constante ou variável com a profundidade), profundidade da camada incompressível, multicamadas, as condições de drenagem e rigidez da fundação, bem como outras variáveis. Na Tabela 2.3 têm-se os valores do fator de influência para diferentes tipos de fundação.

\subsection{INFLUÊNCIA DA SUCÇÃO NOS PARÂMETROS GEOTÉCNICOS DO SOLO}

É de conhecimento geral que a sucção altera a rigidez do solo, Marinho, Chandler e Crilly (1995). A Figura 2.27 mostra que o módulo de cisalhamento máximo cresce com o aumento da sucção até um valor crítico, passando então a decrescer ou manter-se constante, e que este valor crítico está associado ao valor de entrada de ar no corpo de prova. 
Tabela 2.3 - Fator de influência (I) (adaptado de Perloff e Baron, 1976).

\begin{tabular}{|c|c|c|c|c|}
\hline \multicolumn{4}{|c|}{ Sapata Flexível } & \multirow[t]{2}{*}{ Sapata Rígida } \\
\hline Forma & Centro & Canto & Médio & \\
\hline Circular & 1,00 & 0,64 & 0,85 & 0,79 \\
\hline Quadrada & 1,12 & 0,56 & 0,95 & 0,99 \\
\hline $\mathrm{L} / \mathrm{B}=1,5$ & 1,36 & 0,67 & 1,15 & - \\
\hline 2 & 1,52 & 0,76 & 1,30 & - \\
\hline 3 & 1,78 & 0,88 & 1,52 & - \\
\hline 5 & 2,10 & 1,05 & 1,83 & - \\
\hline 10 & 2,53 & 1,26 & 2,25 & - \\
\hline 100 & 4,00 & 2,00 & 3,70 & - \\
\hline
\end{tabular}

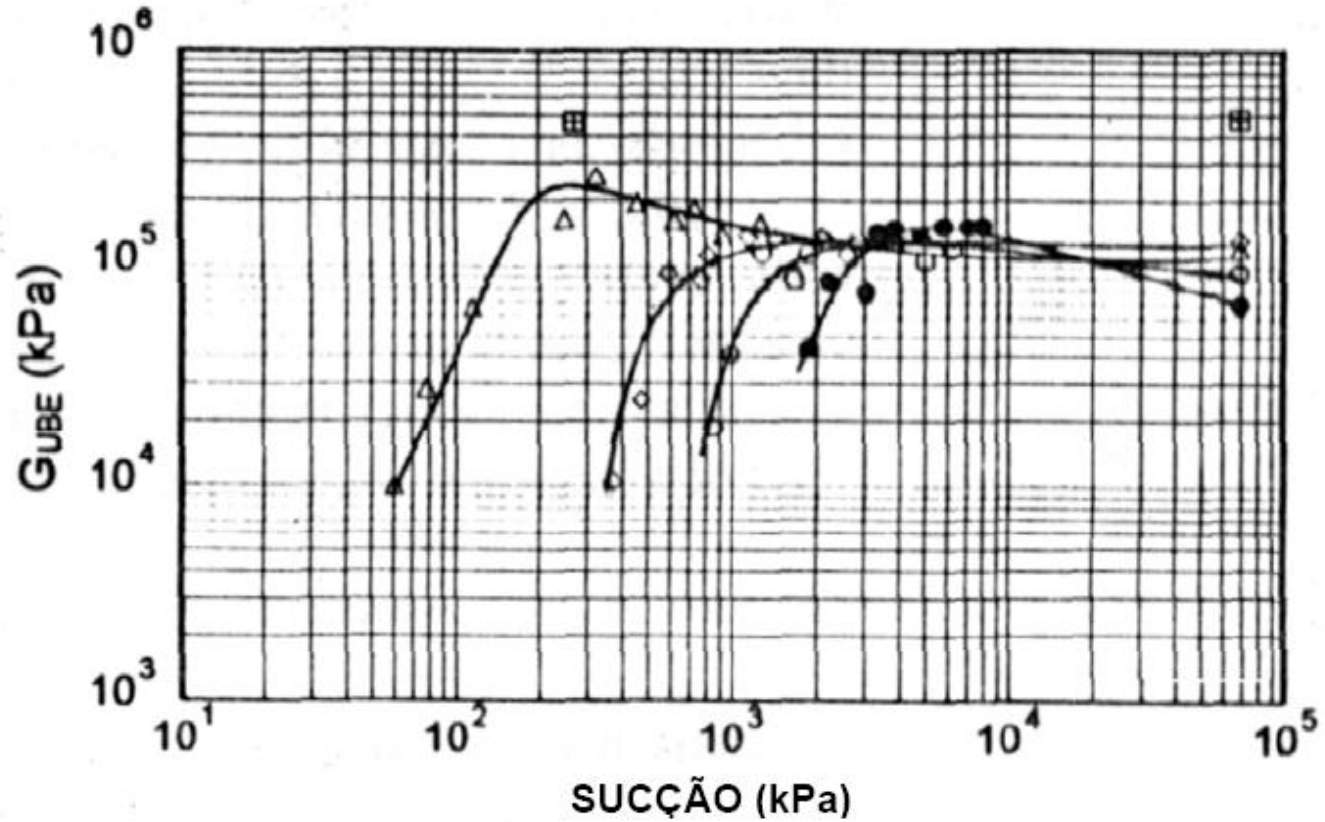

Figura 2.27- Variação do módulo de cisalhamento máximo com a sucção em uma argila de alta plasticidade (Marinho et al, 1995).

Jucá e Escário (1991) em seus estudos em solos argilosos compactados, verificaram o aumento do módulo de deformabilidade do solo com a sucção, sugerindo um relação linear entre esses dois parâmetros, contudo esses mesmos autores chegaram a conclusão que para sucções elevadas essa relação não é tão nítida.

Para o cálculo da capacidade de carga em fundações rasas, Fredlund e Rahardjo (1993) mostram o efeito da variação da sucção matricial na capacidade de carga de fundações por sapatas, utilizando a equação de Terzaghi. Com a adoção de parâmetros geotécnicos para o solo (c, c', $\left.\phi, \phi^{\mathrm{b}}, \gamma\right)$ e considerando sapatas corridas de 0,5 e $1,0 \mathrm{~m}$ de lado, apoiadas a $0,5 \mathrm{~m}$ de profundidade, são obtidos os resultados apresentados na Figura 2.28. 


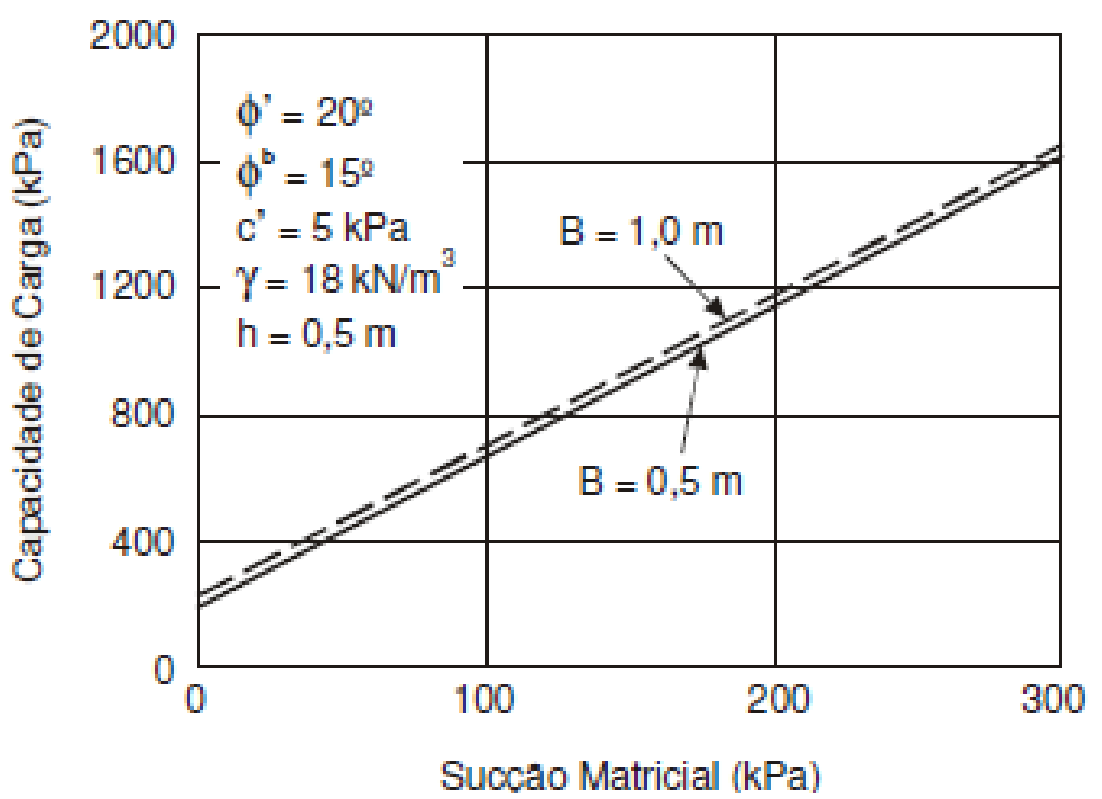

Figura 2.28- Capacidade de carga em função da sucção matricial (Fredlund e Rahardjo, 1993)

Em algumas provas de carga realizadas no campo experimental da EESC/USP em São Carlos/SP, foi constatado a influência da sucção na curva tensão-deformação, conforme mostra a Figura 2.29.

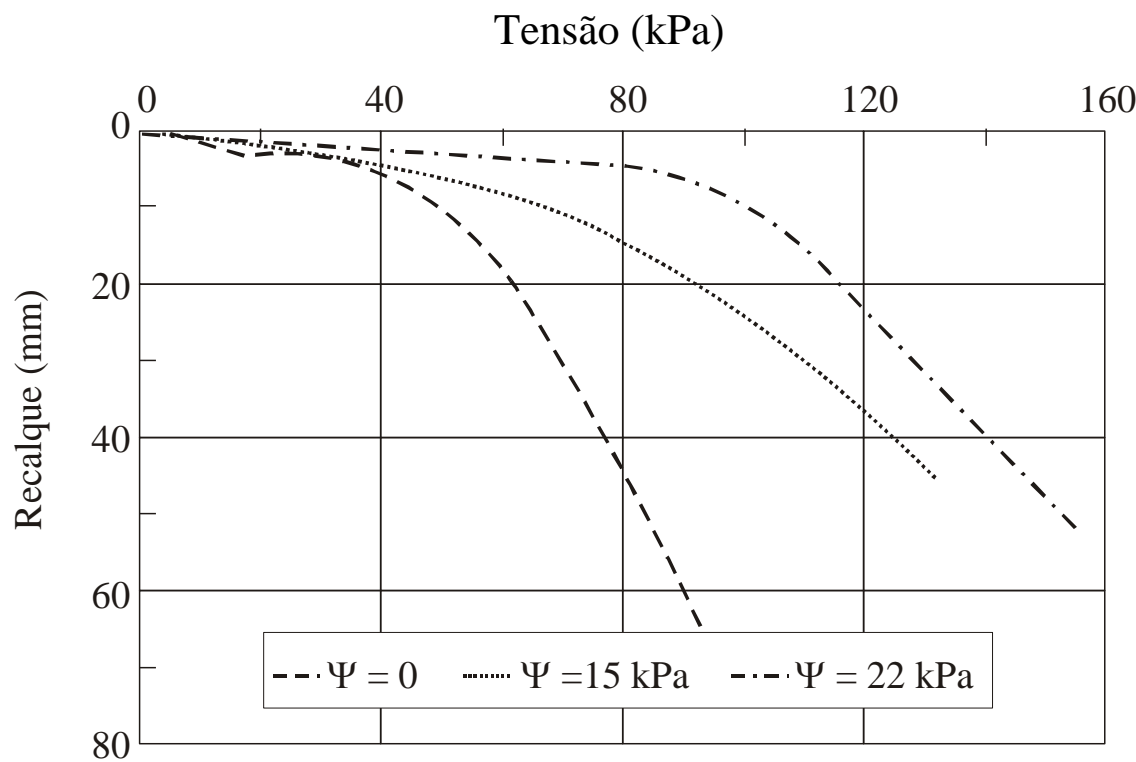

Figura 2.29- Curvas tensão x recalque de provas de carga sobre placa em solo não-saturado com diferentes sucções (Costa, 1999). 


\section{MATERIAIS E MÉTODOS}

\subsection{CONSIDERAÇÕES GERAIS}

Foram realizados ensaios de cone sísmico (SCPT) no campo experimental da EESC/USP e no campo experimental da UNESP em Bauru que permitiram determinar os perfis de variação da resistência de ponta, do atrito lateral, e da velocidade de ondas cisalhantes com a profundidade.

Em São Carlos, provas de carga já executadas nessa área também foram utilizadas com a finalidade de comparar a previsão realizada com base nos resultados dos ensaios SCPT, empregando-se o método de Mayne (2000). Em Bauru, as provas de carga utilizadas para comparação foram executadas por Agnelli (1997). A Figura 3.1 mostra resultados de sondagens de simples reconhecimento (SPT), que permite uma visualização do perfil geotécnico presente nestes dois campos experimentais.

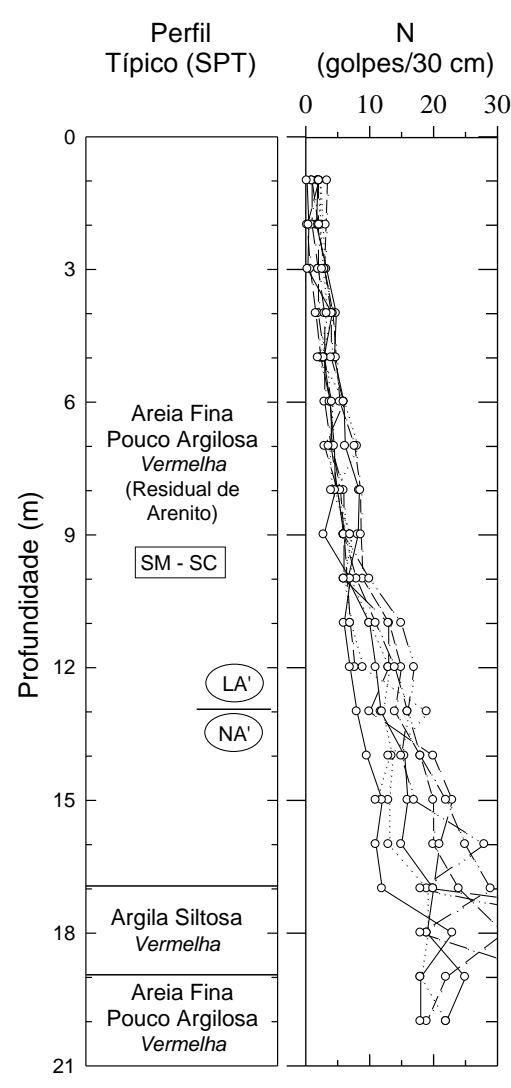

(a) Bauru

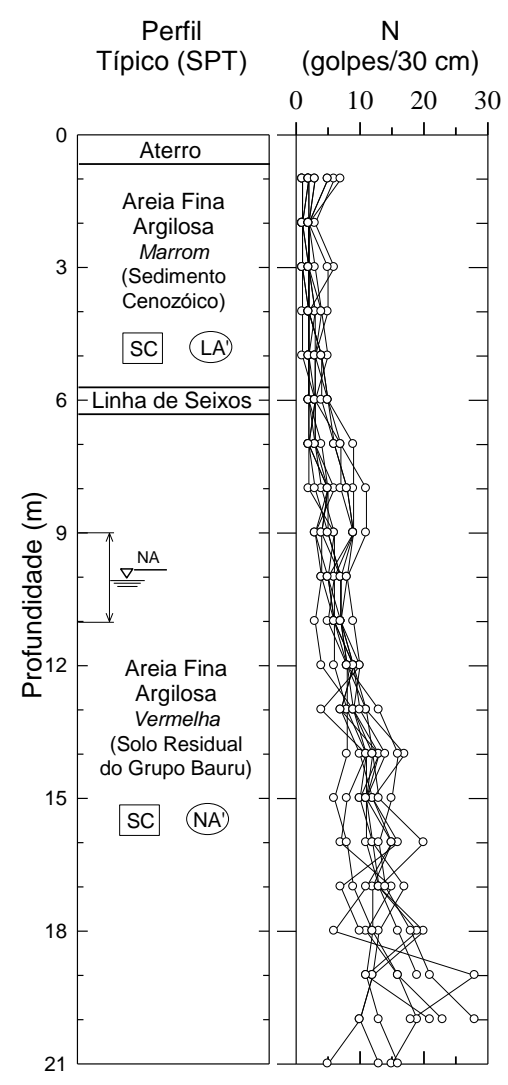

(b) São Carlos

Figura 3.1-Perfis típicos e resultados de sondagens SPT realizadas nos campos experimentais de (a) Bauru, (b) São Carlos (Giacheti et al, 2004).

Através da Figura 3.2, pode-se visualizar a faixa de variação das curvas granulométricas para os solos dos campos experimentais de Bauru e São Carlos e na Figura 3.3 têm-se a variação do tamanho 
das partículas segundo a escala da ABNT/NBR-7181/84 com a profundidade, para os solos das duas áreas investigadas.

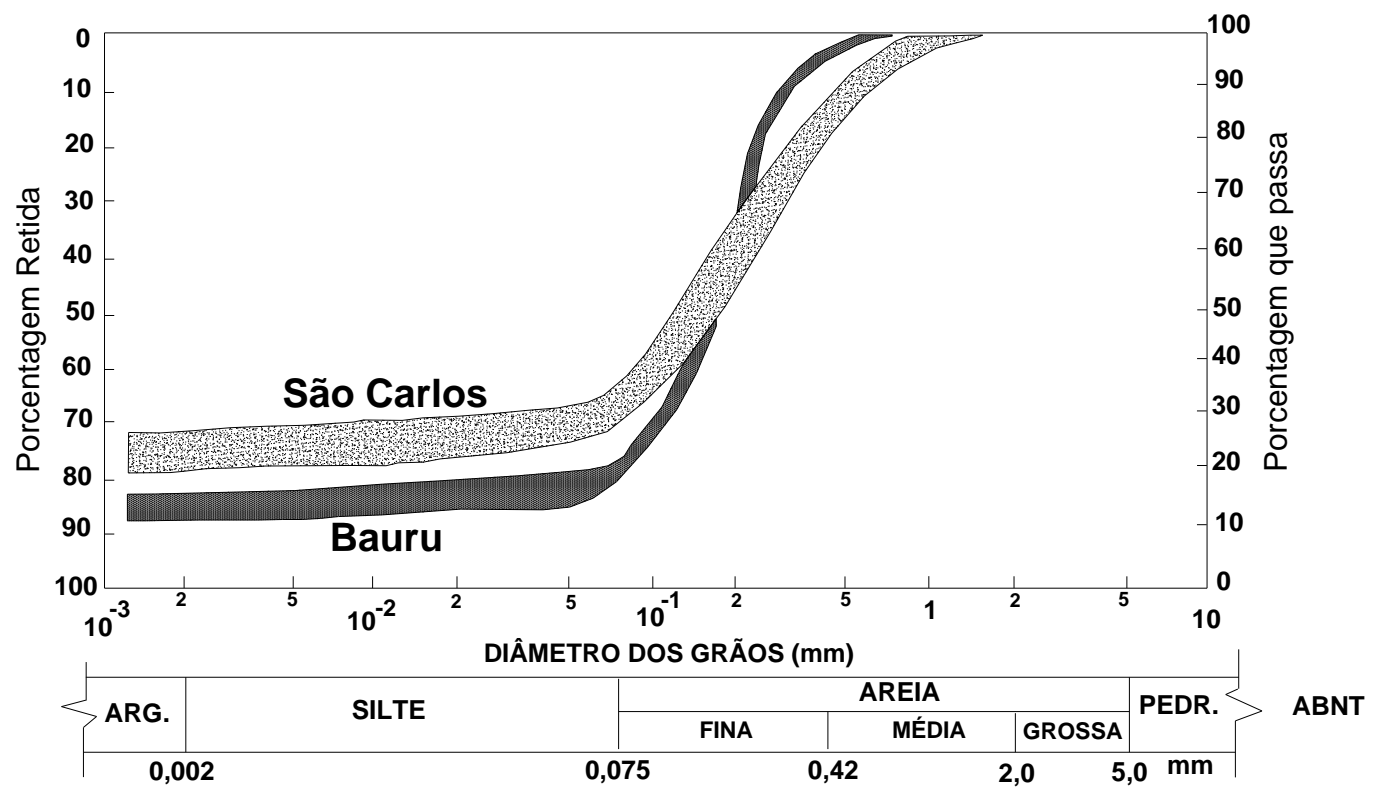

Figura 3.2- Faixa de variação das curvas granulométricas para os solos das duas áreas investigadas. (adaptado de Giacheti, 1991)

\section{(a) Bauru}

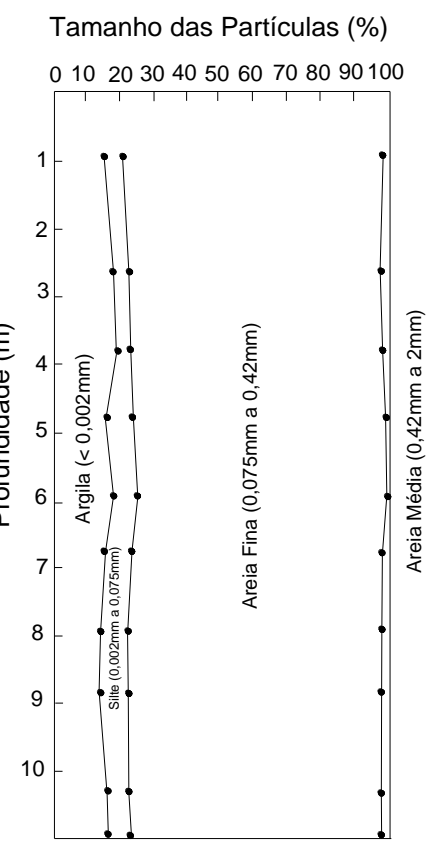

(b) São Carlos

Tamanho das Partículas (\%)

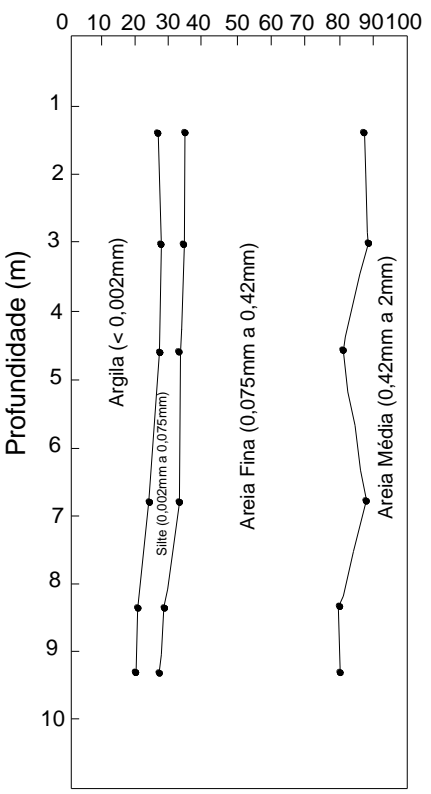

Figura 3.3- Variação do tamanho das partículas com a profundidade para os solos das duas áreas investigadas (adaptado de Giacheti, 1991) 


\subsection{CAMPO EXPERIMENTAL DE SÃO CARLOS}

\subsubsection{Aspectos Geológicos}

A cidade de São Carlos está situada na zona de transição das unidades geomorfológicas, das cuestas basálticas e do planalto ocidental a cerca de $800 \mathrm{~m}$ em relação ao nível do mar, assenta-se sobre as rochas do grupo são Bento, compostas por arenito da formação Botucatu e Pirambóia e derrames de efusivas basálticas da formação Serra Geral. A Figura 3.4 mostra um perfil típico da geologia de pequena superfície da área urbana de São Carlos, com descrição da geologia predominante.

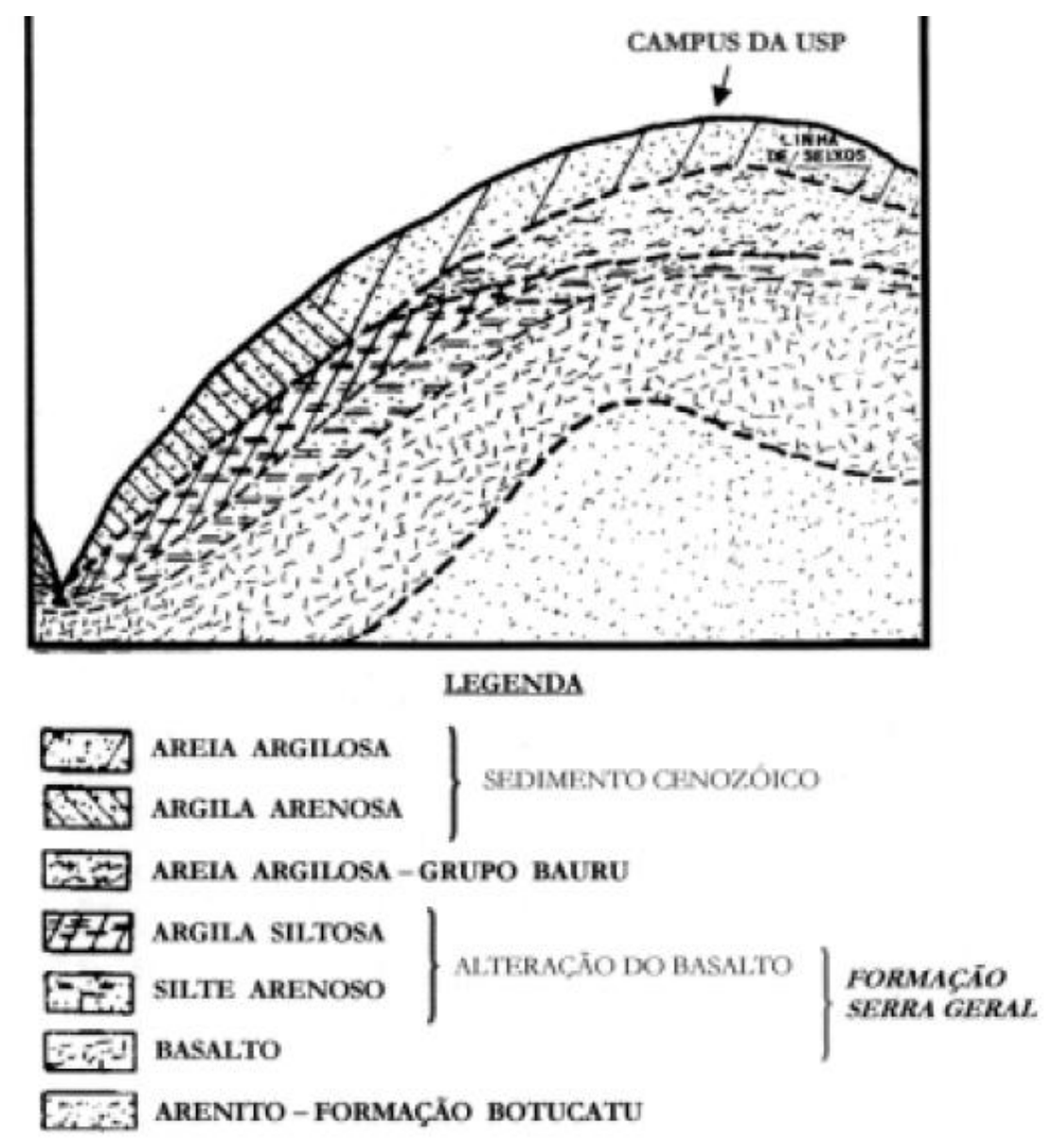

Figura 3.4- Seção esquemática da geologia de pequena profundidade em São Carlos (Bortolucci,1983). 


\subsubsection{Ensaios de Campo}

\subsubsection{Posição dos ensaios de campo}

Várias campanhas de ensaios foram realizadas no campo experimental da EESC-USP, São Carlos. Executaram-se dois ensaios downhole (DH1 e DH2) com o sistema desenvolvido por Vitali (2011), um SCPT (SCPT3) com um cone sísmico comercial e três ensaios CPT (CPT1, CPT2 e CPT3). Dispõe-se ainda dos resultados de dois ensaios crosshole (CH1 e $\mathrm{CH} 2$ ) e de dois ensaios SCPT (SCPT1, SCPT2 e SCPT3) conforme mostra a Figura 3.5. Um esquema com a posição das provas de carga no Campo Experimental também é apresentado na Figura 3.5.

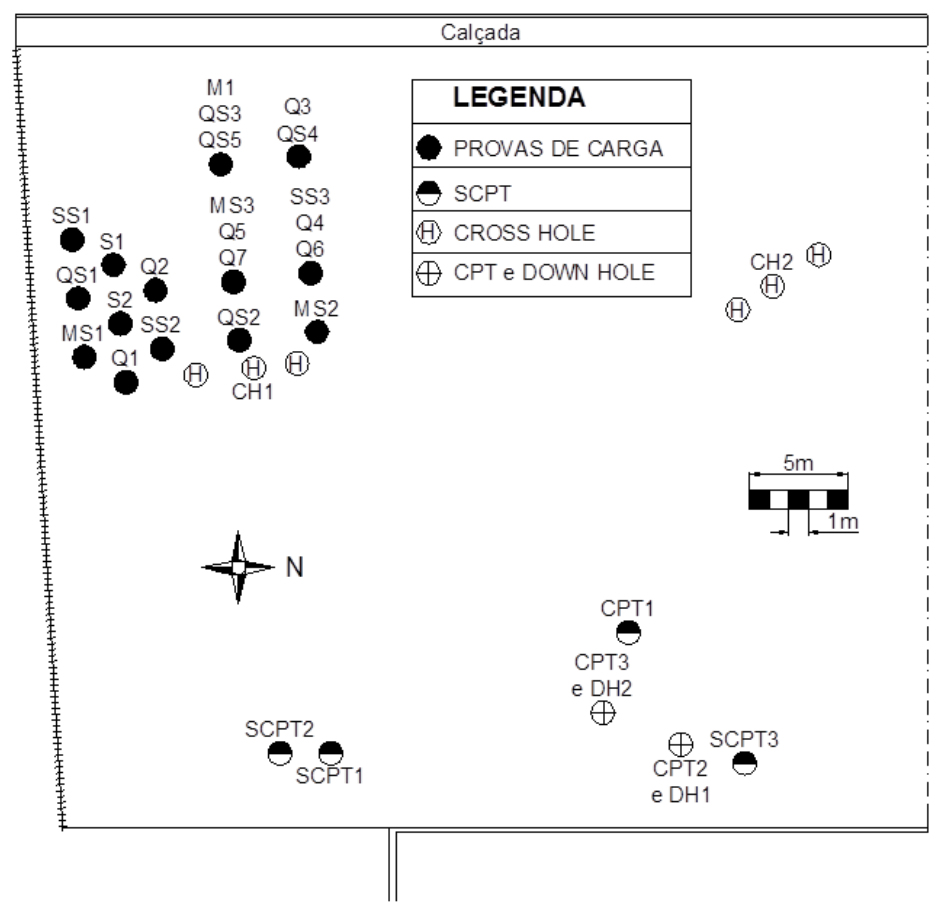

Figura 3.5- Posição dos ensaios de campo realizados no campo experimental da EESC/USP - São Carlos.

\subsubsection{Ensaios de Placa}

Os resultados dos ensaios de placa com diâmetro de $0,8 \mathrm{~m}$ realizados no campo experimental EESC/USP foram utilizados neste estudo para avaliar a aplicabilidade do modelo hiperbólico proposto por Mayne (2000). Foram realizadas 21 provas de carga em placa de 0,8m de diâmetro por diversos pesquisadores do departamento de Geotecnia da EESC/USP, no campo experimental desta instituição. Os ensaios foram executados com 
placas assentadas no terreno a 1,5m, 4,0m e 6,0m por Costa (1999), Macacari (2001), Menegotto (2004), dentre outros pesquisadores.

Para determinação da sucção matricial média do solo abaixo da placa, nos ensaios não inundados, foram instalados tensiômetros no solo do fundo das cavas nas profundidades de 0,1 m, 0,3 m, 0,6 m e 0,8 m abaixo da cota de assentamento da placa. A maior profundidade de instalação dos tensiômetros correspondeu ao diâmetro da placa. Onze desses ensaios foram executados com inundação por um período mínimo de 4horas, utilizando água potável proveniente da rede pública. Quanto ao modo de carregamento aplicado durante as provas de carga foram realizadas cinco do tipo lento (SML), doze do tipo rápido (QML) e quatro do tipo misto (MML). A Tabela 3.1 mostra as principais características de cada ensaio, bem como a sua designação. Mais detalhes sobre os ensaios de placa, bem como os equipamentos e materiais usados no campo experimental da EESC/USP podem ser consultadas em Menegotto (2004).

Tabela 3.1 - Características das provas de carga em placa com diâmetro de 0,80m (Menegotto, 2004).

\begin{tabular}{cccc}
\hline \multicolumn{4}{c}{ Informações Ensaio de Placa } \\
\hline Profundidade & Ensaio & Modalidade & Sucção (kPa) \\
\hline 1,5 & SS1 & Lento Inundado & 0 \\
1,5 & SS2 & Lento Inundado & 0 \\
1,5 & SS3 & Lento Inundado & 0 \\
1,5 & S1 & Lento & 10 \\
1,5 & S2 & Lento & 31 \\
1,5 & QS1 & Rápido Inundado & 0 \\
1,5 & QS2 & Rápido Inundado & 0 \\
1,5 & Q1 & Rápido & 15 \\
1,5 & Q2 & Rápido & 22 \\
1,5 & Q3 & Rápido & 33 \\
1,5 & MS1 & Misto Inundado & 0 \\
1,5 & MS2 & Misto Inundado & 0 \\
1,5 & MS3 & Misto Inundado & 0 \\
1,5 & M1 & Misto & 28 \\
4 & QS3 & Rápido Inundado & 0 \\
4 & Q4 & Rápido & 18 \\
4 & Q5 & Rápido & 28 \\
6 & QS4 & Rápido Inundado & 0 \\
6 & QS5 & Rápido & 0 \\
6 & Q6 & Rápido & 12 \\
6 & Q7 & Rápido & 15 \\
\hline
\end{tabular}




\subsubsection{Ensaios de Laboratório}

Nesse campo experimental foram feitos diversos ensaios de laboratórios, a fim de caracterizar os solos que ocorrem nesse local. A Tabela 3.2 mostra os valores médios de índices físicos dos solos que ocorrem ao longo do perfil do campo experimental de São Carlos.

Tabela 3.2 - Índices físicos médios para o campo experimental São Carlos (Giacheti, 2001)

\begin{tabular}{cccccc}
\hline $\begin{array}{c}\text { Profundidade } \\
(\mathrm{m})\end{array}$ & $\begin{array}{c}\gamma \\
\left(\mathrm{kN} / \mathrm{m}^{3}\right)\end{array}$ & $\begin{array}{c}\mathrm{w} \\
(\%)\end{array}$ & $\begin{array}{c}\mathrm{e} \\
(-)\end{array}$ & $\begin{array}{c}\mathrm{Sr} \\
(\%)\end{array}$ & $(\%)$ \\
\hline 1 & 14,2 & 13,7 & 1,174 & 54 & 38 \\
2 & 15,6 & 14,6 & 0,993 & 50 & 52 \\
3 & 16,0 & 15,8 & 0,965 & 50 & 58 \\
4 & 16,7 & 16,8 & 0,943 & 49 & 70 \\
5 & 14,8 & 16,4 & 0,882 & 47 & 60 \\
\hline
\end{tabular}

As Figuras 3.6 a 3.8 apresentam as curvas características para os solos do campo experimental de São Carlos para as profundidades de 2,0; 5,0 e 8,0 m. Pode-se observar na Figura 3.6 que os valores de entrada de ar nesta profundidade é muito baixa, assim como em outras profundidades pesquisadas por Machado (1998). Para amostra coletada a 5m de profundidade (Figura 3.7), a umidade volumétrica do solo saturado é igual a 47,5 \% e a sucção correspondente ao teor de umidade residual é de aproximadamente $20 \mathrm{MPa}$. Isto ocorre porque o solo ensaiado apresenta estrutura com macro-poros de grande diâmetro, visíveis a olho nu.

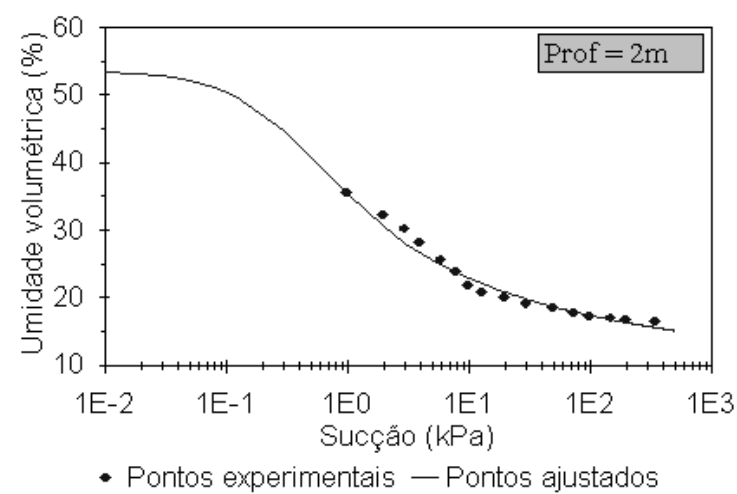

Figura 3.6- Curvas características de sucção do solo para a profundidade de 2,0m (Machado, 1998). 


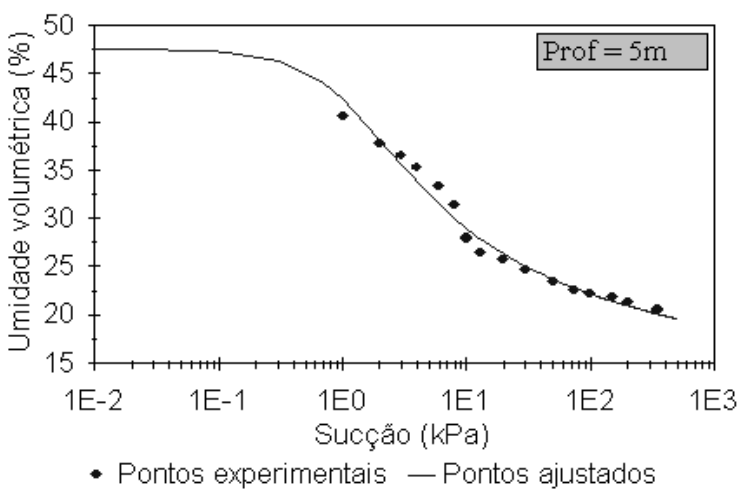

Figura 3.7 - Curvas características de sucção do solo para a profundidade de 5,0 m (Machado, 1998).

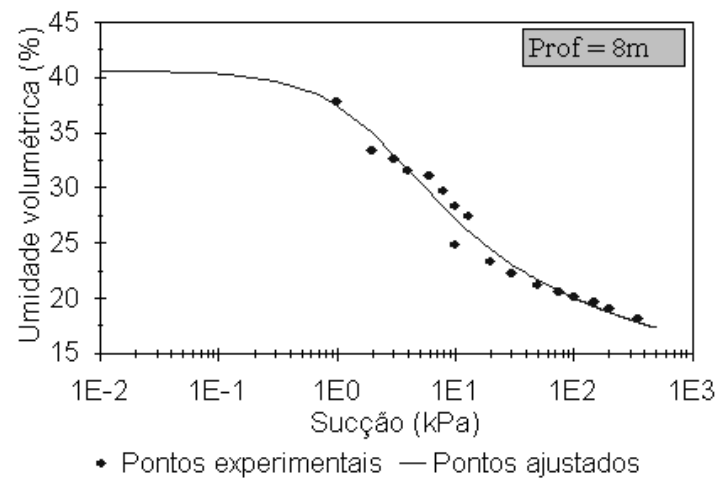

Figura 3.8- Curvas características de sucção do solo para a profundidade de 8,0 m (Machado, 1998).

\subsection{CAMPO EXPERIMENTAL DE BAURU}

\subsubsection{Aspectos Geológicos}

A região de Bauru é constituída predominantemente por sedimentos do Grupo Bauru (Formações Marília e Adamantina), recobrindo as rochas vulcânicas da Formação Serra Geral que afloram em direção ao vale do Rio Tietê. A Figura 3.9 mostra um perfil típico da geologia da área urbana de Bauru.

A geologia do campo experimental é a mesma que predomina na cidade de Bauru. De acordo com Cavaguti (1981), pode-se constatar uma primeira camada de 52m da Formação Marília, seguida de 98m da Formação Adamantina e, abaixo, encontra-se a Formação Serra Geral.

A Formação Marília é constituída por arenitos, conglomerados e lamitos intercalados entre si. A Formação Adamantina é composta por arenitos de granulação média a fina, siltitos arenoso, micáceos, arenitos micáceis, argilitos e arenitos conglomeráticos. Geologicamente, a região de Bauru se encontra totalmente localizada no Planalto Ocidental Paulista. A área é 
coberta, predominantemente, segundo Cavaguti (1981), por sedimentos do Grupo Bauru (Formação Marília e Formação Adamantina), existindo uma relação genética entre o solo e a litologia presente.

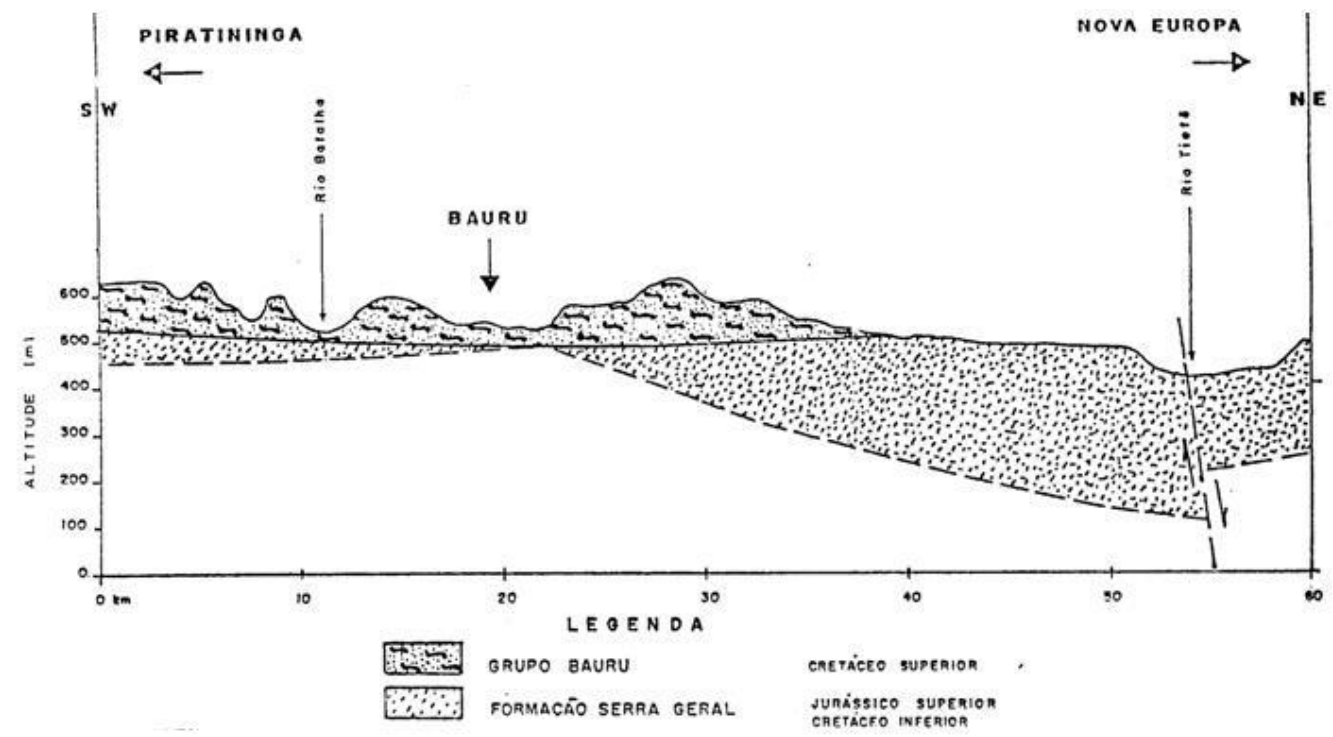

Figura 3.9- Desenho esquemático da formação geológica da cidade de Bauru (DAEE, 1976 in Ferreira, 1991).

De acordo com Cavaguti (1981) o solo que ocorre no campo experimental de Bauru é constituído por uma areia fina pouco argilosa, porosa, colapsível, cuja compacidade aumenta com a profundidade. Esta camada de areia fina, resultante da decomposição do Arenito Bauru, apresenta comportamento laterítico até cerca de $13 \mathrm{~m}$ de profundidade e não laterítico a partir daí.

\subsubsection{Ensaios de Campo}

\subsubsection{Posição dos ensaios}

No campo experimental de Bauru foram realizadas duas campanhas distintas de ensaios de cone elétrico (CPT) e duas de cone sísmico (SCPT), no ano de 2004. A Figura 3.10 mostra a posição dos ensaios, assim como das provas de carga realizadas nesse campo experimental. 


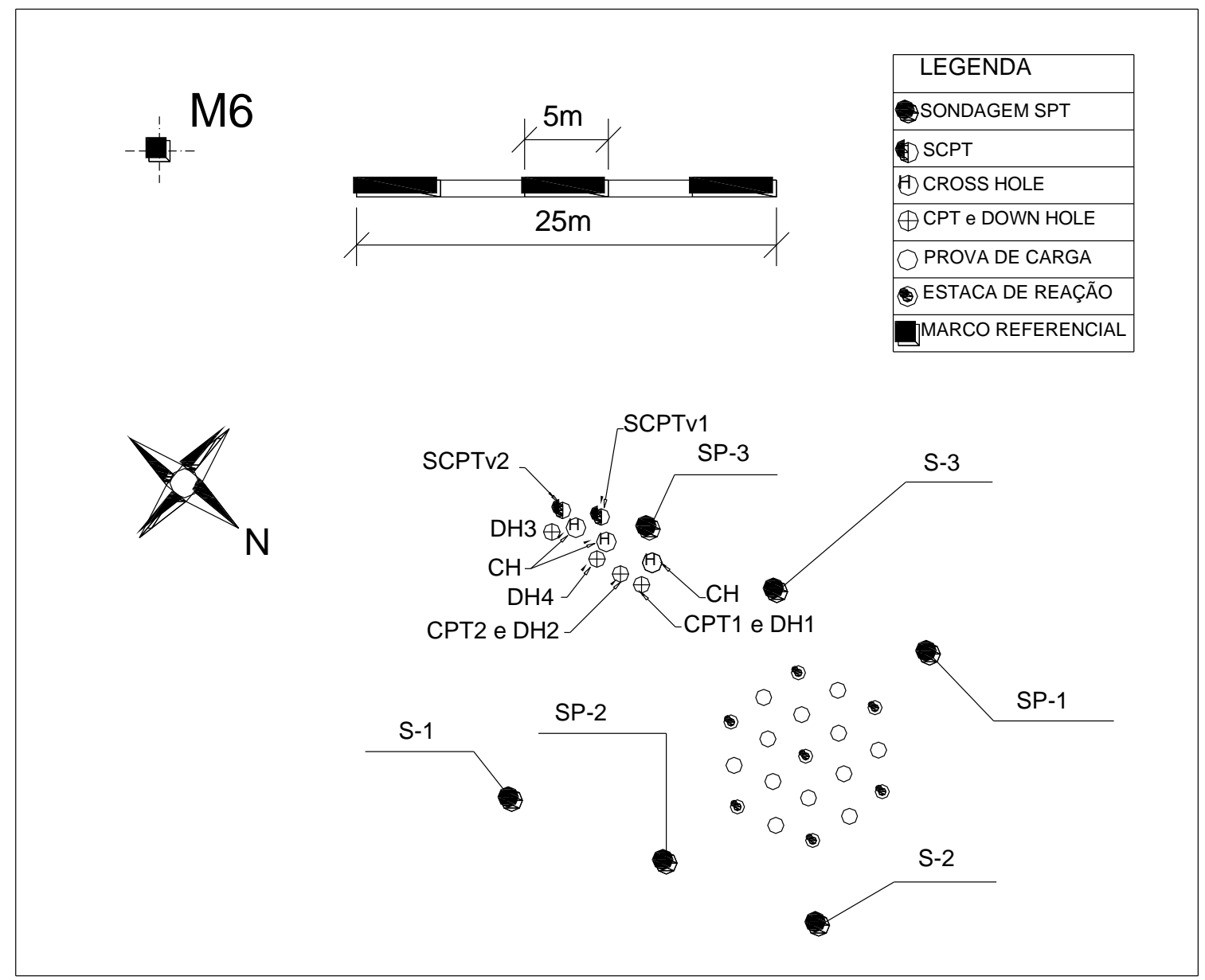

Figura 3.10- Posição dos ensaios de campo realizados no campo experimental da UNESP - Bauru (adaptado de Agneli, 1997 e Giacheti, 2001).

\subsubsection{Ensaios de Placa}

Foram obtidos resultados de provas de cargas em placas, realizadas no Campo Experimental da UNESP de Bauru, no período de 22/02 a 14/06/1996, por Agnelli (1997), nas profundidades de 1, 2, 3 e 4 metros.

Com base em resultados de sondagens SPT realizadas no local, Agnelli (1997) estimou as tensões admissíveis para o solo, na ordem de 40, 60, 80 e $100 \mathrm{kPa}$, respectivamente nas profundidades de 1, 2, 3, 4 metros, remetendo para as tensões de "ruptura" valores na faixa de 80 a $200 \mathrm{kPa}$.

As Provas de Carga realizadas por Agnelli (1997) tiveram uma duração de 15 minutos para cada estágio de carregamento, o que enquadra o ensaio no tipo "rápido". Os deslocamentos, em cada estágio de carregamento, foram registrados no instante zero (imediatamente após a aplicação da carga) e nos tempos de 1, 2, 3, 6, 9, 12 e 15 minutos. 


\subsubsection{Ensaios de Laboratório}

Foram feitos diversos ensaios de laboratórios para caracterizar os solos que ocorrem na área. Na Tabela 3.3 têm-se índices físicos médios para as profundidades de 1, 2, 3 e 4 m.

Tabela 3.3 - Índices físicos médios para os solos que ocorrem no campo experimental de Bauru

(Giacheti, 2001).

\begin{tabular}{cccccc}
\hline $\begin{array}{c}\text { Profundidade } \\
(\mathrm{m})\end{array}$ & $\begin{array}{c}\gamma \\
\left(\mathrm{kN} / \mathrm{m}^{3}\right)\end{array}$ & $\begin{array}{c}\text { w } \\
(\%)\end{array}$ & $\begin{array}{c}\mathrm{e} \\
(-)\end{array}$ & $\begin{array}{c}\text { porosidade } \\
(-)\end{array}$ & $\begin{array}{c}\mathrm{Sr} \\
(\%)\end{array}$ \\
\hline 1 & 16,2 & 9,6 & 0,653 & 0,40 & 32 \\
2 & 16,0 & 9,8 & 0,704 & 0,41 & 25 \\
3 & 16,5 & 9,8 & 0,632 & 0,39 & 23 \\
4 & 17,8 & 9,5 & 0,634 & 0,39 & 22 \\
\hline
\end{tabular}

A Figura 3.11 apresenta a curva característica de um solo coletado em um local próximo ao campo experimental de Bauru obtida para a profundidade de 5,0 m por Giacheti e Rohm (1996). Pode-se observar que nesta figura, a pressão de entrada de ar deste solo é da ordem de $2 \mathrm{kPa}$. Aparentemente, os intra-poros começam a ser drenados com sucção matricial da ordem de 20 a $50 \mathrm{kPa}$.

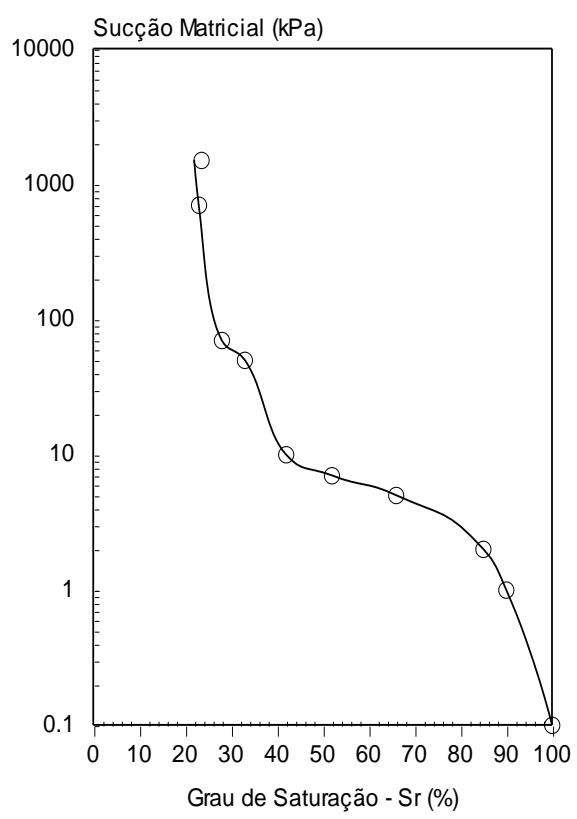

Figura 3.11- Curva Característica típica de solos que ocorrem próximo no campo experimental de Bauru de uma amostra de solo coletada a 5,0m, (Giacheti e Rohm, 1996). 


\section{RESULTADOS E DISCUSSÕES}

\subsection{AJUSTE DOS PARÂMETROS DO MODELO DE MAYNE (2000)}

Quando o modelo do Mayne (2000) foi concebido, os parâmetros de ajuste foram fixados em $\mathrm{f}=1$ e $\mathrm{g}=0,3$ já que a experiência desse autor foi para solos não estruturados e não cimentados. Em 2005, Ealkim propôs, determinar os parâmetros de ajuste desse modelo, conforme já discutido no item 2.4.3 deste trabalho empregando um parâmetro denominado deformação normalizada $\left(\mathrm{X}_{\mathrm{L}}\right)$. A Figura 4.1 mostra curvas de degradação do módulo para diferentes parâmetros de ajuste.
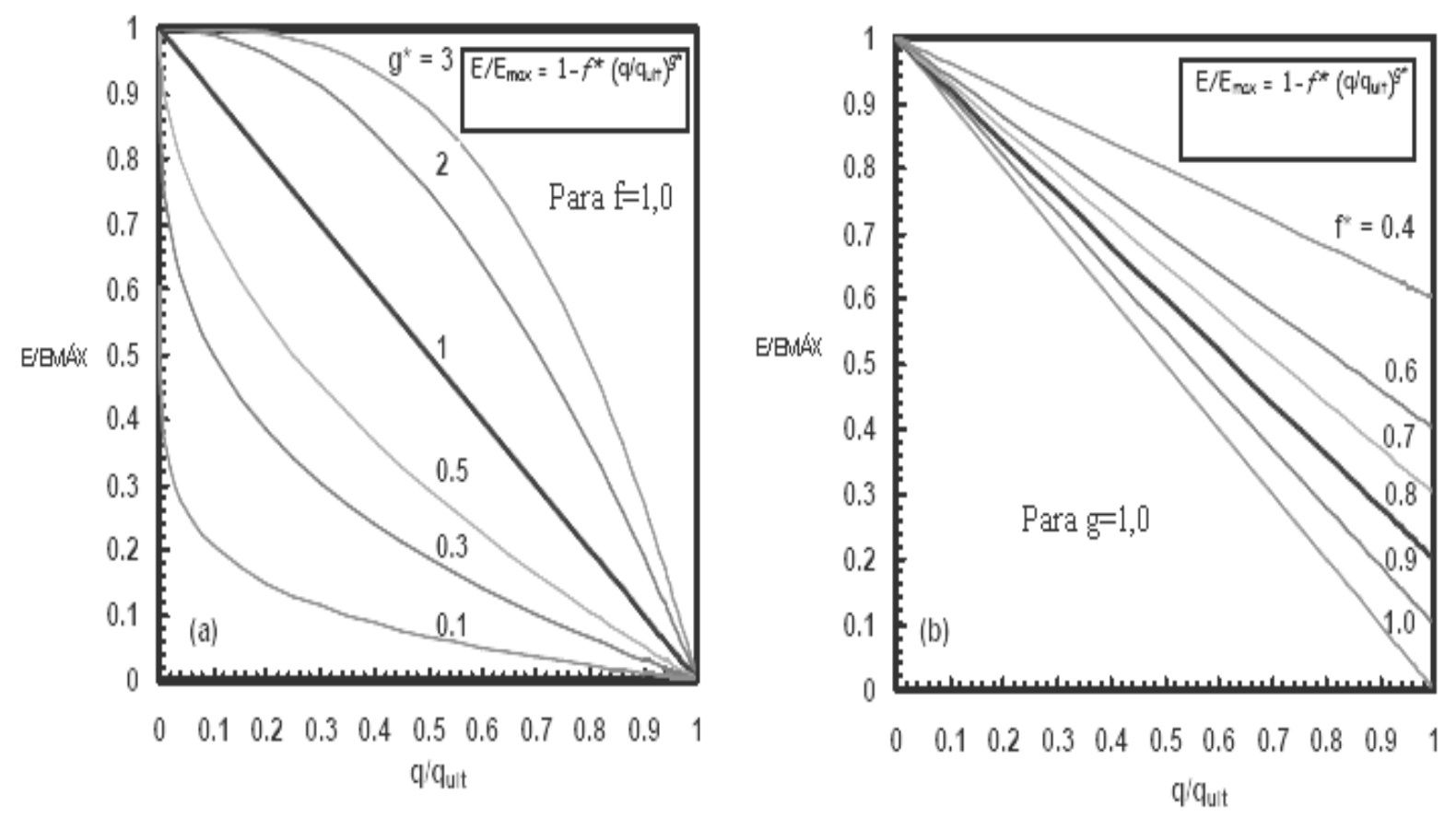

Figura 4.1 - Representação da degradação variando os parâmetros de ajuste (Ealkim, 2005)

Para possibilitar a determinação do $G_{\min }$ para os solos estudados calculou-se o parâmetro $\mathrm{X}_{\mathrm{L}}$. Esse parâmetro foi determinado a partir de resultados de ensaios triaxiais realizados por Machado (1998) em corpos de prova coletados a 2, 5 e $8 \mathrm{~m}$. Na Tabela 4.1 temse os valores de $\mathrm{G}_{\min }$ calculados segundo descrito no item 2.4.3 desse trabalho. 
Tabela 4.1 - Dispersão dos valores de $\mathrm{G}_{\min }$ obtidos em ensaios triaxiais com a profundidade e os valores da média e desvio padrão.

\begin{tabular}{ccc}
\hline \multicolumn{3}{c}{$\mathbf{G}_{\min }(\mathbf{k P a})$} \\
\hline $\mathbf{Z}_{(\mathbf{m})}$ & Média & Desvio padrão \\
\hline $\mathbf{2}$ & 408 & 236 \\
$\mathbf{5}$ & 841 & 385 \\
$\mathbf{8}$ & 2188 & 1362 \\
\hline
\end{tabular}

Os valores de $G_{\max }$ necessário para o cálculo do parâmetro $X_{L}$ foram determinados a partir de resultados de ensaios de cone sísmico. Com os valores de $G_{\max }$ e $G_{\min }$ calculados, foi possível determinar o parâmetro $\mathrm{X}_{\text {Lmedio }}$ como mostra a Tabela 4.2.

Tabela 4.2 - Deformação normalizada $\left(\mathrm{X}_{\mathrm{L}}\right)$ com a profundidade.

\begin{tabular}{llll}
\hline & $\mathbf{2 m}$ & $\mathbf{4 m}$ & $\mathbf{6 m}$ \\
\hline $\mathbf{X}_{\mathbf{L}}$ & 168,17 & 191,39 & 77,70 \\
\hline
\end{tabular}

Com base nas funções hiperbólicas descritas no item 4.2.3 deste trabalho (especificamente a Figura 2.20, já que se trata de carregamento drenado em placa circular), o valor médio da deformação normalizada $\left(X_{\text {Lmedio }}\right)$ foi de 145,75 nas profundidades 2 , 4 e $6 \mathrm{~m}$ e considerando o ângulo de atrito de $30^{\circ}$, chegou-se assim a valores de $\mathrm{f}$ e $\mathrm{g}$ respectivamente iguais a 0,99 e 0,03 para os solos do campo experimental de São Carlos.

Para o campo experimental de Bauru, não existe disponíveis resultados de ensaios triaxiais para os locais que foram feitos os ensaios de cone sísmico, por isso foram assumidos os mesmos parâmetros de ajuste g e f determinados para os solos de São Carlos, quais sejam $\mathrm{f}=0,99$ e $\mathrm{g}=0,03$ uma vez que esse solo tem características semelhantes ao campo experimental de São Carlos.

Na Figura 4.2 tem-se a representação da curva $E / E_{\max }$ versus $q / q_{\text {ult }}$ para os parâmetros de ajustes definidos para os solos estudados. Percebe-se que em um certo ponto a rigidez cai bruscamente. Acredita-se que a fraca cimentação, que resulta em elevado $G_{\max }$ a baixa amplitude de deformação, é o principal fator que causa esse fenômeno, conforme discutido por Giacheti (2001). 


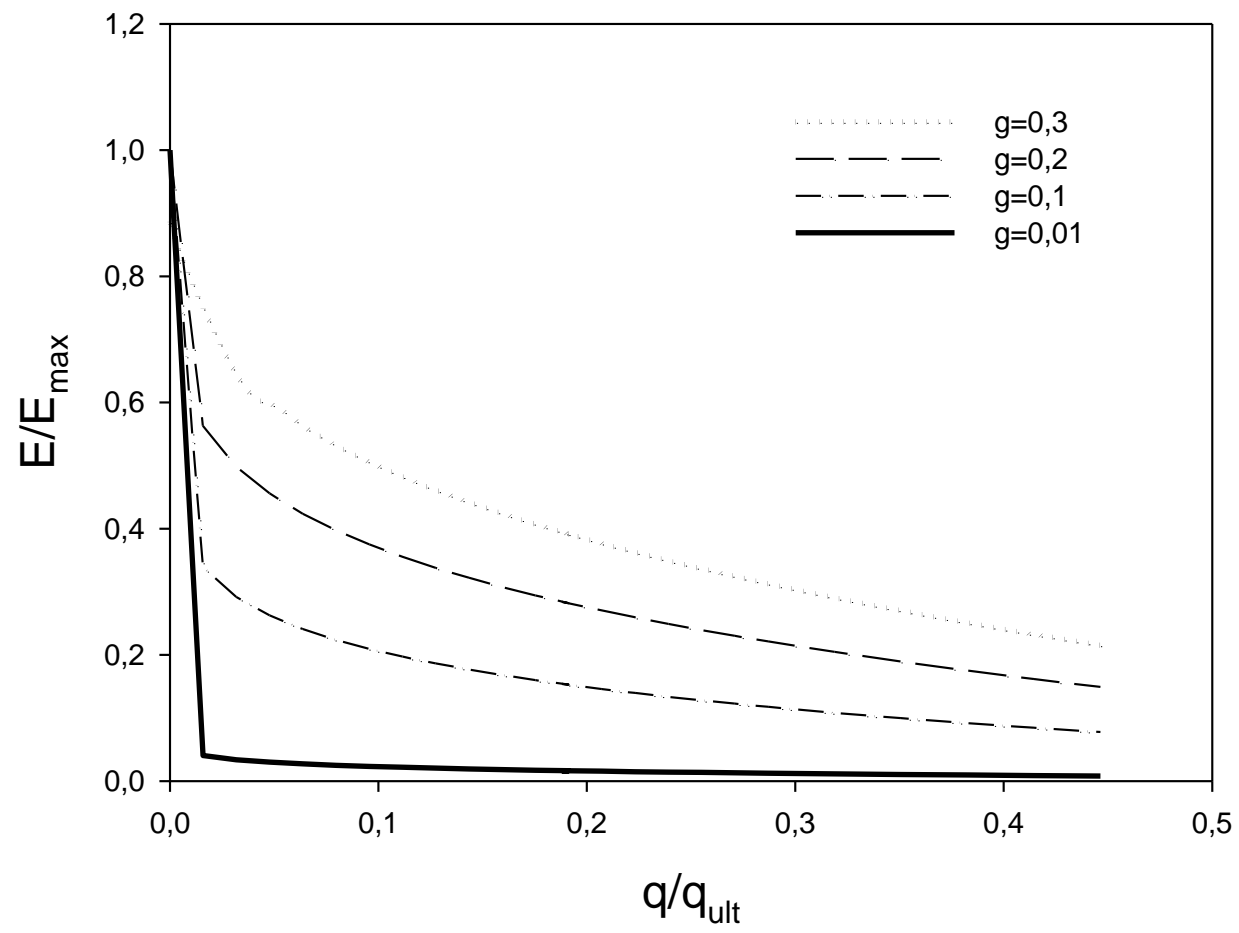

Figura 4.2- Representação da curva de degradação do módulo para o solo que ocorre no campo experimental de São Carlos.

\subsection{CAMPO EXPERIMENTAL BAURU}

\subsubsection{Ensaios de Placa}

As Figuras 4.3 a 4.6 apresentam as curvas tensão-recalque das provas de carga em placa realizadas por Agnelli (1997) nas profundidades 1, 2, 3 e 4m em terreno na umidade natural, no campo experimental da Unesp de Bauru.

\subsubsection{Ensaios de cone sísmico}

Na Figura 4.7 são apresentados resultados dos ensaios SCPT utilizados na previsão da curva tensão-recalque. Os dois ensaios realizados mostram que a resistência de ponta $\left(\mathrm{q}_{\mathrm{c}}\right)$ tem pouca variação até $5 \mathrm{~m}$ de profundidade, aumentando gradativamente a partir daí. A velocidade da onda cisalhante $\left(\mathrm{V}_{\mathrm{s}}\right)$ e conseqüentemente o módulo de cisalhamento máximo do solo $\left(\mathrm{G}_{\max }\right)$, tem o comportamento praticamente crescente com a profundidade, e as maiores diferenças entre os valores de $G_{\max }$ determinados a partir dos resultados dos dois ensaios SCPT realizados ocorrem a $1 \mathrm{~m}$ de profundidade. 


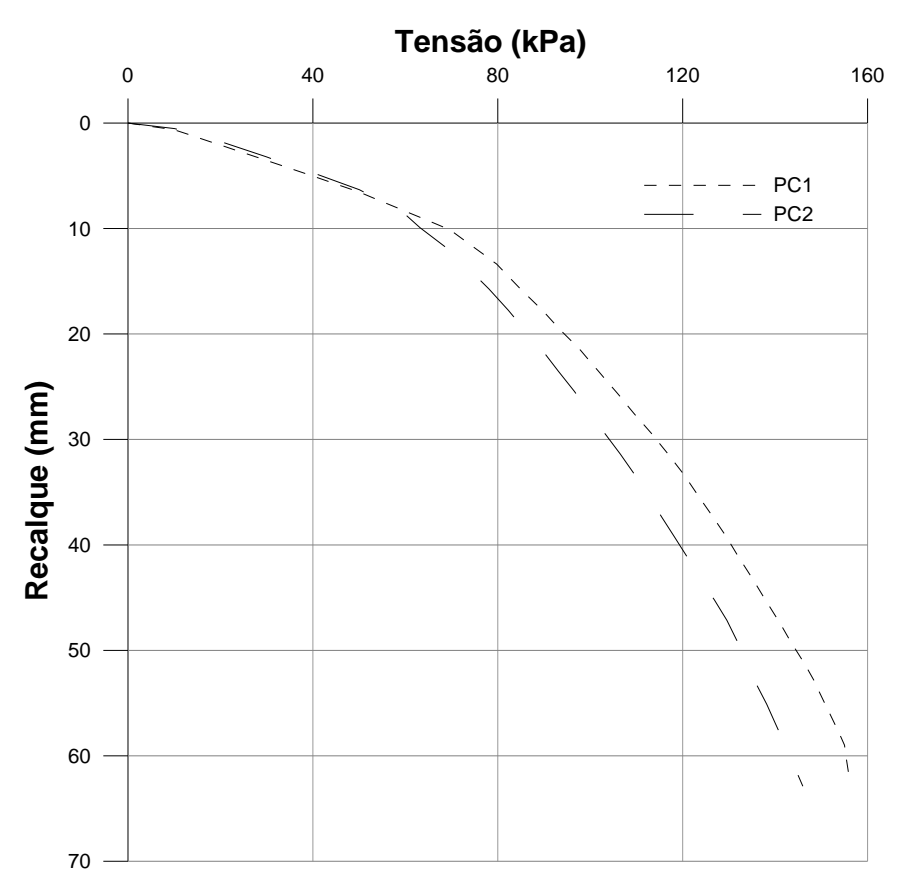

Figura 4.3- Resultados de provas de carga sobre placa em solo natural na profundidade $1 \mathrm{~m}$. Campo Experimental da Unesp de Bauru, SP (Agnelli, 1997).

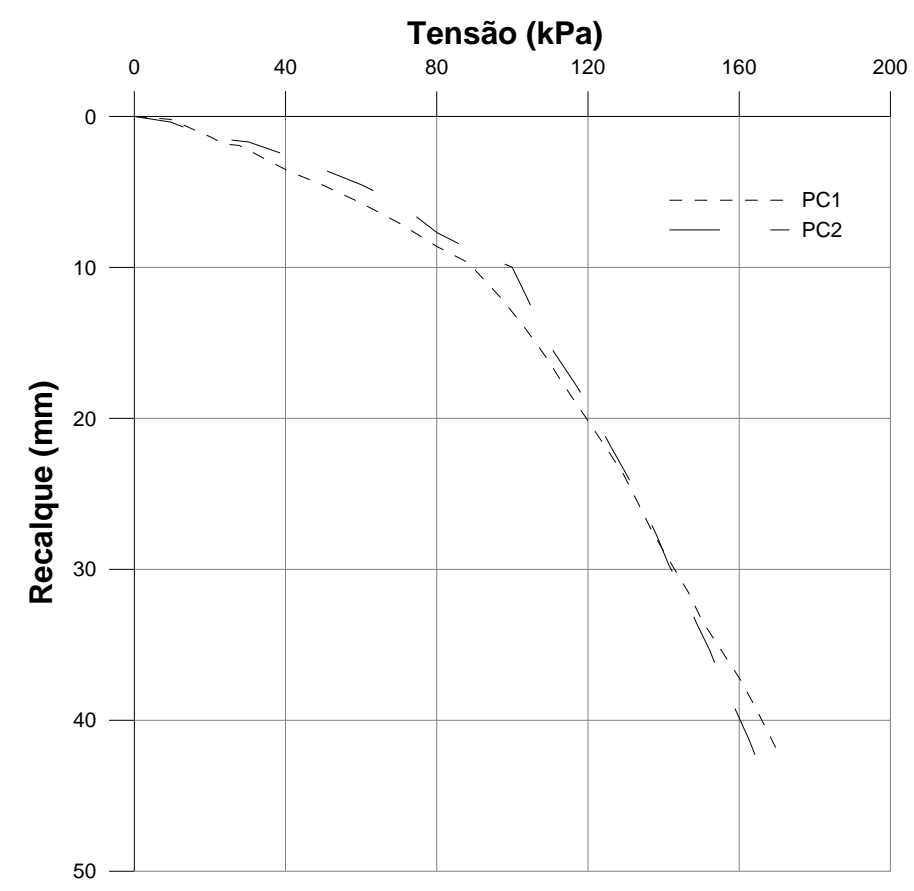

Figura 4.4- Resultados de provas de carga sobre placa em solo natural na profundidade $2 \mathrm{~m}$. Campo Experimental da Unesp de Bauru, SP (Agnelli, 1997). 


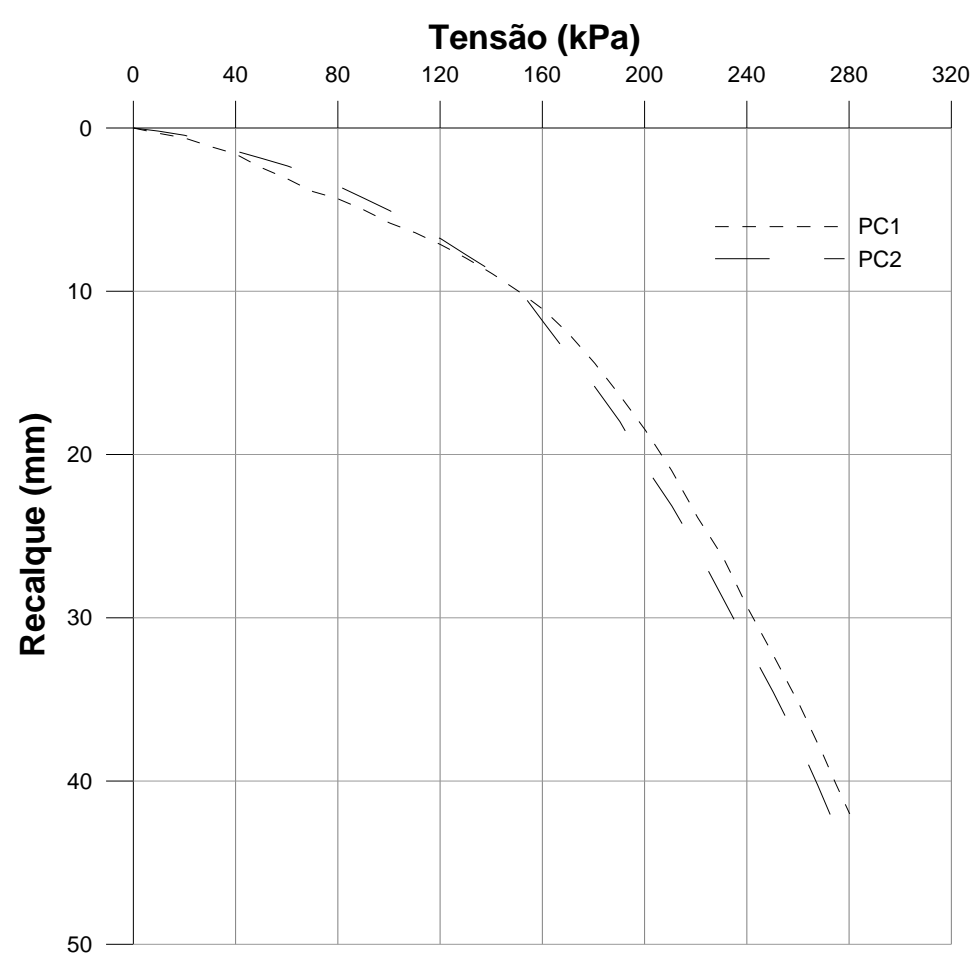

Figura 4.5- Resultados de provas de carga sobre placa em solo natural na profundidade $3 \mathrm{~m}$. Campo Experimental da Unesp de Bauru, SP (Agnelli, 1997).

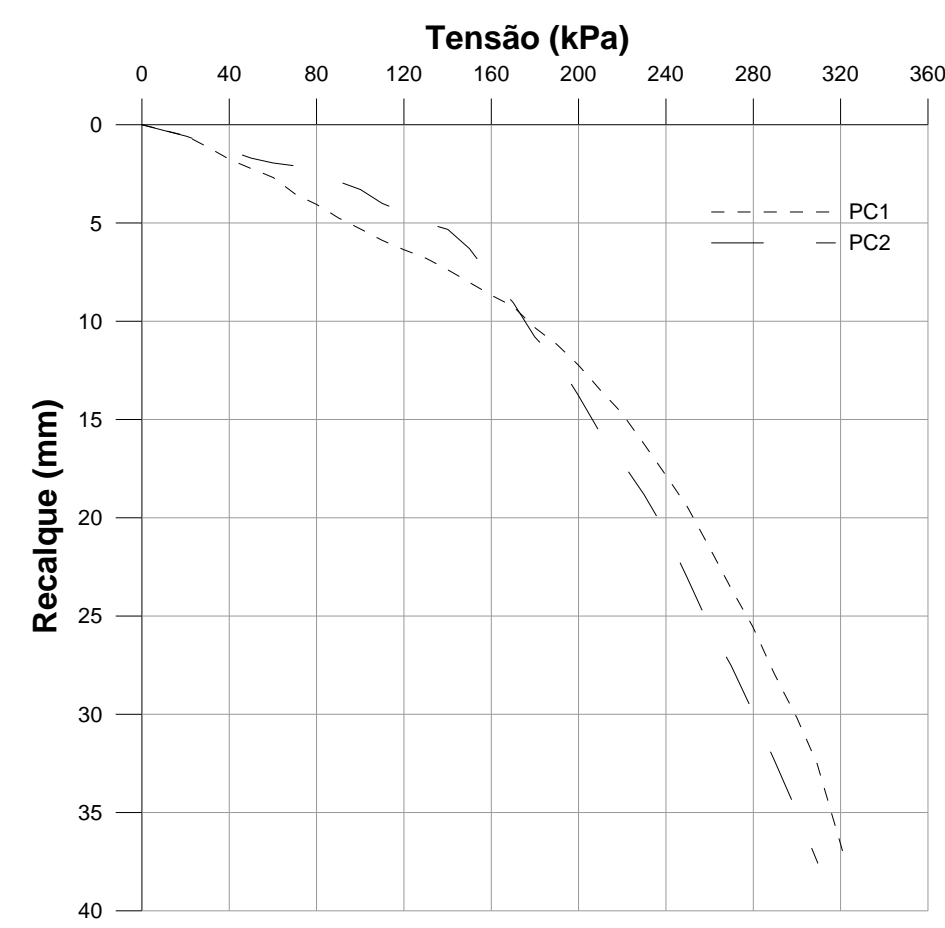

Figura 4.6- Resultados de provas de carga sobre placa em solo natural na profundidade $4 \mathrm{~m}$. Campo Experimental da Unesp de Bauru, SP (Agnelli, 1997). 

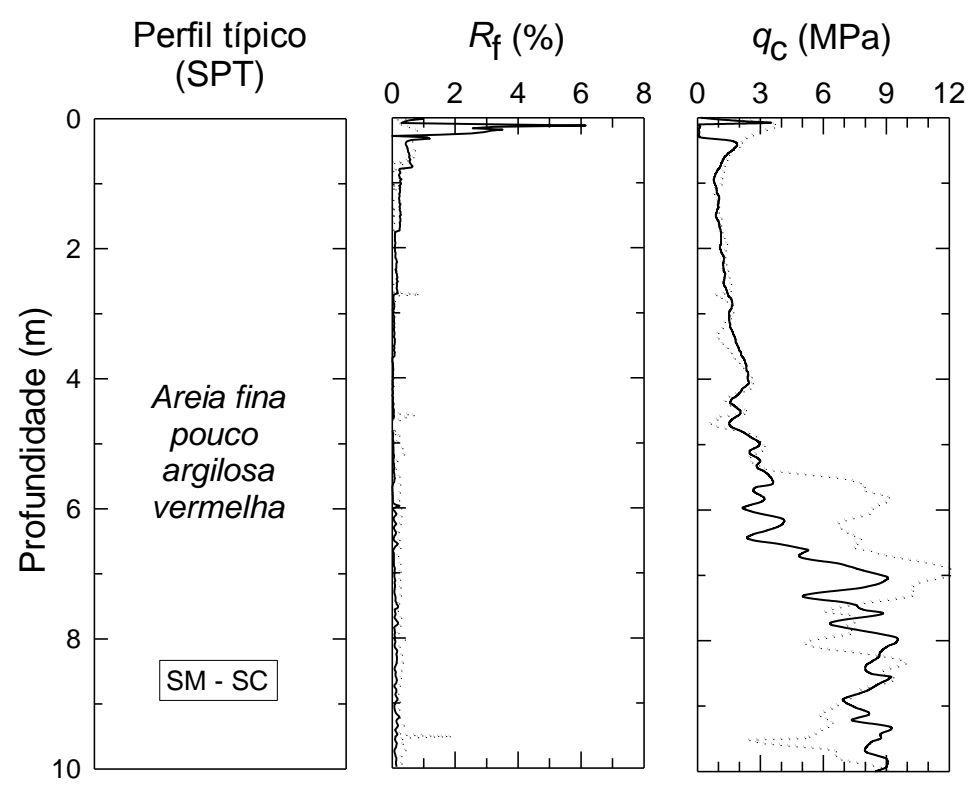

Gmax (MPa)

Figura 4.7- Resultados de dois ensaios SCPT realizados no Campo Experimental da Unesp-Bauru ( adaptado de De Mio, 2005).

\subsubsection{Comparação entre Previsão e Resultados de Provas de Carga}

As comparações entre resultados de prova de carga e a previsão do comportamento de fundação direta em solo arenoso utilizando resultados de ensaio SCPT, estão representadas nas Figuras 4.8 a 4.11. Os parâmetros adotados para representação da curva tensão-recalque foram $\mathrm{f}=0,99$ e $\mathrm{g}=0,03$, conforme apresentado no item anterior. $\mathrm{O}$ fator de influência foi assumido igual a 0,79 , já que se trata de uma placa rígida com seção circular, Perloff \& Baron (1976 apud Cintra et al, 2003) e o coeficiente de Poisson adotado foi de 0,3, conforme a proposta de Bowles (1988) abordada na Tabela 2.2.

Comparando-se os resultados das duas provas de carga realizadas (PC1 e PC2) e a previsão da curva tensão-recalque obtida através dos ensaios SCPT (SCPT1 e SCPT2), constata-se que no primeiro metro de profundidade o ajuste entre curva prevista e medida não foi tão bom quanto nas demais profundidades. Em ensaios sísmicos downhole, que é a técnica empregada para obter $G_{\max }$, a aquisição de sinal para determinação dessa velocidade não é muito boa, pois existem as interferências causadas pela onda de superfície, conforme discute Vitali (2011). A partir do segundo metro de profundidade observa-se uma melhor relação entre as curvas medidas e previstas. 


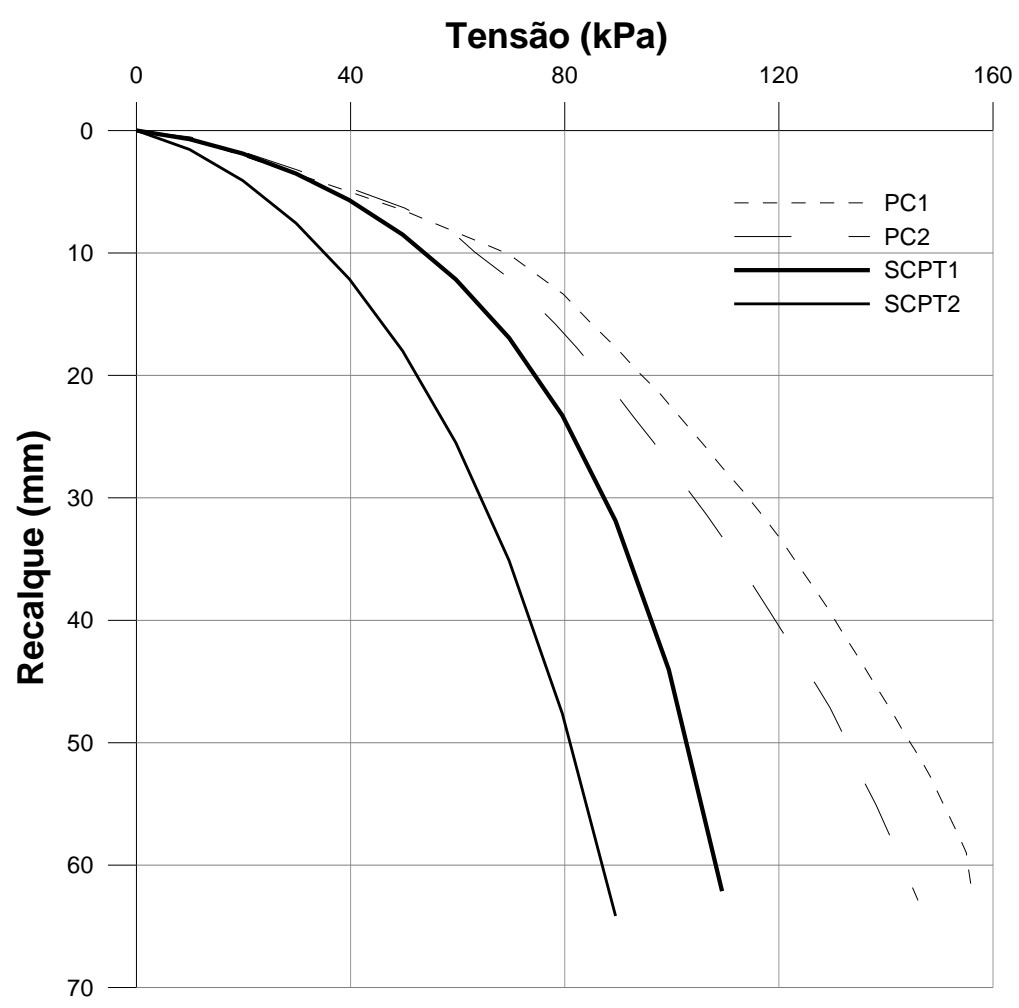

Figura 4.8 - Previsão do comportamento de fundações diretas utilizando o ensaio SCPT, com resultados das provas de carga em placa assentadas a $1 \mathrm{~m}$ de profundidade para o campo experimental de Bauru.

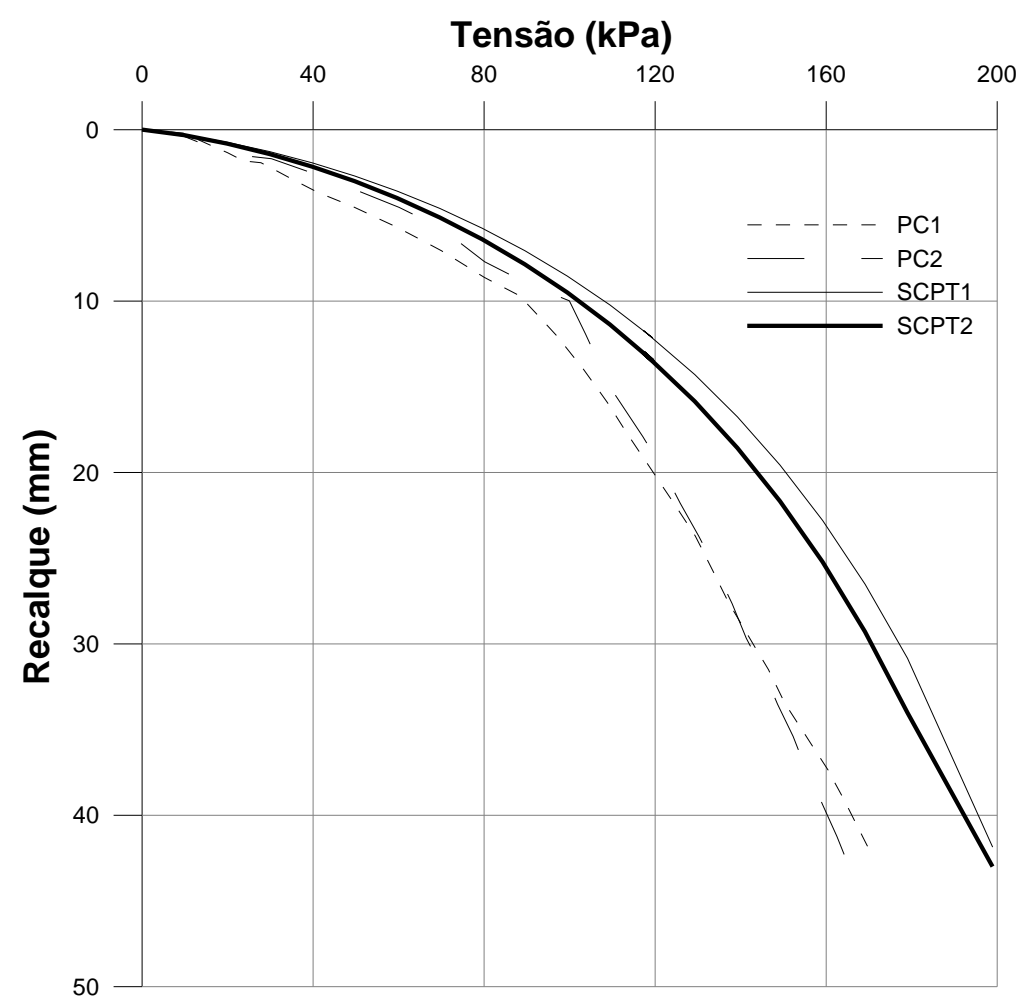

Figura 4.9- Previsão do comportamento de fundações diretas utilizando o ensaio SCPT, com resultados das provas de carga em placa assentadas a $2 \mathrm{~m}$ de profundidade para o campo experimental de Bauru. 


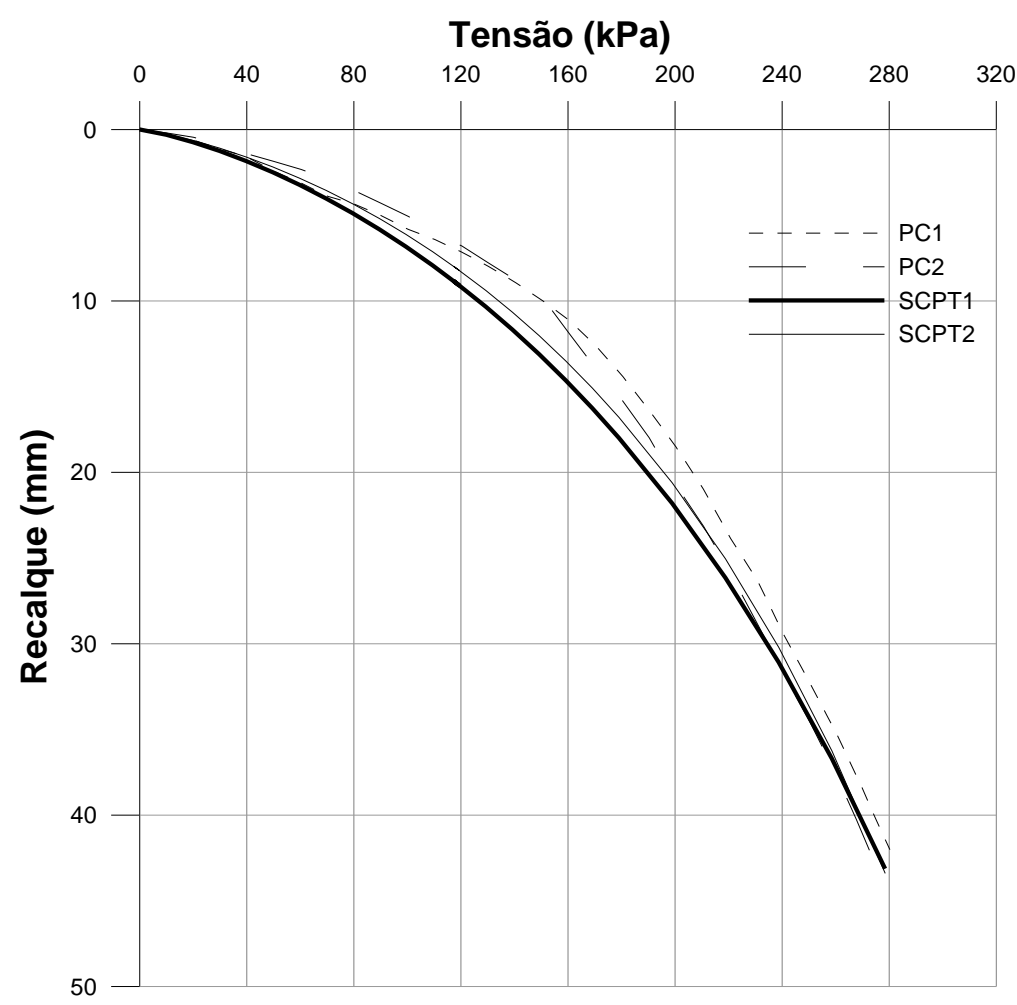

Figura 4.10- Previsão do comportamento de fundações diretas utilizando o ensaio SCPT, com resultados das provas de carga em placa assentadas a $3 \mathrm{~m}$ de profundidade para o campo experimental de Bauru.

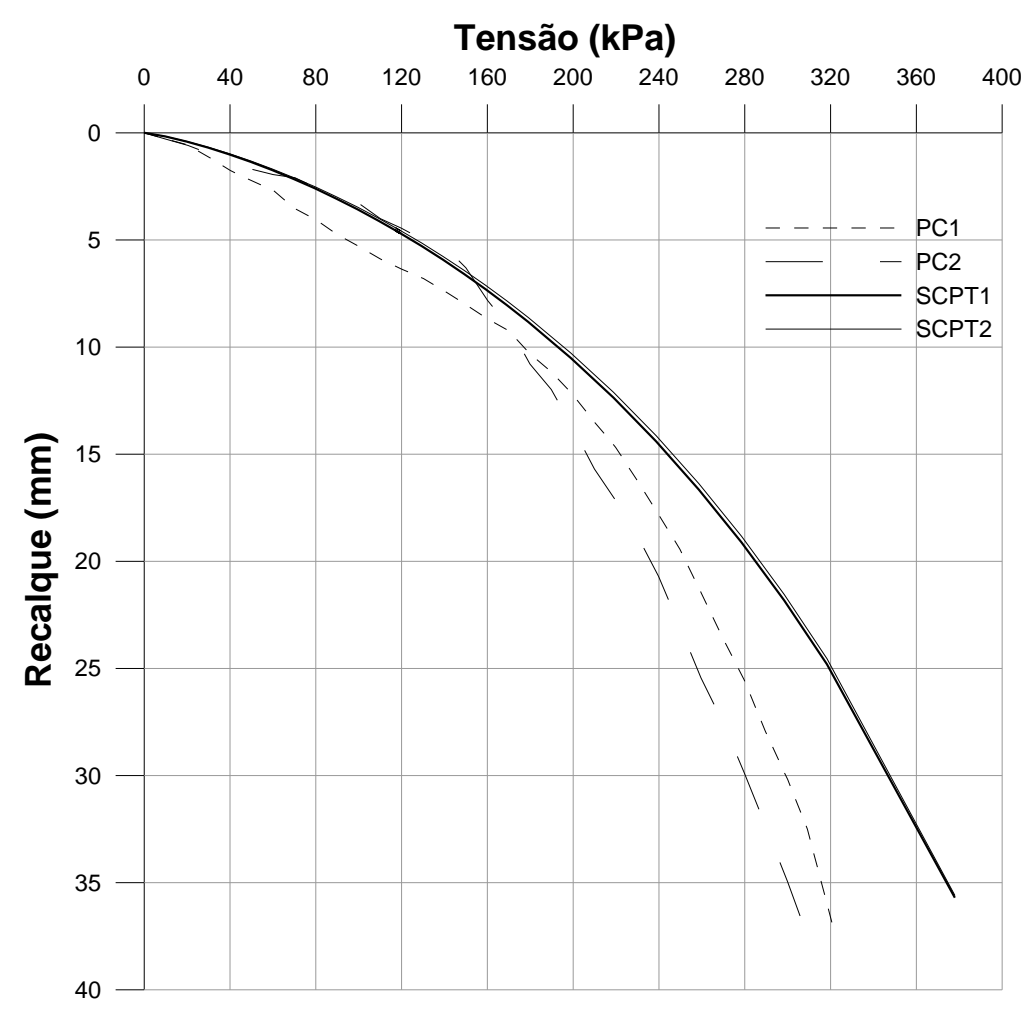

Figura 4.11- Previsão do comportamento de fundações diretas utilizando o ensaio SCPT, com resultados das provas de carga em placa assentadas a $4 \mathrm{~m}$ de profundidade para o campo experimental de Bauru. 
Para calcular o recalque correspondente a uma tensão vertical de $65 \mathrm{kPa}$ empregando o método de Schmertmann (1978) elaborou-se a Tabela 4.3, o que contém as informações necessárias para esse cálculo. Considerando que o método de Schmertmann (1978) é bastante difundido no meio geotécnico, este foi utilizado para comparar a previsão de recalques.

Tabela 4.3 - Dados necessários para o cálculo de recalques aplicando-se o método de Schmertmann (1978).

\begin{tabular}{ccccccc}
\hline Prof. $(\mathrm{m})$ & $\mathrm{q}(\mathrm{kPa})$ & $\sigma(\mathrm{kPa})$ & $\sigma^{*}(\mathrm{kPa})$ & $\mathrm{C} 1$ & $\mathrm{C} 2$ & Izmáx \\
\hline 1 & 14 & 65 & 51 & 0,86 & 1,0 & 0,70 \\
2 & 30 & 65 & 35 & 0,57 & 1,0 & 0,64 \\
3 & 46 & 65 & 19 & 0,50 & 1,0 & 0,62 \\
4 & 62 & 65 & 3 & 0,50 & 1,0 & 0,61 \\
\hline
\end{tabular}

Na Figura 4.12, tem-se os gráficos para a determinação do fator de influência $\left(I_{z m a ́ x}\right)$ nas profundidades 1, 2, 3 e 4m, que são utilizados para o cálculo de recalques pelo método de Schmertmann (1978), descrito no item 2.3.3.1 do trabalho.

As Tabelas 4.4, 4.5, 4.6 e 4.7 contém os coeficientes necessários para a aplicação desse método nas profundidades de $1,2,3$ e $4 \mathrm{~m}$, respectivamente. O resultado da previsão do recalque em cada profundidade, que provém da multiplicação do coeficiente $\mathrm{C} 1, \mathrm{C} 2, \sigma^{*}$, e da somatória da última coluna da tabela, está apresentado logo abaixo das tabelas de coeficientes em cada profundidade. Para a estimativa do módulo de deformabilidade $\left(E_{S}\right)$, podem ser tomados os valores do coeficiente $\alpha$ que são multiplicados pela resistência de ponta obtida no ensaio CPT. Os valores do coeficiente $\alpha$ obtidos na literatura técnica variam, usualmente, entre 1,5 e 8, sendo que os valores mais baixos estão associados aos solos arenosos e valores mais altos abrangendo solos plásticos e compressíveis.

Para a adoção do $\alpha$ nesta pesquisa, utilizou-se a proposta do Teixeira e Godoy ( 1996 ): $\alpha=3$ para solos arenosos, $\alpha=5$ para solos siltosos e $\alpha=7$ para solos argilosos. 
a) $1 \mathrm{~m} \quad$ Fator de influência $\mathrm{Iz}$

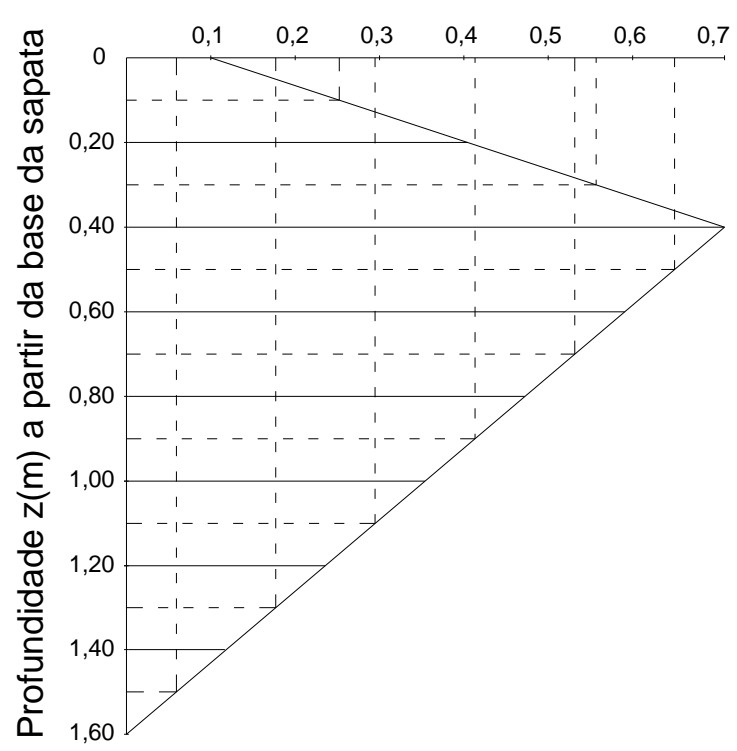

c) $3 \mathrm{~m} \quad$ Fator de influência $\mathrm{Iz}$

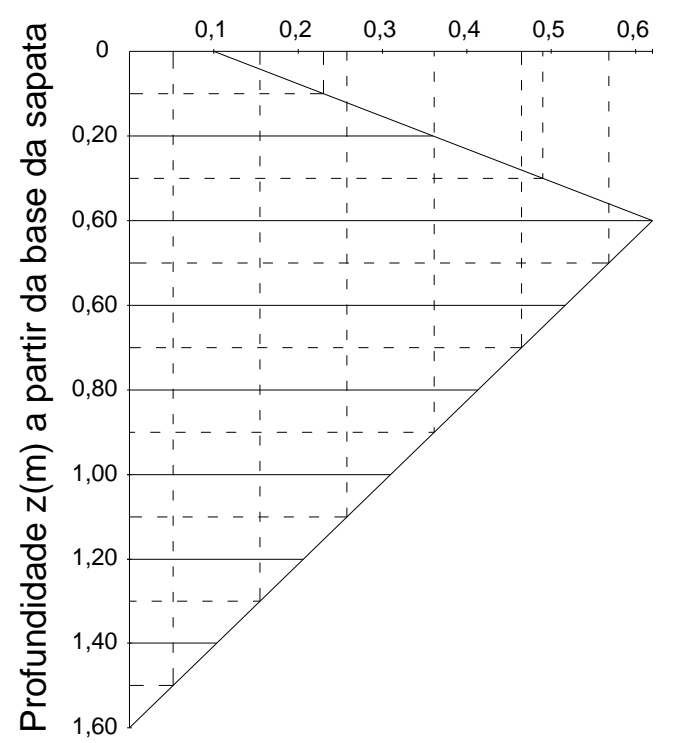

b) $2 m \quad$ Fator de influência $I z$

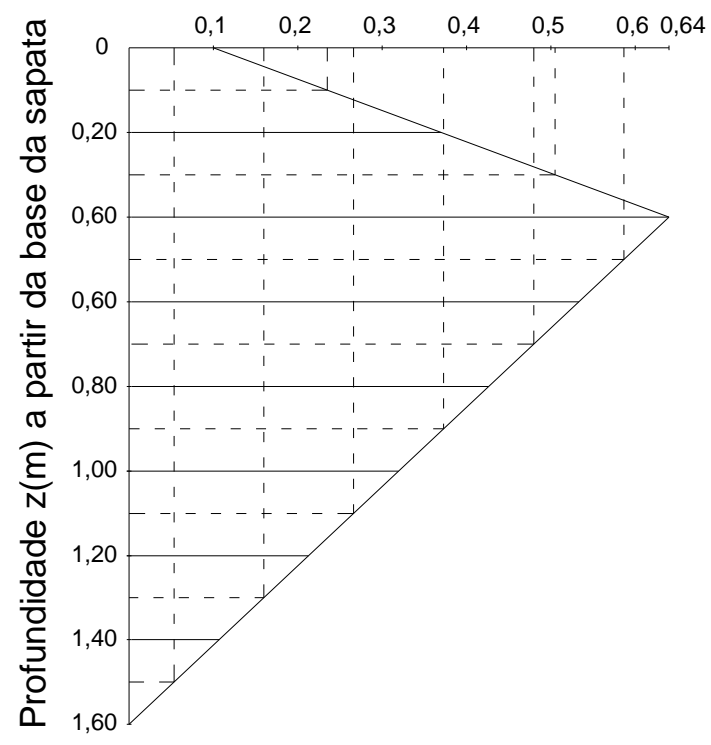

d) $4 \mathrm{~m} \quad$ Fator de influência $\mathrm{Iz}$

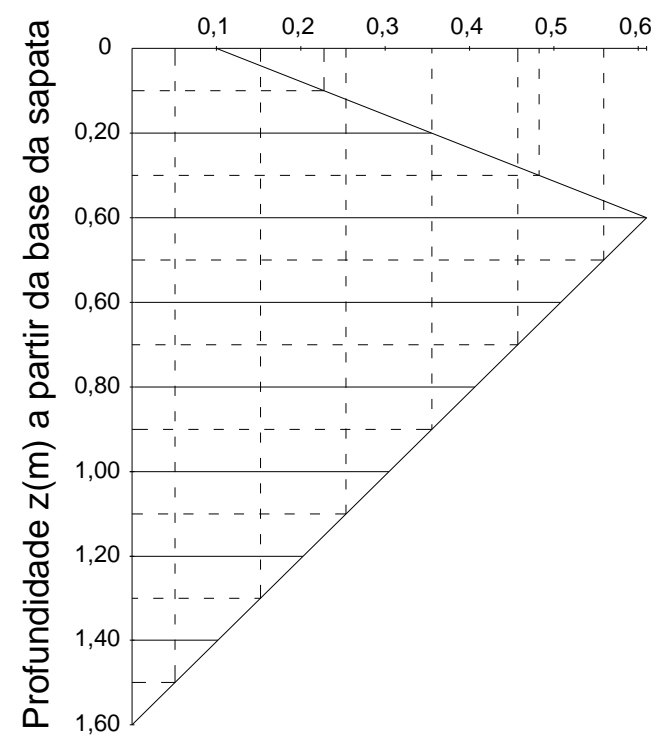

Figura 4.12- Fator de influência (Iz) para as profundidades estudadas 
Tabela 4.4 - Somatória dos recalques das sub camadas a $1 \mathrm{~m}$ de profundidade.

\begin{tabular}{cccccc}
\hline $\begin{array}{c}\mathrm{N}^{\circ} \mathrm{da} \\
\text { camada }\end{array}$ & $\begin{array}{c}\Delta \mathrm{Z} \\
(\mathrm{mm})\end{array}$ & $\mathrm{IZmáx}$ & $\begin{array}{c}\mathrm{q}_{\mathrm{c}} \\
(\mathrm{MPa})\end{array}$ & $\begin{array}{c}\mathrm{E}_{\mathrm{s}} \\
(\mathrm{MPa})\end{array}$ & $\begin{array}{c}\mathrm{IZmáx. \Delta Z/} \\
\mathrm{Es}\end{array}$ \\
\hline 1 & 200 & 0,252 & 0,877 & 3,068 & 16,4 \\
2 & 200 & 0,557 & 0,968 & 3,389 & 32,9 \\
3 & 200 & 0,650 & 0,980 & 3,430 & 37,9 \\
4 & 200 & 0,532 & 1,101 & 3,854 & 27,6 \\
5 & 200 & 0,413 & 1,210 & 4,236 & 19,5 \\
6 & 200 & 0,293 & 1,250 & 4,374 & 13,4 \\
7 & 200 & 0,177 & 1,324 & 4,634 & 07,6 \\
8 & 200 & 0,059 & 1,401 & 4,904 & 02,4 \\
& $\Sigma=1,6 \mathrm{~m}$ & & & & $\Sigma=157,7$ \\
\hline
\end{tabular}

$\rho=0,86 \times 1,0 \times 0,051 \times 157,7=\mathbf{6 , 9} \mathbf{m m}$

Tabela 4.5 - Somatória dos recalques das sub camadas a $2 \mathrm{~m}$ de profundidade.

\begin{tabular}{cccccc}
\hline $\begin{array}{c}\mathrm{N}^{\circ} \text { da } \\
\text { camada }\end{array}$ & $\Delta \mathrm{Z}(\mathrm{mm})$ & $\mathrm{IZmáx}$ & $\mathrm{q}_{\mathrm{c}}(\mathrm{MPa})$ & $\mathrm{E}_{\mathrm{s}}(\mathrm{MPa})$ & $\begin{array}{c}\text { IZmáx. } \Delta \mathrm{Z} / \\
\text { Es }\end{array}$ \\
\hline 1 & 200 & 0,235 & 1,250 & 4,374 & 10,7 \\
2 & 200 & 0,505 & 1,324 & 4,634 & 21,8 \\
3 & 200 & 0,587 & 1,401 & 4,904 & 23,9 \\
4 & 200 & 0,480 & 1,352 & 4,732 & 20,3 \\
5 & 200 & 0,373 & 1,601 & 5,605 & 13,3 \\
6 & 200 & 0,226 & 1,454 & 5,088 & 8,9 \\
7 & 200 & 0,160 & 1,344 & 4,705 & 6,8 \\
8 & 200 & 0,053 & 1,634 & 5,719 & 01,9 \\
& $\Sigma=1,6 \mathrm{~m}$ & & & & $\Sigma=107,6$ \\
\hline
\end{tabular}

$\rho=0,57 \times 1,0 \times 0,035 \times 107,6=\mathbf{2 , 2} \mathbf{m m}$ 
Tabela 4.6 - Somatória dos recalques das sub camadas a 3m de profundidade.

\begin{tabular}{cccccc}
\hline $\begin{array}{c}\mathrm{N}^{\circ} \mathrm{da} \\
\text { camada }\end{array}$ & $\Delta \mathrm{Z}(\mathrm{mm})$ & $\mathrm{IZmáx}$ & $\mathrm{q}_{\mathrm{c}}(\mathrm{MPa})$ & $\mathrm{E}_{\mathrm{s}}(\mathrm{MPa})$ & $\begin{array}{c}\text { IZmáx. } \Delta \mathrm{Z} / \\
\mathrm{Es}\end{array}$ \\
\hline 1 & 200 & 0,230 & 1,454 & 5,088 & 9,0 \\
2 & 200 & 0,490 & 1,344 & 4,705 & 20,8 \\
3 & 200 & 0,568 & 1,634 & 5,719 & 19,9 \\
4 & 200 & 0,465 & 2,028 & 7,097 & 13,1 \\
5 & 200 & 0,361 & 2,382 & 8,338 & 8,7 \\
6 & 200 & 0,258 & 2,359 & 8,257 & 6,2 \\
7 & 200 & 0,155 & 1,579 & 5,526 & 5,6 \\
8 & 200 & 0,052 & 1,844 & 6,454 & 1,6 \\
& $\Sigma=1,6 \mathrm{~m}$ & & & & 85,0 \\
\hline
\end{tabular}

$\rho=0,5 \times 1,0 \times 0,019 \times 85,0=\mathbf{0 , 8 1} \mathbf{m m}$

Tabela 4.7 - Somatória dos recalques das sub camadas a $4 \mathrm{~m}$ de profundidade.

\begin{tabular}{cccccc}
\hline $\begin{array}{c}\mathrm{N}^{\circ} \mathrm{da} \\
\text { camada }\end{array}$ & $\Delta \mathrm{Z}(\mathrm{mm})$ & $\mathrm{IZmáx}$ & $\mathrm{q}_{\mathrm{c}}(\mathrm{MPa})$ & $\mathrm{E}_{\mathrm{s}}(\mathrm{MPa})$ & $\begin{array}{c}\text { IZmáx. } \Delta \mathrm{Z} / \\
\mathrm{Es}\end{array}$ \\
\hline 1 & 200 & 0,228 & 2,359 & 8,257 & 5,5 \\
2 & 200 & 0,483 & 1,579 & 5,526 & 17,5 \\
3 & 200 & 0,559 & 1,844 & 6,454 & 17,3 \\
4 & 200 & 0,457 & 1,420 & 4,971 & 18,4 \\
5 & 200 & 0,355 & 2,765 & 9,679 & 7,3 \\
6 & 200 & 0,254 & 2,779 & 9,726 & 5,2 \\
7 & 200 & 0,152 & 2,879 & 10,078 & 3,0 \\
8 & 200 & 0,051 & 4,860 & 17,010 & 0,6 \\
& $\Sigma=1,6 \mathrm{~m}$ & & & & 74,9 \\
\hline
\end{tabular}

$\rho=0,5 \times 1,0 \times 0,003 \times 74,9=\mathbf{0 , 1 1} \mathbf{m m}$ 
Na Tabela 4.8 tem-se os dados necessários e os resultados da previsão do recalque imediato (assumindo-se uma solicitação de $65 \mathrm{kPa}$ ), empregando-se agora o método de Meyerhof (1974) nas profundidades de 1, 2, 3 e 4m. A escolha pelo método de Meyerhof (1974) se deve ao fato de utilizar de maneira direta resultados de ensaios CPT.

Tabela 4.8 - Aplicação do Método de Meyerhof (1974) nas profundidades estudadas.

\begin{tabular}{cccc}
\hline Prof. $(\mathrm{m})$ & $\sigma^{*}(\mathrm{KPa})$ & $\mathrm{q}_{\mathrm{c} \mathrm{med}}(\mathrm{MPa})$ & Recalque $(\mathrm{mm})$ \\
\hline 1 & 51 & 0,99 & 20,6 \\
2 & 35 & 1,33 & 10,5 \\
3 & 19 & 1,61 & 4,7 \\
4 & 3 & 1,80 & 0,7 \\
\hline
\end{tabular}

Com base nos resultados obtidos empregando os métodos clássicos (Shmertmann, 1978 e Meyerhof, 1974) e nas provas de carga executadas por Agnelli (1997), fez-se um estudo comparativo com a previsão feita empregando o método de Mayne (2000). Para a comparação entre os resultados dos métodos de previsão do recalque com aqueles das provas de carga, foi elaborada as Tabelas 4.9 e 4.10, que contém todos os valores obtidos.

Tabela 4.9 - Valores de recalques segundo diferentes métodos e medidos em provas de carga admitindo-se uma tensão aplicada de $65 \mathrm{kPa}$.

\begin{tabular}{ccccc}
\hline \multicolumn{5}{c}{ Recalque - Valores em mm } \\
\hline $\begin{array}{c}\text { Prof. } \\
\text { (m) }\end{array}$ & $\begin{array}{c}\text { Schmertmann } \\
(1978)\end{array}$ & $\begin{array}{c}\text { Meyerhoff } \\
(1974)\end{array}$ & $\begin{array}{c}\text { Mayne } \\
(2000)\end{array}$ & $\begin{array}{c}\text { PC } \\
\text { (Agnelli, 1997) } \\
\text { (médio) }\end{array}$ \\
1 & & & (médio) & 10,0 \\
2 & 6,9 & 20,6 & 20,5 & 5,5 \\
3 & 2,2 & 10,5 & 4,2 & 2,6 \\
4 & 0,8 & 4,7 & 3,3 & 2,8 \\
\hline
\end{tabular}


Tabela 4.10 - Erro em relação a média das Provas de Carga. Valores em porcentagem.

\begin{tabular}{cccc}
\hline Prof. (m) & $\begin{array}{c}\text { Schmertmann } \\
(1978)\end{array}$ & $\begin{array}{c}\text { Meyerhoff } \\
(1974)\end{array}$ & $\begin{array}{c}\text { Mayne } \\
(2000) \\
\text { média }\end{array}$ \\
\hline $\mathbf{1}$ & 31 & 11 & 105 \\
$\mathbf{2}$ & 54 & 91 & 24 \\
$\mathbf{3}$ & 68 & 81 & 27 \\
$\mathbf{4}$ & 96 & 75 & 21 \\
\hline
\end{tabular}

Conforme observado nas Tabelas 4.9 e 4.10, o método de Schmertmann (1978) levou a valores de recalques variando entre 31 a $96 \%$ inferiores aqueles determinados nas provas de carga. O método de Meyerhof (1974) resultou em recalques maiores do que as provas de carga, com erro relativo variando de 11 a 91\%. Analisando-se os resultados obtidos pela aplicação do método de Mayne (2000), constatou-se, nas profundidades de 2, 3 e 4m, um recalque estimado muito próximo daqueles medidos nas duas provas de carga realizadas. Observa-se também que para qualquer tensão a ser adotada os recalques medidos pela prova de carga ficam bem próximos dos recalques previstos pela proposta do Mayne (2000).

Só no primeiro metro observou-se uma grande discrepância entre os resultados (erro relativo de $105 \%$ ). Portanto, a aplicação desse método para a estimativa da carga de ruptura e do recalque em camadas próximas a superfície podem estar prejudicados.

Assumindo-se um recalque de $25 \mathrm{~mm}$ para a comparação entre os resultados dos métodos de previsão das tensões com aqueles das provas de carga, foi elaborada as Tabelas 4.11 e 4.12 .

Analisando-se as Tabelas 4.11 e 4.12, constatou-se, nas profundidades de 2, 3 e 4m, uma tensão estimada muito próxima daquelas medidas nas duas provas de carga realizadas. Só no primeiro metro observou-se uma significativa discrepância entre os resultados (erro relativo de $52 \%$ ). Constatou-se, portanto, que após o ajuste nos parâmetros g e f da proposta de Mayne (2000), o método empregado levou a uma melhor estimativa da curva tensãorecalque, pois foi o que apresentou um menor erro relativo quando comparado aos demais métodos empregados, para profundidades superiores a $1 \mathrm{~m}$. 
Tabela 4.11 - Valores de tensões segundo diferentes métodos e medidos em provas de carga admitindo-se um recalque de $25 \mathrm{~mm}$.

\begin{tabular}{rrrr}
\hline $\begin{array}{l}\text { Prof. } \\
(\mathrm{m})\end{array}$ & $\begin{array}{c}\text { Mayne } \\
(2000)\end{array}$ & $\begin{array}{c}\mathrm{PC}_{\text {médio }} \\
(\text { Agneli, } \\
1997)\end{array}$ & $\begin{array}{c}\sigma_{\text {medida }} / \\
\sigma_{\text {prevista }}\end{array}$ \\
\hline 1 & 100 & 66 & 0,66 \\
2 & 163 & 128 & 0,79 \\
3 & 216 & 220 & 1,01 \\
4 & 316 & 266 & 0,84 \\
\hline
\end{tabular}

Tabela 4.12 - Erro em relação a média das Provas de Carga. Valores em porcentagem.

\begin{tabular}{cc}
\hline Prof. (m) & $\begin{array}{c}\text { Mayne } \\
(2000)\end{array}$ \\
\hline 1 & 52 \\
2 & 27 \\
3 & 7 \\
4 & 19 \\
\hline
\end{tabular}

\subsection{CAMPO EXPERIMENTAL SÃO CARLOS}

\subsubsection{Ensaios de Placa}

Nas Figuras 4.13 a 4.15 têm-se as curvas tensão-recalque das provas de carga em placa realizadas por vários pesquisadores nas profundidades 1,5, 4,0 e 6,0 m a diferentes níveis de sucção no campo experimental da EESC/USP. 
Tensão (kPa)

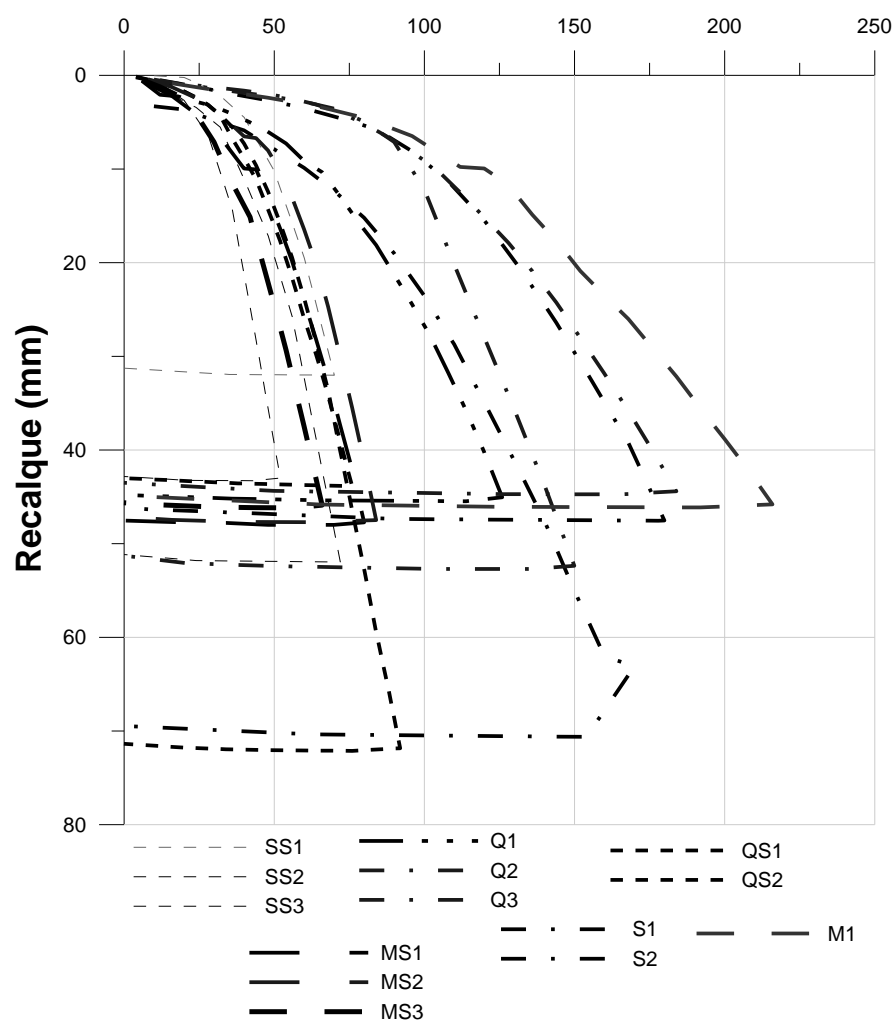

Figura 4.13- Curva tensão-recalque para diferentes níveis de sucção na profundidade $1,5 \mathrm{~m}$ para o campo experimental de São Carlos (Menegotto, 2004).

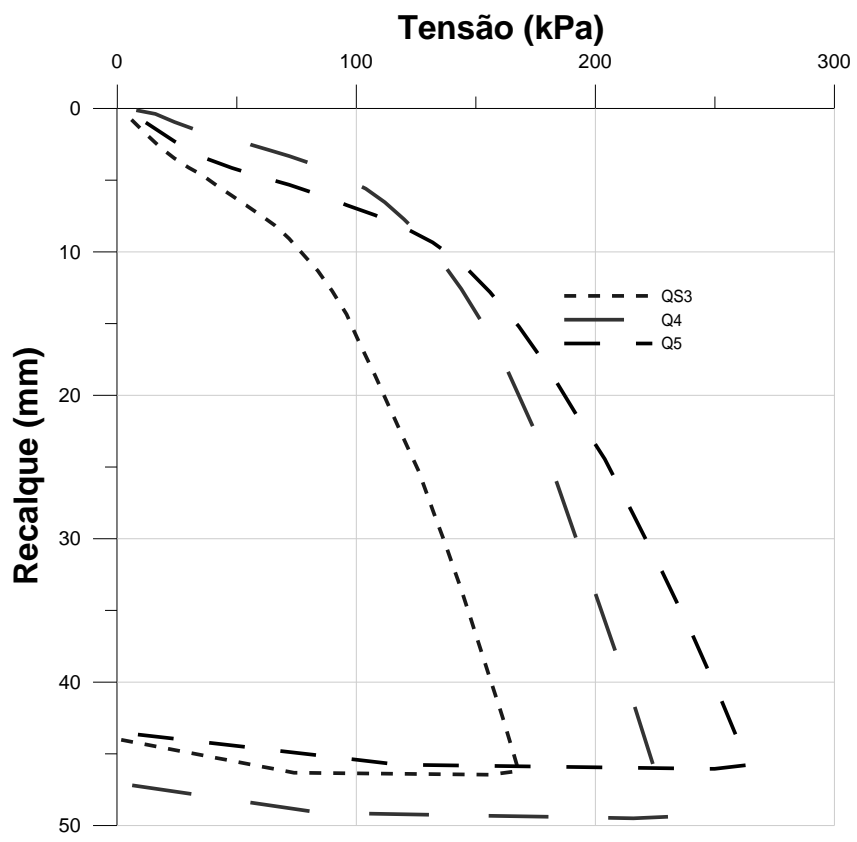

Figura 4.14- Curva tensão-recalque para diferentes níveis de sucção na profundidade 4,0m para o campo experimental de São Carlos (Menegotto, 2004). 


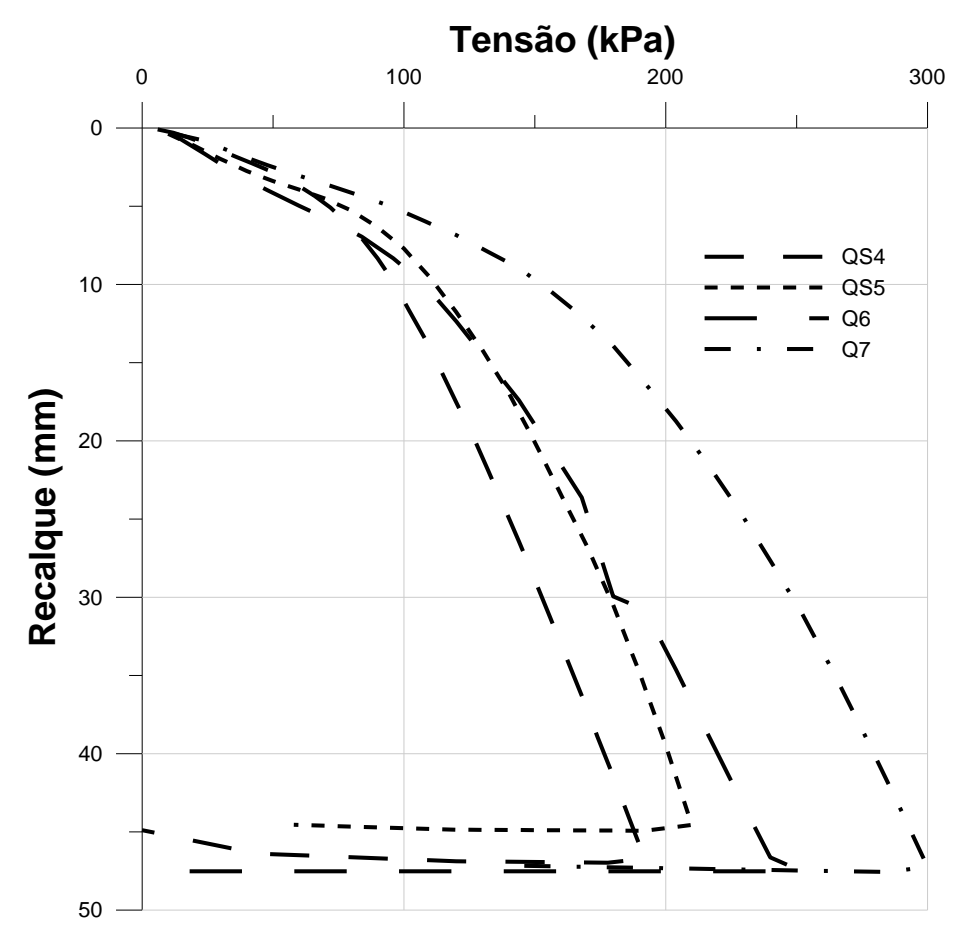

Figura 4.15- Curva tensão-recalque para diferentes níveis de sucção na profundidade 6,0m para o campo experimental de São Carlos (Menegotto, 2004).

\subsubsection{Ensaios de cone sísmico}

Na Figura 4.16 estão representados os resultados dos ensaios CPT e SCPT utilizados na previsão da curva tensão-recalque. Apresentam-se também resultados de ensaios cross-hole realizados na área, representado apenas para mostrar que os valores de $G_{\max }$ determinados pelas duas técnicas (cross-hole e SCPT) estão na mesma ordem de grandeza. Vitali (2011) discute com detalhes as diferenças observadas em ensaios SCPT e cross-hole para a determinação da velocidade de propagação de ondas de cisalhamento. Os resultados dos ensaios apresentados na Figura 4.16 indicam a grande variabilidade nos valores da resistência de ponta do cone $\left(\mathrm{q}_{\mathrm{c}}\right)$ até $2 \mathrm{~m}$ de profundidade, que diminui a partir dai. Observa-se também grande variabilidade nos valores de $\mathrm{G}_{\max }$, que se intensifica próximo a linha de seixos, devido a uma provável reflexão de ondas, que afeta a interpretação dos resultados de ensaios SCPT.

Para possibilitar um melhor entendimento da variabilidade do solo que ocorre no campo experimental de São Carlos, e pelo fato de vários ensaios SCPT e cross-hole terem sido realizados em diferentes épocas na área, representa-se a curva de variação com a profundidade de $\mathrm{q}_{\mathrm{c}}$ e $\mathrm{G}_{\max }$ (Figura 4.17) incluindo ainda nessa figura a variação de valores médios, média mais desvio, média menos desvio e coeficiente de variação $(\mathrm{CV})$. 
$\operatorname{Gmax}(\mathrm{MPa})$

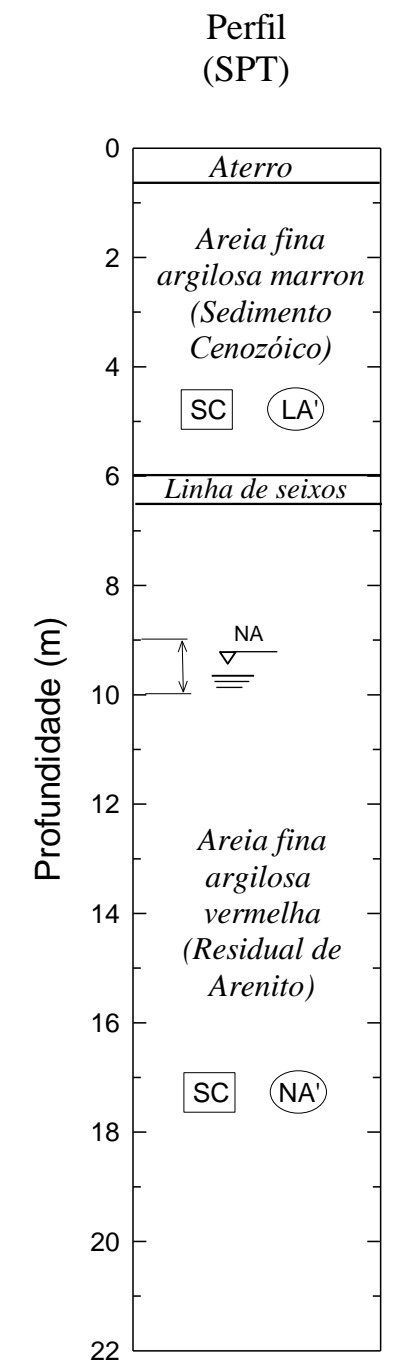

Perfil

(SPT)
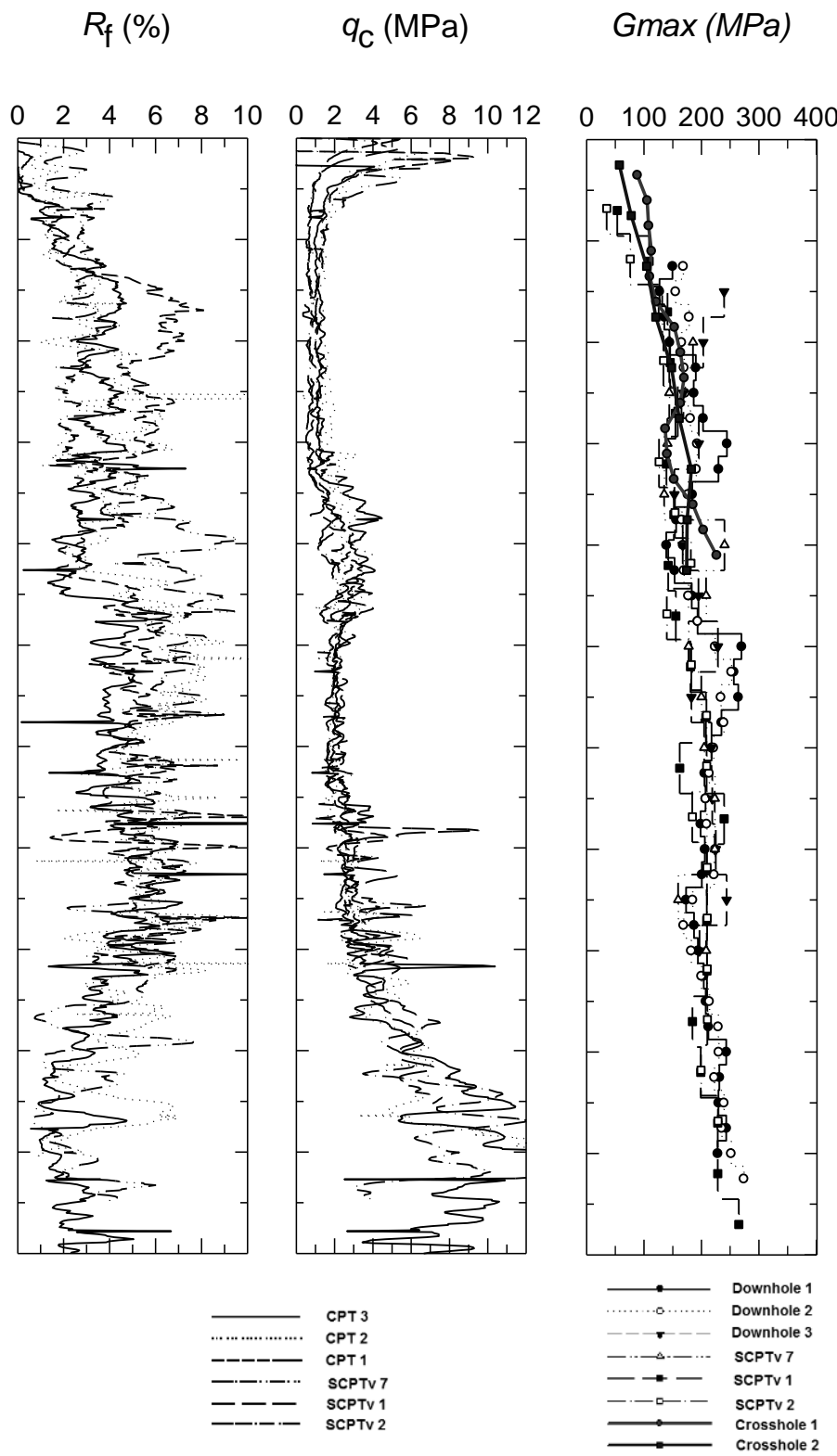

Figura 4.16- Resultados de ensaios SCPT, Downhole e Crosshole realizados no Campo Experimental de São Carlos (Vitali, 2011).

Observa-se na Figura 4.17 que a $1,5 \mathrm{~m}$ de profundidade há uma maior variação em valores de $\mathrm{G}_{\text {máx }}(\mathrm{CV}=44,9 \%)$ e em $\mathrm{q}_{\mathrm{c}}(\mathrm{CV}=49,9 \%)$. Nota-se que para as profundidades de 4,0 e 6,0m, há uma menor dispersão em relação a média, tanto na resistência de ponta como no módulo de cisalhamento máximo.

A variação no módulo de cisalhamento máximo $\left(\mathrm{G}_{\max }\right)$ até a profundidade de $1,5 \mathrm{~m}$ pode estar associado a variação na compactação da camada superficial de solo, na sua composição, na variação da sucção matricial bem como numa possível interferência de ondas de superfície na interpretação dos valores de Vs. 

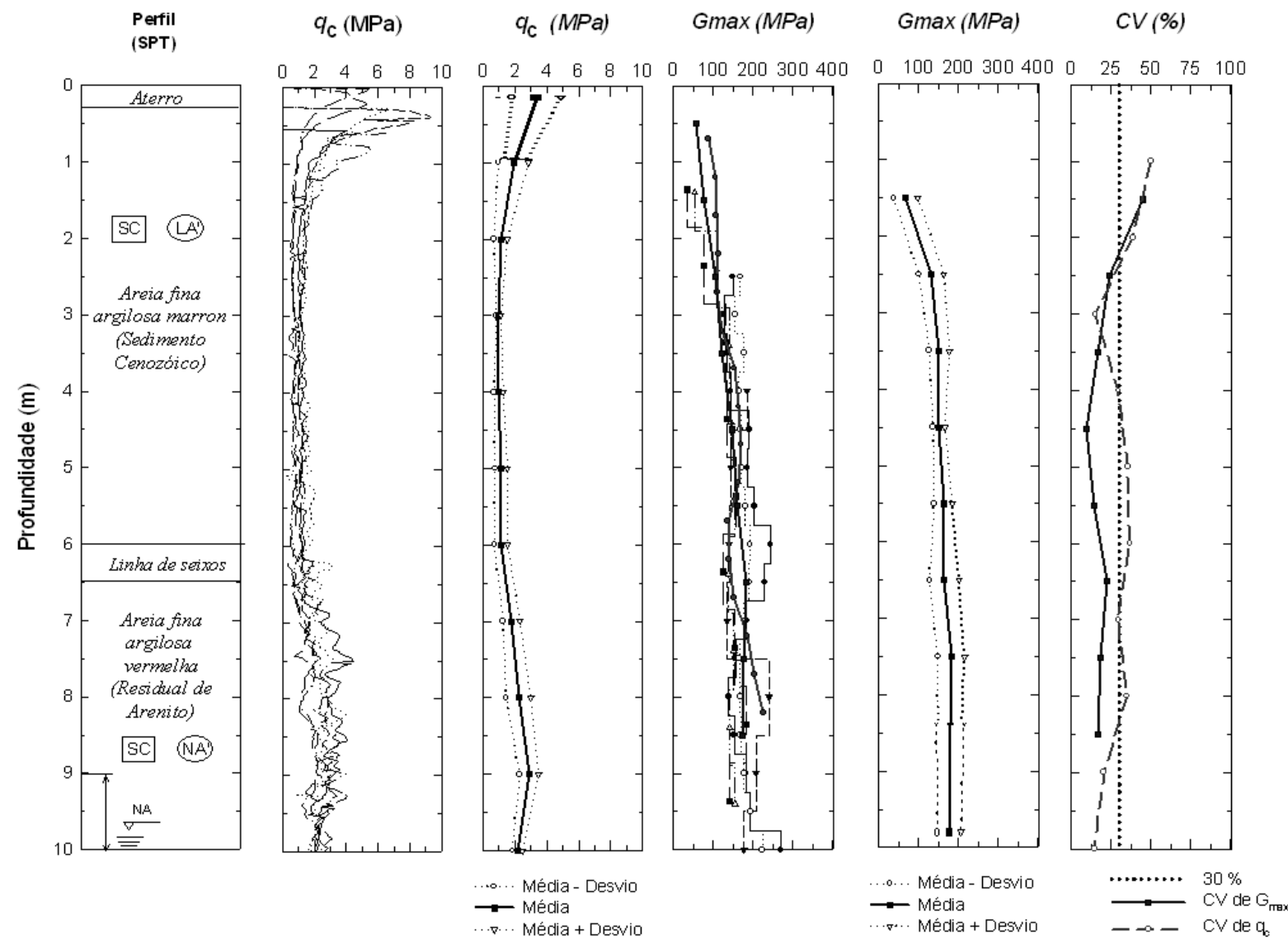

Figura 4.17- Representação da variação de valores de $\mathrm{q}_{\mathrm{c}}$ e $\mathrm{G}_{\max }$ em ensaios SCPT e Cross-Hole ao longo da profundidade bem como valores médios, média mais desvio, média menos desvio e coeficiente de variação $(\mathrm{CV})$.

Com base nos resultados de dois ensaios de cross-hole, e cinco ensaios de cone sísmico, procurou-se avaliar a variabilidade dos parâmetros necessários para a previsão da curva tensão-recalque assim assumiu-se os valores médios com seus respectivos desvios, tanto para o módulo de cisalhamento máximo como para a resistência de ponta, afim de fazer a previsão da curva tensão-recalque que, por sua vez, indicou um comportamento similar as curvas obtidas na prova de carga, com diferentes sucções e diferentes modalidades de ensaios (lento, rápido e misto), conforme mostram as Figuras 4.18 a 4.20 . 


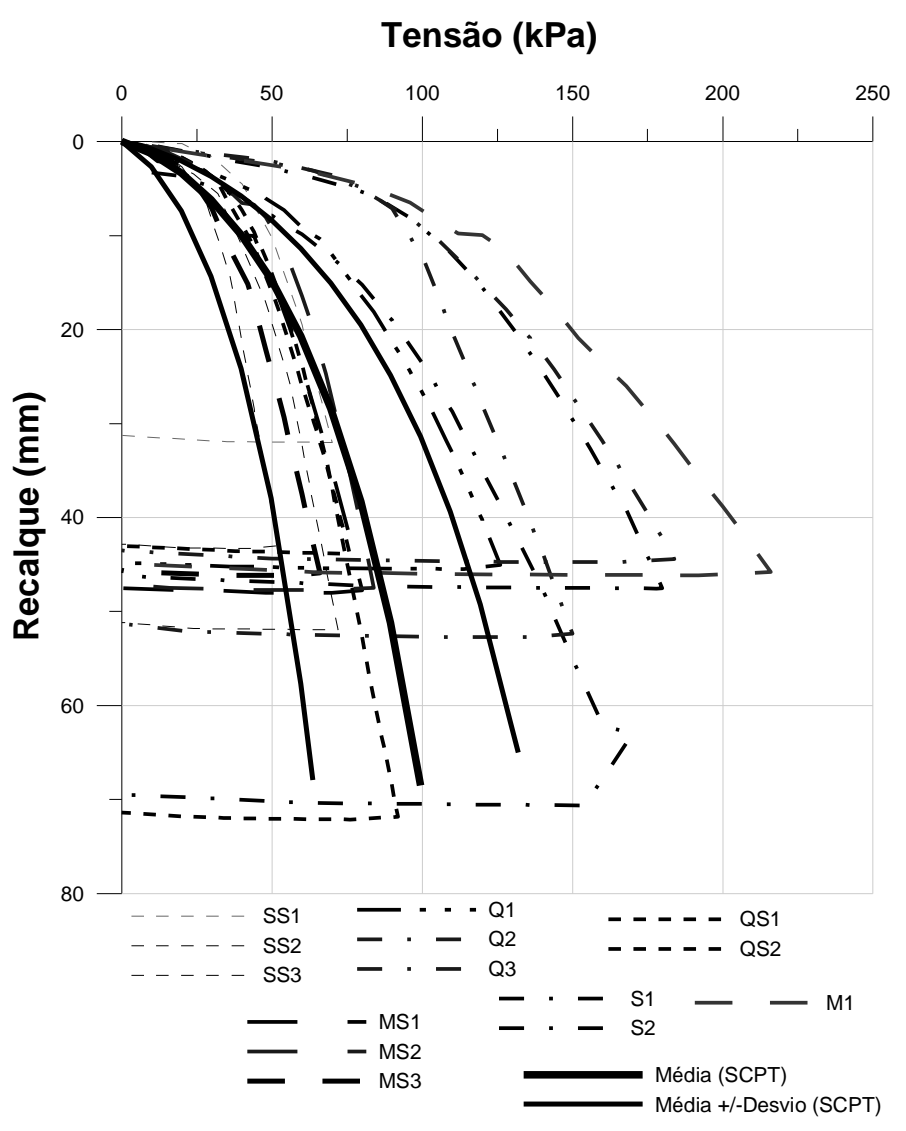

Figura 4.18- Previsão do comportamento de fundações diretas utilizando ensaio SCPT, com resultados de provas de carga em placa assentadas a 1,5m de profundidade no campo experimental de São Carlos.

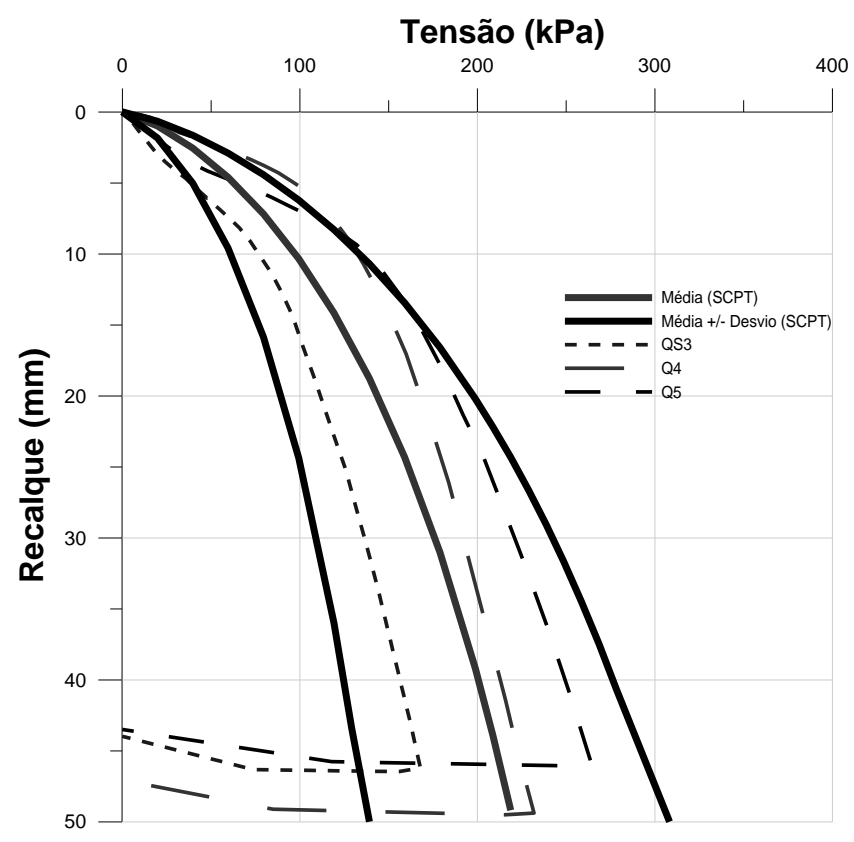

Figura 4.19- Previsão do comportamento de fundações diretas utilizando ensaio SCPT, com resultados de provas de carga em placa assentadas a 4,0m de profundidade no campo experimental de São Carlos. 


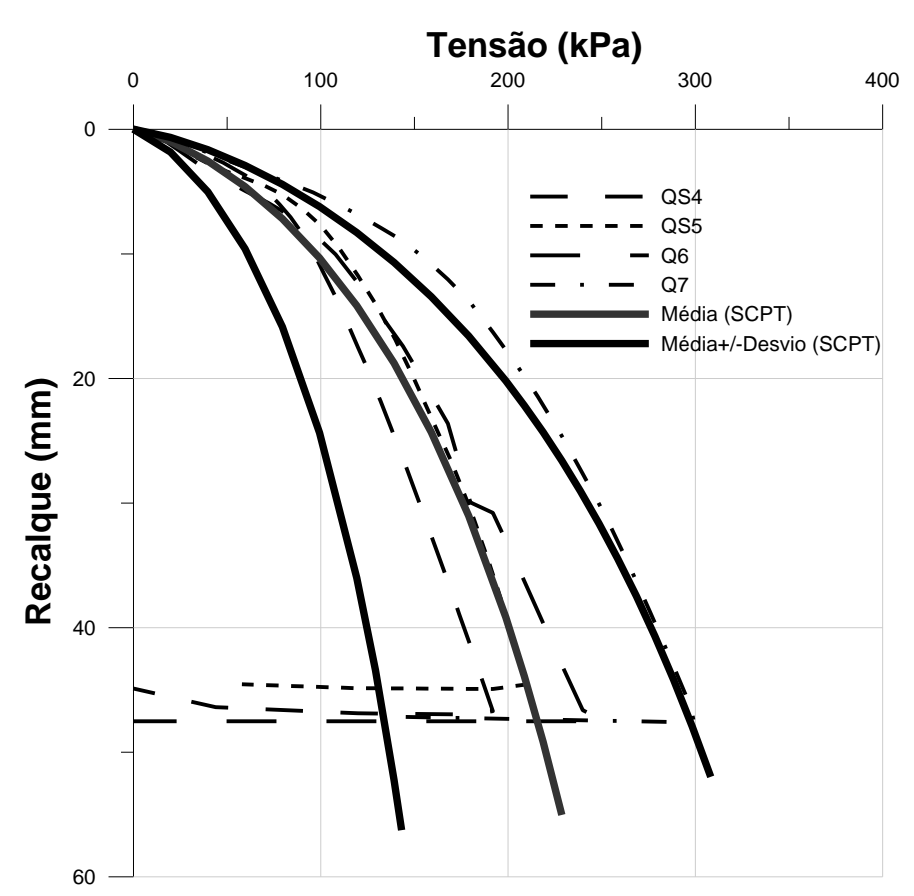

Figura 4.20- Previsão do comportamento de fundações diretas utilizando ensaio SCPT, com resultados de provas de carga em placa assentadas a 6,0m de profundidade no campo experimental de São Carlos.

Comparando-se os resultados das provas de carga em placa e a previsão da curva tensão-recalque obtida através dos resultados dos ensaios SCPT, constata-se que na profundidade de 1,5m (Figura 4.18) as curvas previstas não estão totalmente dentro das faixas de valores das curvas obtidas nas provas de carga. Uma possível justificativa para esse fato é que em ensaios sísmicos downhole, que é a técnica empregada para determinação da velocidade de propagação de onda $S$, a qual permite o cálculo de $G_{\max }$, a aquisição de sinal para determinação dessa velocidade não é muito boa, pois existe interferências causadas pela onda de superfície conforme discutido por Vitali (2011). Além disso, outras variáveis como a compactação do solo superficial, ressecamento e sucção matricial influenciam esses resultados. Portanto, a aplicação desse método para a estimativa da carga de ruptura e do recalque em camadas próximas a superfície podem estar prejudicados. Já, nas profundidades de $4 \mathrm{~m}$ e $6 \mathrm{~m}$ observa-se uma boa relação entre as curvas previstas e medidas (Figuras 4.19 e 4.20) que demonstra a aplicabilidade da proposta de Mayne (2000) após ajuste dos parâmetros f e g, mesmo para o solo de comportamento não convencional. Destaca-se, portanto, que os ensaios sísmicos têm vantagens interessantes por trabalharem a baixos níveis de deformação e que resultam em parâmetros médios reduzindo assim os efeitos da variabilidade do maciço. Além disso, evitam os inconvenientes dos processos de amostragem necessários aos ensaios laboratoriais, vantagem que se intensifica quando se pretende fazer a previsão do comportamento de estacas. 


\section{CONSIDERAÇÕES FINAIS}

Neste trabalho avaliou-se a aplicabilidade de um modelo para previsão da curva tensãorecalque de fundações diretas a partir dos resultados de ensaios SCPT. Optou-se pelo uso desse ensaio, pois é possível determinar o módulo de cisalhamento máximo $\left(\mathrm{G}_{\mathrm{max}}\right)$ ao mesmo tempo em que se mede resistência de ponta $\left(\mathrm{q}_{\mathrm{c}}\right)$ e o atrito lateral $\left(\mathrm{f}_{\mathrm{s}}\right)$.

Pelas peculiaridades do comportamento de solos tropicais foi necessário definir novos parâmetros de ajuste do modelo empregado a partir de resultados de ensaios sísmicos (crosshole e SCPT) e triaxiais realizados nos solos que ocorrem no campo experimental de São Carlos. Assim, os novos parâmetros de ajuste determinados para o modelo foram $\mathrm{f}=0,99$ e $\mathrm{g}=0,03$. Atribui-se o baixo valor do parâmetro $\mathrm{g}$ ao efeito da cimentação e da sucção matricial na rigidez dos solos arenosos lateríticos no local estudado. Esses solos apresentam elevada rigidez à baixa amplitude de deformação, representada por $\mathrm{G}_{\max }$, entretanto sua degradação é intensa e rápida, conforme discutida por alguns autores, como Giacheti (1991) e Barros (1997).

Os estudos realizados para o campo experimental de Bauru mostraram que as previsões das curvas tensão-recalque pelo método de Mayne (2000) foram melhores que aquelas feitas com outros métodos clássicos para as profundidades de 2, 3 e $4 \mathrm{~m}$. Constatou-se, portanto, que após o ajuste nos parâmetros g e f que o modelo empregado levou a uma melhor estimativa da curva tensão-recalque, pois foi o que apresentou um menor erro relativo quando comparado aos demais métodos empregados. Só a um metro de profundidade observou-se uma maior discrepância entre os resultados, fato que deve estar associado à deficiência na aquisição dos registros das ondas $\mathrm{S}$, por conta da interferência das ondas de superfícies a baixas profundidades, conforme discutido por Vitali (2011). Além disso, acredita-se que outras variáveis como a compactação do solo superficial, ressecamento e sucção matricial influenciam também influenciam esses resultados.

Para o campo experimental de São Carlos, os resultados dos ensaios indicam a variabilidade nos valores da resistência de ponta do cone $\left(\mathrm{q}_{\mathrm{c}}\right)$, muito intensa até $2 \mathrm{~m}$ de profundidade, que diminui a partir dai. Observa-se também grande variabilidade nos valores de $\mathrm{G}_{\max }$ até $1,5 \mathrm{~m}$ de profundidade, que também se intensifica próximo a linha de seixos, devido a uma provável reflexão de ondas, que afeta a interpretação dos resultados de ensaios SCPT.

As previsões das curvas tensão-recalque para o campo experimental de São Carlos foi representada de modo a incorporar a curva média e o desvio padrão nas três profundidades 
estudadas, de modo a poder levar em conta a variabilidade dos parâmetros $G_{\max }$ e $q_{c}$. Os resultados mostram que todas as previsões, em termos de média e desvio, se encontram dentro da faixa das provas de carga para diferentes sucções matriciais. Também para esse campo experimental as previsões foram melhores para 4 e $6 \mathrm{~m}$ de profundidade. Para 1,5 m de profundidade, Menegotto (2004) mostra a grande variação no comportamento de fundações diretas devido ao efeito da sucção. Destaca-se que a determinação de $G_{\max }$ a partir de ensaios SCPT apresenta limitações na aquisição dos registros das ondas S, por conta da interferência das ondas de superfícies, o que dificulta o emprego dessa técnica para baixas profundidades.

Concluiu-se que o método de Mayne (2000) para a previsão da curva tensão-recalque com base em resultados de ensaios de cone sísmico levou a resultados próximos aqueles obtidos nas provas de carga, após os ajustes nos parâmetros g e f do modelo.

Após a realização dessa pesquisa ficam as seguintes sugestões para trabalhos futuros:

- Avaliar a influência da sucção nos valores de $G_{\max }$ e de $\tau_{\max }$ para possibilitar um melhor entendimento do comportamento tensão-recalque de solos tropicais.

- Por se tratar de um trabalho pioneiro no Brasil, é necessário realizar ensaios SCPT em outros tipos de solos tropicais, a fim de melhor avaliar a aplicabilidade dessa proposta para estimativa de recalques em solos de comportamento não convencional.

- Estender esse estudo para avaliar o comportamento de fundações profundas a partir de resultados de ensaios SCPT em solos tropicais. 


\section{REFERÊNCIAS}

ABNT (1984). Associação Brasileira de Normas Técnicas. NBR 6489. Prova de carga direta sobre Terreno de Fundação. Rio de Janeiro.

ABNT (2006). Associação Brasileira de Normas Técnicas. NBR 12131. Estacas-Prova de Carga Estática. Rio de Janeiro.

ABNT (2010). Associação Brasileira de Normas Técnicas. NBR 6122. Projeto e execução de Fundações. Rio de Janeiro.

AGNELLI, N. (1997). Comportamento de um solo colapsível inundado com líquidos de diferentes composições químicas.Tese de Doutorado, EESC, USP.

ALMEIDA, M. (1996). Aterros Sobre Solos Moles. Da concepção à Avaliação do Desempenho. Rio de Janeiro: Editora UFRJ.

ALONSO, U. R (1991). Previsão e controle das fundações. São Paulo: Editora Edgard Blücher.

AMOROSI, A, MARCHI, N. (1999). High-resolution sequence stratigraphy from piezocone tests: example from the Late Quaternary deposits of the southeaster Po Plain. Sedimentary Geology, V. 128, pp. 67-81.

AOKI, N; CINTRA J. A. A. (2003). Verificação do comportamento de fundações isoladas por meio de provas de carga estática e dinâmica. Notas de aula; aula $\mathrm{n}^{\circ}$ 6; SGS-404: Fundações; Departamento de Geotecnia; São Carlos: Escola de Engenharia de São Carlos, USP.

BARATA, F. E. (1984). Propriedades mecânicas dos solos: uma introdução ao projeto de fundações. Rio de Janeiro: Livros Técnicos e Científicos Editora S.A. 
BEGEMANN, H. K. S. P. (1963). The use of the static Soil Penetrometer in Holland, in:New Zealand Engng. 18 (2), 41-49.

BARENTSEN, P. (1936). Short Description of a Field-testing Method with Coneshaped Sounding Apparatus. Int.Conf. Soil Mech. Found. Engng. Cambridge: Havard University.

BARROS, J. M. C. (1997). Módulo de cisalhamento dinâmico de solos tropicais, Tese de doutorado, Escola Politécnica, Universidade de São Paulo, São Paulo.

BORTOLUCCI, A. A. (1983). Caracterização geológica-geotécnica da região urbana de São Carlos-SP, São Carlos. Dissertação de mestrado. Escola de Engenharia de São Carlos. Universidade de São Paulo.

BOWLES, J. E. (1988). Foundation Analysis and Design. 4th Ed., McGraw-Hill Book co., New York, N.Y.

BURGHignOli, A., PANE, V., CAVALERA, L. (1991). Modeling stress-strain-time behavior of natural soils: monotonic loading. Proceedings, 10th European Conf. on Soil Mechanics and Foundation Engineering, Vol. 3, Firenze, (Balkema, Rotterdam), 959-979.

BUTCHER, A. P; POWELL, J. J. M. (1996) Practical Considerations for field geophysical techniques used to assess ground stiffness. Advances in site investigation practice.Thomas Telford, London, 1996, p.701-714.

CAMPANELlA R. G., ROBERTSON P. K. (1986). Current status of the piezocone test. First International Symposium on Penetration Testing, p.1-24.

CAMPANElla R. G.; STEWART W. P (1992). Seismic Cone Analysis Using Digital Signal Processing for Dynamic Site Characterization. Cdn. Geot J; 29(3): 477-486.

CAVAGUTI, N. (1981). Geologia, estruturas e características hidrogeológicas mesozóicas da Região de Bauru - SP, Tese de Doutorado. Bauru: Faculdade de Filosofia, Ciências e Letras, Universidade do Sagrado Coração.

CESTARI, F. (1990). Prove Geotecniche in sito. 401 p. Ed Geo-Graph - Segrate, Italy. 
CINTRA, J. C. A; AOKI, N; ALBIERO, J. H. A. (2003). Tensão admissível em fundações diretas. São Carlos: RIMA. 142p.

COSTA,Y. D. J. (1999). Estudo do Comportamento de solo não saturado através de provas de carga e placa. Dissertação de mestrado, USP/São Carlos, 131p.

DAVIES, M. P; CAMPANElla, R. G. (1995). Piezocone Technology: Down-hole Geophysics for the Geoenvironmental Characterization of Soil, Proceedings of SAGEEP 95. Orlando: Florida. 11 p.

DÉCOURT, L; QUARESMA FILHO, A. R. (1996). Estabelecimento das curvas carga recalque de fundações através de provas de carga em mini placa. In: III SEMINÁRIO DE ENGENHARIA DE FUNDAÇÕES ESPECIAIS E GEOTECNIA, 1996, São Paulo. Anais São Paulo. CD-ROM.

DE MIO, G. (2005). Aspectos geológicos na interpretação de ensaios de piezocone em solos tropicais, Tese de doutorado, São Carlos: Escola de Engenharia de São Carlos, USP.

EALKIM, A. F. (2005). Evaluation of Shallow Foundation Displacements using soil Small-Strain Stiffness. Dissertation present to the Academic Faculty. Georgia Institute.

ESLAMI, A; GHOLAMI, M. (2005). Bearing capacity analysis of shallow foundations from CPT data proceedings of ICSMGE", 16th International Conference on Soil Mechanics and Geotechnical Engineering, Osaka, Japan (Sept. 12-16).

FAHEY, M.; CARTER, J. P. (1993). A finite element study of the pressuremeter test in sand using a nonlinear elastic plastic model. Canadian Geotechnical Journal, 30 (2), 348362.

FAHEY, M. (2001). Soil stiffness values for foundation settlement analysis. Pre-Failure Deformation Characteristics of Geomaterials, Vol. 2, Balkema, Rotterdam, pp.1325-1332.

FERREIRA,C.V. (1991). Caracterização Geotécnica de um solo de uma área da cidade de Bauru-SP. Dissertação de mestrado, São Carlos: Escola de Engenharia de São Carlos, USP. 
FREDLUND, D. G; RAHARDJO, H. (1993). Soil Mechanics for Unsaturated Soils. New York, John Wiley \& Sons.

GIACHETI, H. L. (1991). Estudo experimental de parâmetros dinâmicos de alguns solos tropicais do Estado de São Paulo. Tese de doutorado, EESC-USP/SP.

GIACHETI, H. L. (2001). Os ensaios de campo na investigação do subsolo: Estudos e considerações quanto à aplicação em solos tropicais. Tese de livre docência, FEBUNESP.Bauru/SP.

GIACHETI, H. L; PEIXOTO, A. S. P.; MONDELLI, G. (2004). Comparação entre resultados de ensaios de penetração com os cones mecânico e elétrico em solos tropicais. Solos e Rochas, São Paulo, v. 27, n. 2, p. 191-200.

GIACHETI, H. L.; RÖHM, S. A. (1996). Efeito da sucção matricial no módulo de cisalhamento máximo de um solo laterítico, In: 8o. Congresso Brasileiro de Geologia de Engenharia, V.1. Rio de Janeiro/RJ, p. 239-250.

HARDIN, B. O; DRNEVICH, V. P. (1972). Shear modulus and damping in soils. Journal of the Soil Mechanics and Foundations Division, ASCE, 98 (7), 667-692.

JARDINE, R.J; POTTS, D.M., FOURIE, A., and BURLAND, J.B. (1986). Studies on the influence of nonlinear stress-strain in soil-structure interaction. Geotechnique 36 (3), 377-396.

KONDNER, R. L. (1963). Hyperbolic stress-strain response: cohesive soils. Journal of the Soil Mechanics and Foundations Division, ASCE, 89 (1), 115-143.

LANCELLOTTA, R. (1995). Geotechnical Engineering. A. A. Balkema/ Rotterdam.

LUNA, R.; JADI, H. (2000). Determination of Dynamic Soil Properties Using Geophysical Methods, Proceedings of the First International Conference on the Application of Geophysical and NDT Methodologies to Transportation Facilities and Infrastructure, St. Louis, MO, December. 
MACACARI, M. F. (2001). Variação da capacidade de carga com a sucção e profundidade em ensaios de placa em solos colapsivel. Dissertação de Mestrado, USP/São Carlos, 96p.

MACHADO, S. L. (1998). Aplicações de conceitos de elastoplasticidade a solos não saturados, Tese de Doutoramento-EESC-USP, São Carlos-SP.

MARINHO, F. A. M, CHANDLER, R.J, CRILLY, M. S. (1995), Stiffness measurements on an unsatured high plasticity clay using bender elements.In:International conference on unsatured soils, Paris. Proceedings v2,p.535-539.

MASCARENHA, M. M. A; CORDÃO NETO, M. P; MURRIETA, P; ROMERO, M., ALONSO, E. (2008). Comportamento de Solos Não Saturados a Pequenas Deformações. XIV Congresso Brasileiro de Mecânica dos Solos e Engenharia Geotécnica, Buzios, V.2, 1599-1606.

MAYNE, P. W. (1995). Application of $\mathbf{G} / \mathbf{G}_{\max }$ modulus degradation to foundation settlement analyses. Proceedings, U.S.-Taiwan Workshop on Geotechnical Collaboration, National Science Foundation/Washington D.C. and National Science, Council/Taipei, 136148.

MAYNE, P. W. (2000). Enhanced geotechnical site characterization by seismic piezocone penetration tests. I Fourth International Geotechnical Conference. Cairo University; p.95120.

MAYNE, P.W.; POULOS, H.G. (1999). Approximate displacement influence factors for elastic shallow foundations. Journal of Geotechnical and Geoenvironmental Engineering, Vol. 125, No. 6, pp. 453-460.

MAYNE, P. W; SCHNEIDER A. J (2000). Evaluation axial drilled shaft response by seismic cone. Foundations \& Ground Improvement, GPS 113, ASCE, Reston/VA, pp. 665669. 
MELLO, L. G. F. S; CEPOLINA, M. (1978). Sobre a interpretação de provas de carga sobre placas visando previsão de recalques. ln: Congresso Brasileiro de Mecânica dos Solos e Engenharia de Fundações, 6, Rio de Janeiro.Anais. São Paulo: ABMS.v.1,p.165-180.

MENEGOTTO, M. L. (2004). Previsão da curva tensão x Recalque de ensaios de placa em solo não saturado. Tese de doutorado, USP/ São Carlos, 219p.

MEYERHOF, G. G. (1974). Ultimate bearing capacity of footings on sand layer overlying clay. Can Geotech J, 11(2):223-229.

MEYERHOF, G. G. (1976). Bearing capacity and settlement of ASCE, Journal of Geotechnical Engineering, 102(GT3), pp 195-228.

MILITITSKY, J; CONSOLI, N. C; SCHNAID, F. (2008). Patologia das fundações, São Paulo, oficina de textos.

NEVES, L. F. S. (2004). Metodologia para a determinação da eficiência do ensaio SPT através de prova de carga estática sobre o amostrador padrão. Dissertação de mestrado, EESC/USP.

NOGUEIRA, J. B. (1995). Mecânica dos Solos-Ensaios de Laboratório, EESC/USP, 1995.

PERLOFF, W. H.; BARON, W. (1976). Soil mechanics: principles and applications. New York: Jonh Wiley and Sons Co.745p.

PINTO, C. S (1996). Propriedades dos solos. ln:Hachich ET AL. (Eds.). Fundações: teoria e prática. São Paulo:PINI.Cap2, p51-118.

POUlOS, H. G; DAVIES, E. H. (1974). Elastic Solutions for Soil and Rock Mechanics, Wiley \& Sons, New York, 411 p. (available from University of Sydney Press, 1994).

PUZRIN, A. M; BURLAND, J. B. (1998). Nonlinear model of small-strain behavior of soils. Geotechnique 48 (2), 217- 233.

REZNIK, Y. M. (1995). Rigid plate settlements on soils with varying deformation properties.Geotechnical Testing Journal.ASTM, v18, n2, p.194-203, June. 
RICE, A. (1984). The Sismic Cone Penetrometer, M.A.SC. [Thesis] Vancouver: The University British Columbia.

ROBERTSON, P. K; CAMPANELlA, R. G; GILLESPIE, D.; GREIG, J. (1986). Use of Piezometer Cone data. Proc. In situ-86.ASCE Specialty Conference, pp 1263-1280.

ROCHA FILHO, P; ALENCAR, J. A. (1985). Piezocone tests in the Rio de Janeiro soft clay deposit, in: $11^{\text {th }}$ Int. Conf. Soil Mech. Found. Eng., 2, 859-862, San Francisco. Amsterdã: A. A. Balkema.

ROCHA FILHO, P.; SALES, M. M. (1994). O uso do Piezocone em ensaios off shore em águas profundas", in: 10th Cong. Brasileiro Mec. Solos Eng. Fund. ,2, 531-538. Foz do Iguaçu.

SCHMERTMANN, J. H. (1970). Static Cone to compute static settlement over sand. Journal of the soil mech. And Found. Div., ASCE, v.96, n.SM3, p. 1011-1043.

SCHMERTMANN, J. H. (1978). Guidelines do Cone Penetration test performance and design. Report FHWA-TS-78-209, US. Dept. of Transportation: Federal Highway Adm: Washington D.C.

STOKOE II, K. H. (1980). Dynamic Response of Pile-Supported Foundation, Report, University of Texas-Department of Civil Engineering, 29p.

TATSUOKA, F.; SHIBUYA, S. (1992). Deformation characteristics of soils and rocks from field and laboratory tests. Rept. of the Inst. of Industrial Science, Vol. 37, No. 1, Univ. of Tokyo, $136 \mathrm{p}$.

TEACHAVORASINSKUN, S.; SHIBUYA, S.; TATSUOKA, F. (1991). Stiffness of sands in monotonic \& cyclic torsional simple shear. Geotechnical Engineering Congress, Vol. II (Boulder), GSP No. 27, ASCE, New York, 863-878.

TEIXEIRA, A. H. (1966). Fundações rasas. In: III Congresso Brasileiro de Mecânica dos solos, Belo Horizonte. Anais... Belo Horizonte, 1966, p. 73-89, Vol II. 
TERZAGHI, K. (1943). Theoretical soil mechanics. New York: john wiley and sons co. $510 \mathrm{p}$.

TIMOSHENKO, S.; GOODIER, J. N. (1951). Theory of Elasticity. McGraw-Hill, New York (USA).

VESIC, A. S. (1975). Bearing Capacity of Shallow Foudations.ln: Winterkorn, H.F;Fang,H.Y. (eds). Foundations engineering handbook.New York.Ed Van Nostrand Reinhold Co. Cap. 3, p.121-147.

VITALI, O. P. M. (2009). Um novo sistema para realização de ensaios sísmicos Down Hole; Relatório de Pesquisa de iniciação Científica, Faculdade de Engenharia de Bauru, Unesp, Bauru/São Paulo/ Brasil.

VITALI, O. P. M. (2011). Desenvolvimento de um sistema para realização de ensaios sísmicos Down-Hole em conjunto com o CPT. Dissertação de mestrado, EESC/USP. 